Florida International University FIU Digital Commons

3-29-2001

\title{
Influences on immigrant students' perceptions of the chances of making it in the United States
}

Velmarie L. Albertini

Florida International University

DOI: $10.25148 /$ etd.FI13101564

Follow this and additional works at: https:// digitalcommons.fiu.edu/etd

Part of the Education Commons, and the Sociology Commons

\section{Recommended Citation}

Albertini, Velmarie L., "Influences on immigrant students' perceptions of the chances of making it in the United States" (2001). FIU Electronic Theses and Dissertations. 1190.

https://digitalcommons.fiu.edu/etd/1190 


\section{FLORIDA INTERNATIONAL UNIVERSITY}

Miami, Florida

INFLUENCES ON IMMIGRANT STUDENTS' PERCEPTIONS OF THE CHANCES OF MAKING IT IN THE UNITED STATES

A dissertation submitted in partial fulfillment of the requirements for the degree of

DOCTOR OF PHILOSOPHY

in

SOCIOLOGY

by

Velmarie L. Albertini 
To: Dean Arthur W. Herriott

College of Arts and Sciences

This dissertation, written by Velmarie L. Albertini, and entitled Influences on Immigrant Students' Perception of the Chances of Making It in the United States, having been approved in respect to style and intellectual content, is referred to you for judgment.

We have read this dissertation and recommend that it be approved.

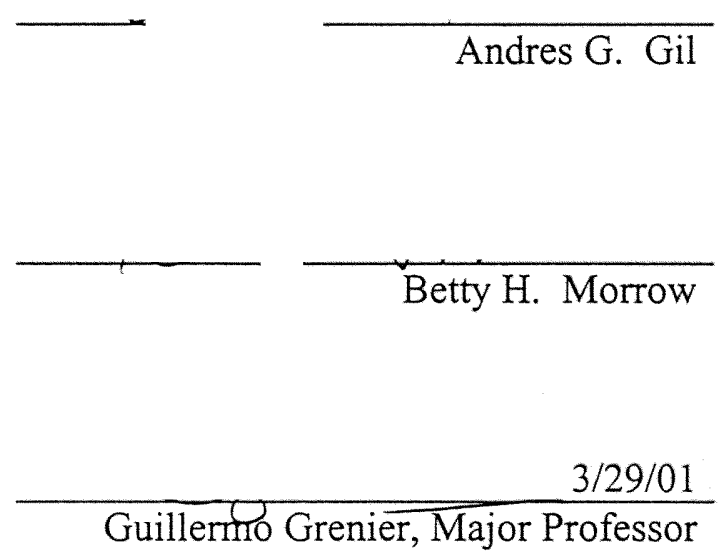

Date of Defense: March 29, 2001

The dissertation of Velmarie L. Albertini is approved.

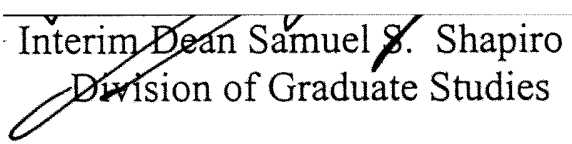

Florida International University, 2001 
(C) Copyright 2001 by Velmarie L. Albertini

All rights reserved. 


\section{DEDICATION}

I dedicate this dissertation to the most important people in my life, my husband Guy and my children Kevin and Krysten. I also dedicate it to my mother Petulind Blake, father James Blake and my two sisters Kay and Margaret who encouraged me to go all the way. I will always cherish the love and encouragement I received from the members of my immediate and extended family. 


\section{ACKNOWLEDGMENTS}

I am very grateful to the chair and members of my dissertation committee for the help and encouragement they provided during the dissertation process.

I give special thanks to Dr. Guillermo Grenier for his time, effort and commitment. His listening ear and timely comments kept me on track throughout my dissertation. I am particularly grateful to him for his open door policy.

I am extremely grateful to Dr. Better Morrow for her time, effort and commitment. She has taught me much more than she will ever realize about the academy.

I am indeed grateful to Dr. Andres Gil who generously allowed me to access to the rich data set that was used in this project. His guidance and encouragement is also appreciated. 
ABSTRACT OF THE DISSERTATION

\title{
INFLUENCES ON IMMIGRANT STUDENTS' PERCEPTIONS OF THE CHANCES \\ OF MAKING IT IN THE UNITED STATES
}

by

\author{
Velmarie L. Albertini
}

Florida International University, 2001

Miami, Florida

Professor Guillermo Grenier, Major Professor

This study examined immigrant minority students' perceptions of race relations and of the chances for social mobility in the United States (U.S.) using cohort samples of West Indian $(\mathrm{N}=173)$ and Haitian $(\mathrm{N}=191)$ students. The Students' responses collected during the 6 th and 7 th, 8 th and 9 th grades were analyzed to determine whether perceptions of racial mistrust, teacher derogation and social mobility varied depending on the student's length of stay in the U.S. or self-concept. Quantitative methodology was applied to data extrapolated from a larger epidemiological longitudinal study consisting of 7, 386 middle school students in Miami (Vega and Gil, 1998).

Results show that West Indian and Haitian students' perceptions of racial mistrust, teacher derogation and social mobility were associated more with student's self-concept than length of stay. Students with more favorable self-concepts reported greater optimism toward social mobility than those with less favorable self-concepts. Results also indicate that in the context of parental education and SES that racial mistrust is the strongest predictor of these students' level of optimism towards social mobility. 


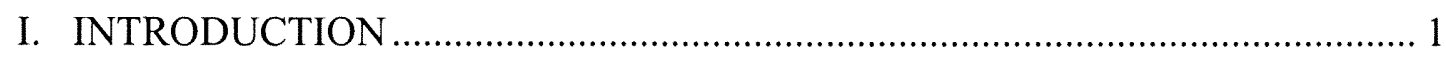

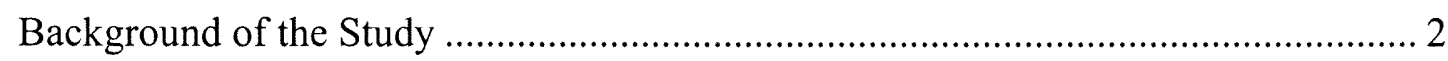

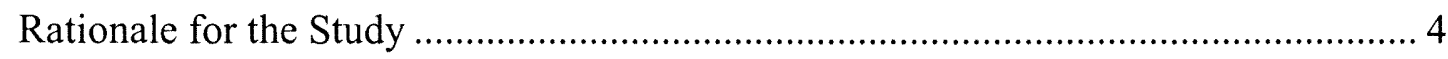

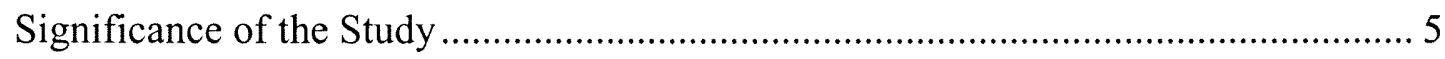

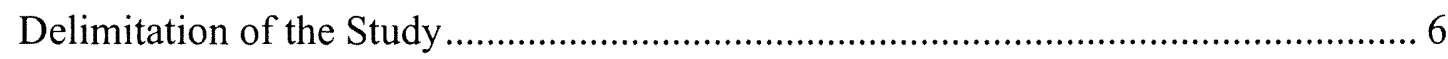

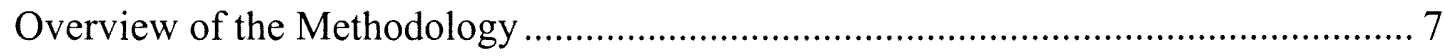

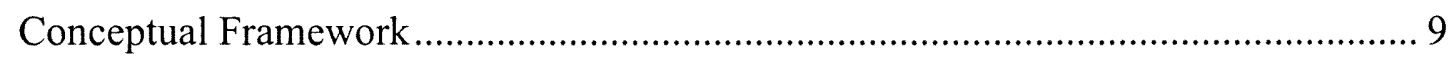

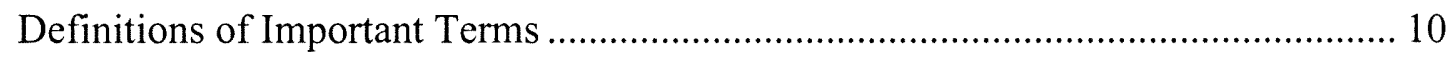

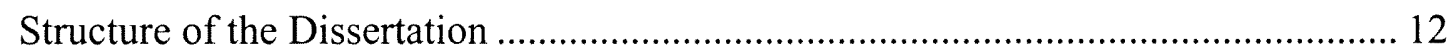

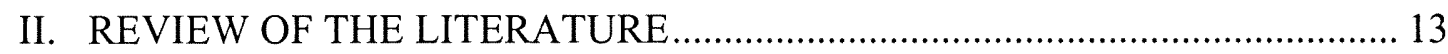

United States Educational Challenges and Race Relations ...................................... 14

West Indian and Haitian Students and School Adjustment ...................................... 17

Immigration Trends and the Influence of Anti-immigrant Attitudes......................... 20

Association between Length of Stay and West Indian and Haitian Students'

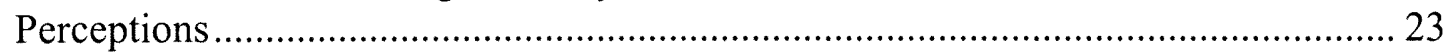

Role of Self-concept Theory in the Understanding of West Indian and Haitian

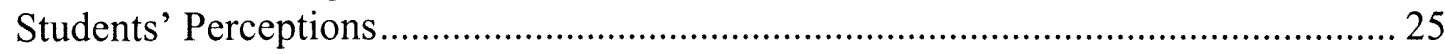

Teacher Derogation and Race-related Mistrust: West Indian and Haitian Students'

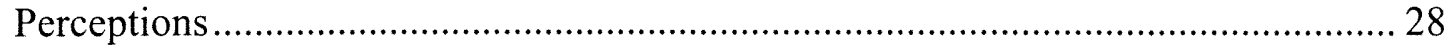

Using Acculturation and Segmented Assimilation Theories to Understand West

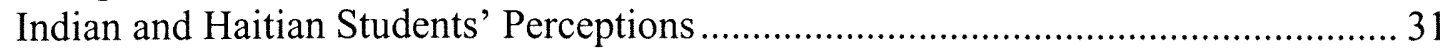




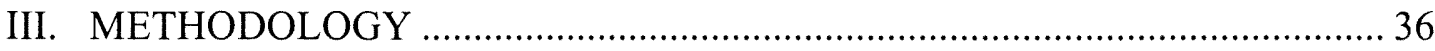

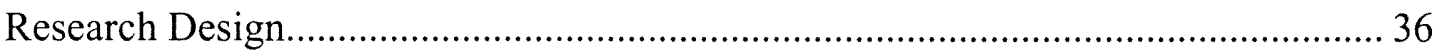

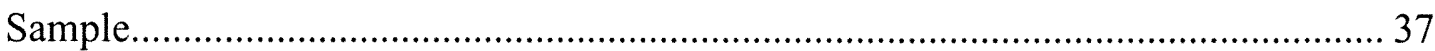

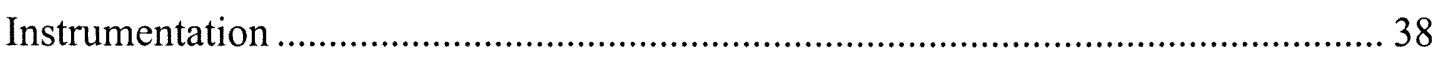

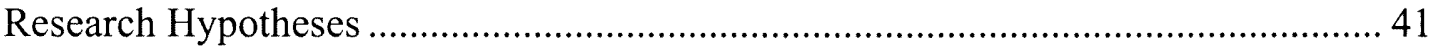

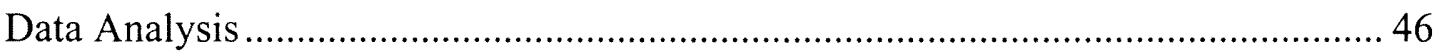

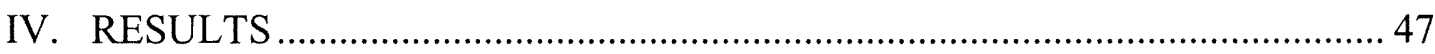



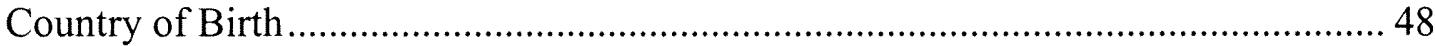

Age

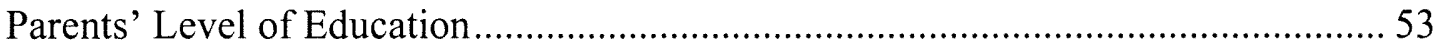

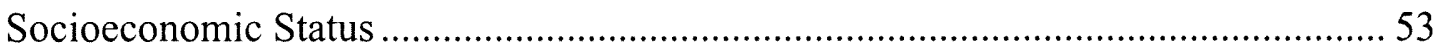

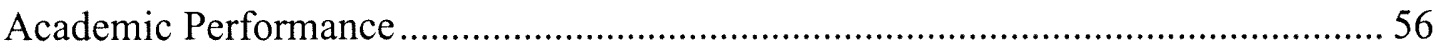

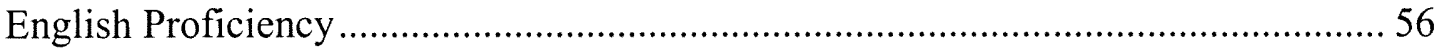

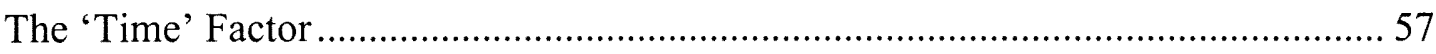

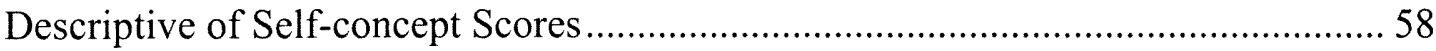

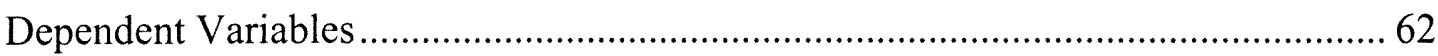

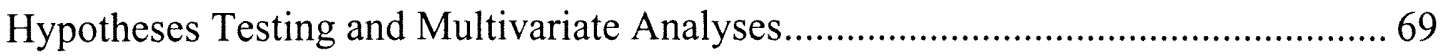

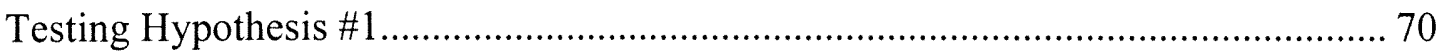

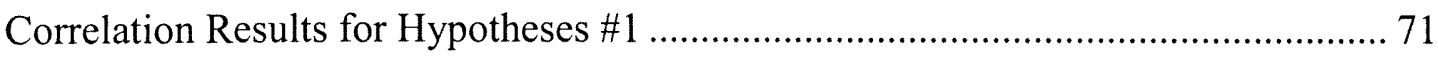

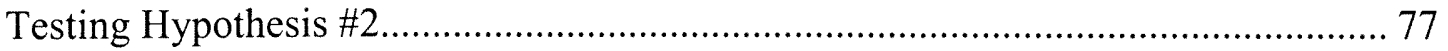

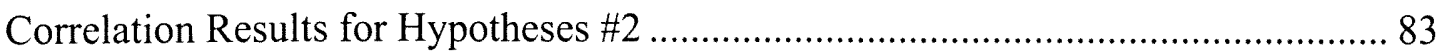




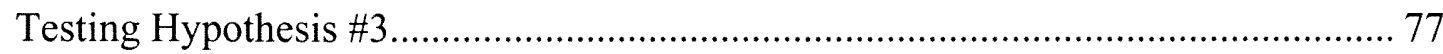



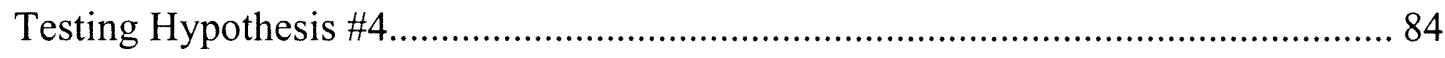

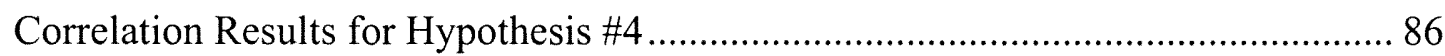

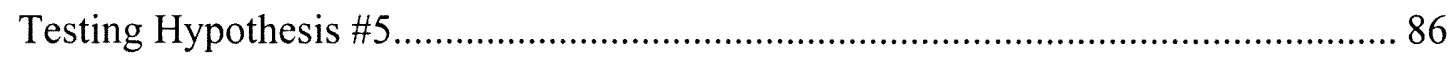

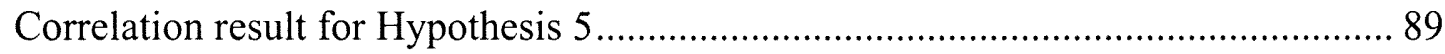

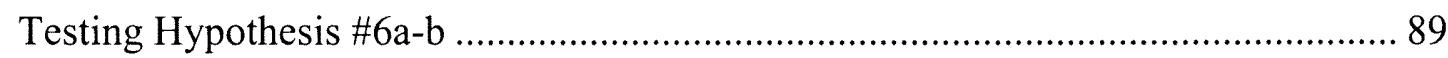

Correlation Results for Hypothesis 6a ….............................................................. 90

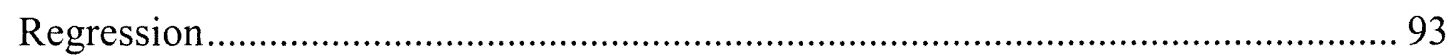

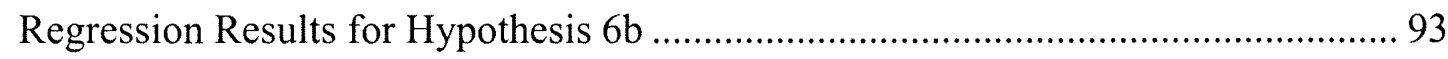

Summary of the results of the Hypotheses Testing ................................................... 96

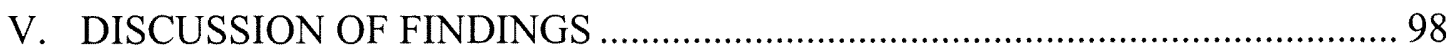

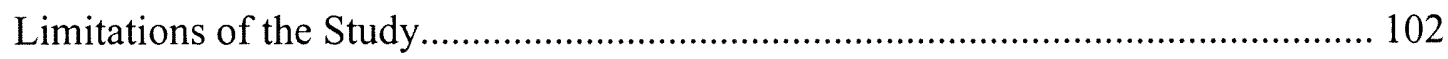

Implication for Research and policy evaluation .............................................. 103

REFERENCES.......................................................... 105

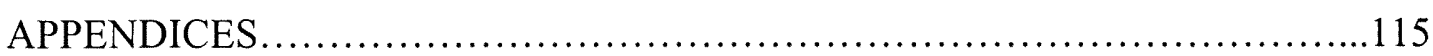

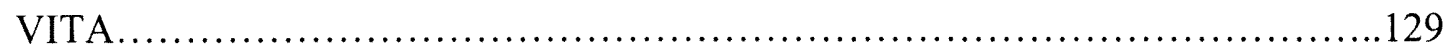




\section{LIST OF TABLES}

TABLE

PAGE

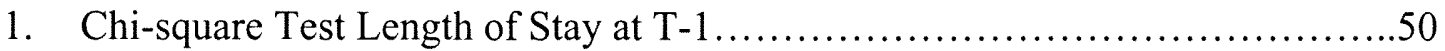

2. Descriptive of the Sample's Demographic Characteristics......................52

3. Grade Point Average by Ethnicity.........................................55

4. Self-concept Descriptive Statistics by Ethnic Group........................6 60

5. Racial Mistrust Descriptive Statistics by Ethnic Group......................66

6. Teacher Derogation Descriptive Statistics by Ethnic Group...................65

7. Optimism for Social Mobility Descriptive Statistics by Ethnic Group..........68

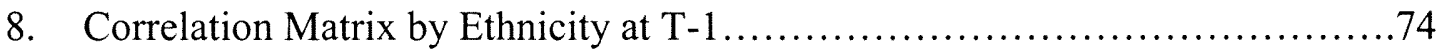

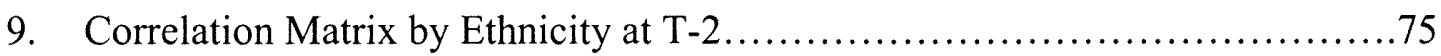

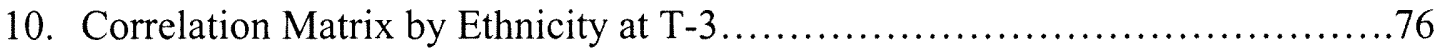

11. Regresssion of Social Mobility on Racial Mistrust, Teacher Derogation and

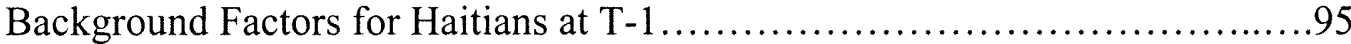




\section{LIST OF CHARTS}

CHART

PAGE

1. Influence of Length of Stay on Perceptions of Racial Mistrust by Ethnicity.....73

2. Relationship between Length of Stay on Perceptions of Teacher Derogationby

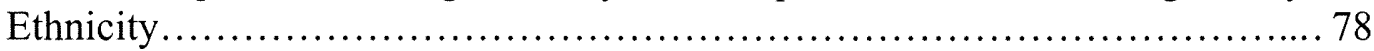

3. Relationship between Self-concept and Perceptions of Racial Mistrust........ 82

4. Relationship between Self-concept and Perceptions of Teacher Derogation......85

5. Relationship between Length of Stay and Perceptions of Chances for Social Mobility .............................................................. 88

6. Percent Change: Self-concept on Social Mobility T-1, T-2 and T-3 ...........92 


\section{Chapter 1}

Influences on Immigrant Students' Perceptions of the Chances of

Making It in the United States

Introduction

This dissertation is a quantitative study that examined immigrant adolescents' perceptions of race relations and chances for social mobility in the United States. Numerous studies of minority students' adjustment indicate negative relationships between the awareness of prejudice and discriminatory practices and expectations for upward mobility (Perlmann and Waldinger, 1997; Portes, 1997; Portes and Rumbaut, 1996; Waters, 1994, 1999; Gibson, 1989; Suarez-Orozco, 1989). In light of such findings this study focused specifically on two understudied immigrant minority groups in Miami: West Indian and Haitian students. The specific aim was to learn whether the length of time that students spent in the U.S (amount of exposure) and students' self-concepts are associated with their perceptions concerning race-related mistrust, teacher derogation and opportunities for social mobility. As such, these students' perceptions of White teachers' attitudes or derogatory behaviors toward Black students were analyzed to determine whether these students' perceptions varied according to lengths of stay or self-concepts. Students' perceptions of racial mistrust, teacher derogation and social mobility were analyzed at separate times to determine whether their perceptions changed over time.

This first chapter of the dissertation presents the background of the study and describes the nature of the problem. The chapter continues with the rationale, significance and delimitation of the study and provides an overview of the methodology. 
The chapter concludes with definitions of important terms used in the study and an outline of the structure of the dissertation.

\section{Background of the Study}

This study sought new information on West Indians and Haitians two racial minority groups that share African ancestry yet are ethnically and culturally very different. The study was conducted at a time when native and immigrant minority groups were experiencing great difficulties in using formal education to achieve upward social mobility in the U.S. (Ogbu, 1987; Waters, 1994a, 1994b, 1999). It was also a period when much attention was placed on school failures and particularly the disproportionate school failures and dropout rates among native and immigrant minority students. Roper and Pence (1995) among many others drew attention to institutional racism that persisted in schools arguing that institutional racism could be seen in attendance and graduation rates among immigrant-minority groups across the nation. Also emphasized was the view that institutional discrimination is indicated by factors such as, who attends school, who attends what school, what is taught, and even how students are treated in classrooms (Ropers and Pence, 1995).

In addition to identifying educational problems researchers sought to understand underlying causes of school failures and to provide policy makers and educators with reliable and useful information about factors that contribute to the alarming dropout and failure rates among minority groups. Some studies looked at background factors such as socio-economic status and family history to find solutions (Sanders, 2000; Rumbaut, 1997). Others identified prejudices in the form of racism and discriminatory practices in 
schools as primary factors affecting minorities (Larkin and Sleeter, 1995; Tatum, 1992;

Wellman, 1993). Educational difficulties were sufficiently emphasized in cities heavily populated by immigrant minorities to indicate that the problem merits greater attention from researchers of the twenty-first century (Ropers and Pence, 1995; Waters, 1994, 1999; Rambaut, 1988; Vega and Gil, 1998).

The current study meets that challenge focusing on the perceptions of Caribbean immigrants of middle-school age in Miami Florida. The choice of those age and ethnic groups was based on the knowledge that the children of middle school age typically struggle with questions about their sense of academic competence, ethnic-identity, and self-concept (Rumbaut, 1997). Yet for West Indians and Haitians the school environment may be the very place where their sense of competence, ethnic-identity and self-concept is threatened or undermined (Maehr and Midgley, 1996; Waters 1999). Despite Ropers and Pence's (1995) argument concerning the presence of institutionalized racism in schools the current study did not seek a determination of whether racism exist in Miami schools. It simply sought to determine whether West Indian and Haitian students perceived race-related mistrust, teacher derogation and fewer opportunities for social mobility. It also determined whether relationships existed between those perceptions and the student's length of stay and self-concept.

As Waters (1999) explains, certain social forces that traditionally affect AfricanAmerican students, namely racism and discrimination also affect second-generation West Indian and Haitian students (Waters, 1999). Similar to African-Americans, Caribbean students who experience "white against black" discrimination in school have lower expectations that education will lead to upward social mobility than their white 
counterparts (Waters, 1994; Bell, 1996). Waters (1999) studies of West Indians and Haitians in New York also presents evidence indicating length of stay or length of exposure to negative aspects of U.S. race relations as a crucial factor to be considered when studying immigrant students' school experiences.

\section{Rationale for the Study}

Although the experiences of Caribbean immigrants has been studied for more than a half a century (see Reid, 1939; Frazier, 1957) the majority of early studies focused on adults (Kalmijn and Kraaykamp, 1996). Very few examined West Indian and Haitian adolescents. Few studies looked at the youths' perceptions of race relations and of their chances of upward social mobility during early adolescence. The rationale behind this current study was to incorporate the students' own perceptions of self (self-concept) in relation to others during a very crucial stage of development, an understudied topic (Vega and Gil, 1998). 
In this study three theoretical approaches: self-concept theory, acculturation theory and segmented assimilation theory are relied on to explore immigrant children's educational adjustment and their outlook on their chances of "making it" in the U.S. It incorporates findings from empirical research on immigrant minority students in order to develop a conceptual framework for identifying and understanding factors that are associated with the students' perceptions. Combining acculturation, segmented assimilation theories and self-concept theory, a plausible theoretical framework emerged for the inquiry specific to West Indian and Haitian students' personal and social adaptation in the context of the school environment and society.

The rationale for using the school setting was based on scores of studies that identify schools as primary institutions that acculturate immigrant children into the dominant culture (Pryor, 1992; Waters, 1999, 1994; Kalmijin and Kraaykamp, 1996; Dodoo, 1997; Rumbaut, 1990).

Significance of the Study

This study is significant for four primary reasons. First, it is innovative in that it uses students' self-appraisal to measure their awareness of race relations using the students' report of their perceptions of race-related mistrust, teacher derogation and opportunities for social mobility. The self-appraisal process integrates many aspects of the student's life that, in turn, portrays their sense of personal identity and perception of the self in the context of school and the larger society. Second, the study sought a deeper understanding of the extent to which immigrant students' perceptions of racism within the teacher-student relationship may impeded their belief that education is a viable means 
for attaining upward social mobility. Third, this study offers empirical data to support the search for further development and implementation of culturally sensitive curricula and educational policies in schools heavily populated by immigrant students. Finally, the fourth reason that this study is significant relates to its unique longitudinal data and cohort grouping of two ethnically diverse groups of students sharing the same racial background. It provides the empirical information needed for an in-depth understanding of minority students' perceptions of U.S. race relations and their chances of upward social mobility.

\section{Delimitation of the Study}

In addition to its strengths, the study had some weaknesses. To begin, the samples were small and were drawn from a geographically distinct area. This raises questions about the generalizability of the findings. Replication in other regions would provide insight into the extent to which these findings have general relevance. Secondly, using secondary data the research questions were limited to those designed for the larger study encompassing different topics and a broader sample group from Miami-Dade County middle schools.

Finally, the usual difficulties associated with the use of secondary data must be considered in this study. For example, the original questionnaires administered to the West Indians and Haitians in the sample were developed and administered in English, not French or Creole, causing some concerns about language barriers particularly for the Haitian population. This language issue was addressed using a number of different administration procedures to facilitate the gathering of information (Warheit, 1998: p.35). 
As it turned out, only three Haitian students in the sample were identified as having special language difficulties.

Overview of the Methodology

In approaching the methodology an overarching hypothesis and several subhypotheses were designed to examine the perceptions of West Indian and Haitian students in Miami. The aim was to learn how certain factors might be associated with students' school experiences and perceptions of U.S. race relations on a whole. The sample includes a cohort sample of 173 West Indian and 191 Haitian adolescent students (ages ranging from 11-17 years), their parents and teachers. The data were originally collected as part of a larger epidemiological longitudinal study of middle school students in Miami (Vega and Gil, 1998). The data for the current study were examined in three waves. The first wave of data was collected in the fall 1990 as the students were entering the sixth and seventh grades. The second set of data was collected during the eighth grade. The final set of data was collected during the ninth grade, as the students were transitioning to high school.

The study included 9 variables from multiple dimensions, including ethnicity, nativity, socioeconomic status, mother and father's level of education and student's academic performance (grade point average). In addition, it included the Haitian students' level of English proficiency, student's length of stay in the U.S., and selfconcept. Collectively, the variables provided information on the profiles between the respective ethnic groups. 
Frequency distribution, descriptive analyses and chi-square test were used to identify the differential profiles of ethnicity, length of stay, self-concept and perceptions for the two groups concerning: racial mistrust, teacher derogation and social mobility. Spearman's correlation test was utilized in identifying the relationships between the independent and dependent variables across all three waves of data collection. Finally, regression analyses were used to determine whether length of stay, self-concept and certain background factors were associated with students' levels of racial mistrust, teacher derogation and social mobility independently. Figure 1 below presents the basic conceptual framework for the study, indicating the independent, dependent variables and background factors. After the conceptual framework, some definitions are presented as well as an outline the structure of this dissertation. 
Figure 1.

Conceptual Framework

Variables and factors associated with students' perceptions: classroom and society contextual

\begin{tabular}{l|l|}
\multicolumn{1}{c|}{ VARIABLES: } & \multicolumn{1}{c|}{ Independent } \\
\cline { 2 - 2 } & $\begin{array}{l}\text { Length of Stay } \\
\text { in the U.S. } \\
\text { Self-concept }\end{array}$ \\
BACKGROUND \\
FACTORS: \\
Parent's education \\
Socioeconomic status \\
Haitian student's level \\
of English proficiency \\
Students grade point \\
average
\end{tabular}

\begin{tabular}{|l|c|}
\multicolumn{1}{c|}{ Dependent } & Upward Social \\
\hline Perceptions of & Mobility \\
Racial-mistrust \\
Teacher-derogation \\
Social mobility
\end{tabular}




\section{Definitions of Important Terms}

The following are definitions of some terms crucial to the current study:

Acculturation: refers to changes that take place in immigrants' behavior and social activities, thinking and self-identification after contacts with another culture (Williams and Berry, 1991)

Assimilation (traditional): refers to a process in which immigrants give up cherished ideas or values to become part of the mainstream culture either through coercion or force (Gordon, 1964).

Assimilation (segmented): recognizes that immigrants are dispersed across various segments of society, spreading over the most affluent to the most impoverished sectors (Portes, 1995; Portes and Zhou 1993).

Discrimination: is the prejudgment and negative treatment of people based on identifiable characteristics such as race, gender, religion or ethnicity. Racial and ethnic discrimination involves denying to members of a minority group equal access to opportunities, education, residential housing areas, access to community services and so forth (Baker, 1999, p.133).

Institutional Racism: refers to discriminatory acts and policies against a racial group that pervade the major macro systems of society, including the economic and educational systems. Institutional racism is reflected in policies, practices and procedures embedded in bureaucratic structures that systematically lead to unequal outcomes for people of color (Baker, 1983). 
Length of stay: refers to the number of years the individual has lived in the U.S. Length of stay is often linked to the acculturation process (Waters, 1994).

Race and Ethnicity: although a racial group is often an ethnic group, the two groups are not necessarily the same. While the two groups examined in this study are of the same racial group, West Indians and Haitians are separated due to the differences in their ethnicity. West Indians and Haitians share common sets of physical characteristic that link them to Africa. However, members of the respective group may or may not share the sense of togetherness or identity this distinguishes each from the other as an ethnic group.

Racism: racism is stereotyping and generalizing about people, usually negatively, because of their race. Commonly it is the basis for discrimination against members of racial minority groups (Baker, 1983, p.397). Similar to ethnocentric ideologies, most racist ideologies assert that members of other racial groups are inferior.

Racial mistrust: refers to the defensive cognitive and behavioral responses to racism that members of the group deemed to be inferior may experience.

Self-concept: refers to the positive and negative thoughts and feelings that one holds toward one's self. Each person develops a unique theory regarding who exactly he or she is. This personal impression is referred to as the self-concept. It is often used interchangeably with terms such as self-image, sense of self-esteem, and identity. However, here it is considered to be distinct (Purkey, 1988). Teacher Derogation: any attitudes or behavior (directed from teachers towards students) that are of a disparaging nature. 
West Indians: peoples of the English-speaking regions of the Caribbean, including the islands of Jamaica, Trinidad, Barbados, Antigua, Cayman Islands, Grenada, Guyana, St Lucia, St Vincent and Bahamas.

\section{Structure of the Dissertation}

Chapter 1 in the dissertation presents the background of the study, specifies the problem, describes its significance, and provides an overview of the methodology. The chapter concludes with the delimitation of the study and definitions of some special terms used. Chapter 2 reviews relevant literature, theoretical conceptualizations and variables used. Chapter 3 discusses the methodology, research design, subjects, data collection and instrumentation. The chapter concludes with a presentation of the study's research hypotheses and data analysis. Chapter 4 provides the results of the study. Chapter 5 presents the discussion of the results as well as the limitations of the study and its implications for future research and policy evaluation or development. 
Review of the Literature

This chapter presents a review of research literature focusing on immigrant minority adolescents of West Indian and Haitian ethnic backgrounds. It reviews empirical research identifying personal factors as well as other factors within educational institutions that are associated with West Indian and Haitian students' perceptions looking specifically at student's experiences of race-related mistrust, teacher derogation and social mobility. Each factor is discussed in respect to its relationship with the students' lengths of stay in the U.S. and self-concepts.

The literature review begins with an overview of educational challenges that minorities in the U.S. Accordingly, studies that view educational institutions as microcosms of the broader society are explored with the intent of acquiring a deeper understanding how immigrant students interpret U.S. race relations. The review places immigration trends and patterns of West Indian and Haitian students' educational experiences within the context of school and society. As such, anti-immigrant attitudes in the U.S. are explored in order to develop an understanding of how those attitudes may relate to educational problems faced by minorities.

This chapter concludes with a discussion on the applicability of self-concept, acculturation, and segmented assimilation theories to this study of immigrant minority students' school experience. 
The $20^{\text {th }}$ century population growth was accompanied by a tremendous surge in research studies focusing on educational failures and the effects of $U$. S. race relations on minority children educational experiences (Ogbu, 1992; Hacker, 1995; Miles, 1996; Phillips, 1998; Lawrence and Tatum, 1997). Ogbu (1992) in his work concerning the experiences of voluntary and involuntary minorities emphasizes that many of the barriers that minority students encounter in using formal education to achieve upward social mobility originates in problematic school environments. Also looking at the education dilemma and race relations, Delgado-Gaitan (1988) cautions that immigrant minorities face multiple barriers in U.S. institutions that are national-origin, race as well as age specific.

Overall, the literature reflects the growing concerns, particularly over disproportionate academic failures and dropout rates among U.S. native and immigrant minority students across all levels of education. In fact, some researchers question whether minority students are receiving appropriate social and academic encouragement from educators in primary and secondary educational years to effect their enrollment and level of participation in higher education (Roper and Pence, 1995). As many researches track school successes and failures in higher education many trace failures back to primary and secondary educational experiences (Roper and Pence, 1995; Ogbu, 1993; Kailin, 1999; Herr, 1999).

Despite the concerns raised in the literature historically U.S. educational institutions have reported great commitment to redressing racial conflict and the underlying themes 
of bias, prejudice and injustice that affect minority students. However, those reports present varying degrees of success (Lawrence, 1997; Weissglass, 1997; Gollnick, 1995; Grant and Tate, 1995; Ladson-Billings, 1995). Since the 1930s much attempts have been made to develop curricula to change negative racial attitudes among school personnel while encouraging appreciation for people of all races in schools (Vernay, 1990). There were also efforts made toward the dissemination of information on the psychological aspects of prejudice and advocacy for assimilation models that incorporate minorities into the mainstream (Vernay, 1990; 1990; Benedict and Ellis, 1942; Lynch, 1987; Olneck, 1990).

A myriad of other approaches and policies were attempted mostly with the aim of raising the self-esteem of students from minority groups while concentrating on improving access to good schooling (Grant, 1988). During the 1980s a more global focus emerged in education systems with greater emphasis on reducing racial tensions in schools. The expectations were that the combined effort would result in the creation of a new educational culture. One that reflects tolerance and acceptance of all children brought about through multicultural education programs geared toward educating for peace and justice. Through these efforts, racial conflicts would reduce and there would be much greater equity in education (Mitchell, 1990; Kinder, 1986; McGinnis, 1984).

While public support for overtly racist practices in educational institutions such as segregation and claims of racial inferiority have declined many studies have documented more subtle forms of racism that have persisted. Many describe the $1980 \mathrm{~s}$ as a period of steady retrenchment in affirmative action policies and government programs geared toward redressing economic and social power disparities among the races (Kinder, 1986; 
Survey Research Center, 1986; Swanson, Spenser and Petersen, 1998). As Swanson, Spenser and Peterson (1998) recently pointed out, a great deal of racial tension persists in U.S. schools. In fact as long as schools remain bounded to the values and norms of a society that reflects persistent biases and racism then the school personnel will serve to reinforce those norms. As such U.S. schools are described in the literature as microcosms of the larger society.

Holding to a similar premise Ropers and Pence (1995) argue that school environments are the primary places to search for root causes as well as solutions for educational and subsequent economic problems that ethnic minority groups encounter. These authors attribute the problem of declining enrollments and increasing dropout rates among minority groups to the debilitating affects of institutionalized racism on minority students' outlook on opportunities for economic and social mobility. Thus, as long as schools reflect negative attitudes and values that pervade society, schools and schoolpersonnel will have profound affects on the opportunity structure for minorities.

Focusing on school dropout rates in a historical context Jaschik (1986) documents a significant reduction in the number of immigrant and native minority students who completed high school and continued onto college over two decades. After the U.S. Supreme Court's decision in Brown v Board of Education in 1954, national minority students' enrollment in college increased by 246 percent. By 1986 however, minority student college-enrollment reached a virtual standstill, and later began to plummet. Many minority students also left college without graduating.

In the mid-eighties only thirty-two percent of the minority students who enrolled in colleges graduated within six years, compared to fifty-six percent of white students. 
Equally disturbing were the number of minority students leaving high schools without diplomas (Jaschik, 1986). Jaschik (1986) suggests that there is a direct connection between school experiences in the early years of education and the problems that are evident in higher education among minorities. Despite tremendous increases in the availability of information on dropout rates, many questions remain as to the long-term affects of negative school experiences during the early educational years on specific minority groups, including West Indian and Haitian students. This area is in need of greater exploration

West Indian and Haitian Students and School Adjustment

Few studies have looked at West Indian and Haitian students' educational adjustment. However, using a sample of 83 adolescent students in New York, Waters (1994) explored the adaptation and accommodation to the U.S. experiences of both West Indian and Haitian students. She surmised that West Indian and Haitian students' adjustment process involving the interpretation and integration of U.S. race relations is very complicated. For these youths even those who were born in the U.S. the social and educational adjustment process involve complex changes in their self and ethnic-identity.

Waters also describes an adjustment process wherein West Indian and Haitian students experience great pressures on multiple levels to function not as Caribbean immigrants but rather as African-Americans (Waters, 1994, 1999). Woldemikael, (1989) also explains that second-generation Haitian students in particular face tremendous pressure to become not so much Americans, but African-Americans. In 
school settings, Haitian youths are engaged in an adjustment process involving adapt to African-American dialect, speech pattern, dress style and behaviors.

Rumbaut (1994) who studied West Indian also found a similar pattern wherein West Indian students are influenced by their peers to adapt African-American attitudes and behaviors concerning education in the schools and the streets. In addition to pressures for West Indians and Haitians to African-Americanize Waters $(1994,1999)$ describes erosion in these immigrant adolescents' positive attitudes toward education that is associated with their exposure to racism and discrimination in school settings.

The findings indicate that when West Indian and Haitian immigrants first arrive in the U.S they possess optimistic assessments of educational and economic opportunities and American race relations that facilitate their integration into American society. However, overtime as their exposure to American race relations begin to overwhelm their positive cultural values their awareness of persistent racism and discrimination increases. Thus, contrary to beliefs in the benefits of assimilation it is those who resist Americanization that are most likely to succeed in terms of education and economics, especially among the second generation (Waters 1999).

As race related barriers become more apparent the students expectation that educational attainments result in upward social mobility decreases (Waters, 1999). For the immigrants of African descent there is a gradual awareness about how their social and economic opportunities are limited due to racism (Ropers and Pence, 1995). In another study Walters (1993) argues that many of the educational problems minority students face relate to the awareness that for Blacks society's meritocracy is a hoax. Walters argues further that it is because of minority students' lack of trust in the educational 
system and disbelief in equal economic opportunity that many drop out or experience school failures in early education.

Fernandez-Kelly (1994) presents a slightly different argument in suggesting that the educational problems are attributable largely to the political and economic changes that took place during the Bush-Reagan years of 1980s. In her view, the origin of the problem lies in the sharp reductions in federal support for education that began in the early 1980s, as well as persistent wage discrimination against minority groups. Despite the differences in those authors' views, collectively they illustrate that more attention must be paid to school environments. More researchers need to examine attitudes of school personnel and the policy makers in order to understand factors the are associated with the ways in which minority students view the world (Woldemikael, 1989; Rumbaut ,1994, 1990; Waters, 1999; Walters, 1993; Roper and Pence, 1995; Fernandez-Kelly, 1994).

Focusing on solutions to school failures many researchers have examined the roles of school personnel as agents of change who are instrumental in setting or reducing educational barriers minority students encounter. As early as 1924 , one strong commentary emphasized the importance of the role education and educator suggesting that:

It is the business of schools to help children to acquire attitudes toward inequalities of life, whether in accomplishment or in reward, in order for them to adjust themselves to its conditions with the least possible friction (Freeman, 1924: p.102).

Modern educational reformers continue to identify factors in schools that need to be addressed in order for children, particularly minorities, to develop perceptions toward inequalities of life that helps them to adjust and succeed (Hodgekinson, 1989; Fernandez- 
Kelly, 1994). Education reformers of the 1980s and 1990s called for comprehensive and national evaluations of teaching materials to specifically redress racial, cultural and gender biases in education. Levels of cultural competence and awareness training for teachers were also identified as areas of concern, particularly in urban schools (Hodgekinson, 1989; Fernandez-Kelly, 1994).

Despite four decades of dramatic attempts to alter U.S. school systems many reformers still argue that educators have made insufficient progress toward creating multicultural environments needed to accommodate students' diversified ethnic backgrounds and native languages (Dentler and Hafner, 1997). Some even argue that schools have lagged behind in addressing the diversity in economic backgrounds, family situations, and educational levels of students from different ethnic groups (Hodgekinson, 1989; Fernandez-Kelly, 1994). Other reformers suggest that education policy makers have been remise in not doing enough to equip or recruit teachers with the cultural sensitivity conducive to supportive classroom environments and the fostering of educational successes among immigrant minority students. Thus, school failures reflected in increasing dropout rates are expected to persist, affecting minority students well into the twenty-first century (Ropers and Pence, 1995; Moultry, 1988; Vernay, 1990).

Immigration Trends and the Influence of Anti-immigrant Attitudes

The last forty years have been a period of unprecedented immigration from the English and French-Creole speaking regions of the Caribbean. The presence of the hundreds of thousands of West Indian and Haitian children in U.S. schools are firmly 
rooted as a historical phenomenon subsequent to 1965 changes in U.S. immigration laws. Those changes facilitated greater family-based and refugee migration (Bryce-Laporte, 1987; Kasinitz, 1992; Portes and Stepick, 1993; Grenier, 1999; Garcia-Zamor, 1998). Four decades of heavy immigration has contributed greatly to diversification of the age, ethnic, racial and socioeconomic background of the U.S. population. This diversity is especially evident in Miami-Dade, Florida school system (U.S. Bureau of Census, 1996; Patterson, 2000).

Assuming those immigration trends persist, by the year 2010 about thirty percent of the population under the age of eighteen years will be of African, Asian or Hispanic descent. In major cities where most immigrants settle more than one-half of the children will be ethnic minorities (Klauke, 1989). By 2010 the projected ethnic minority population for states such as California, Texas, New York, Florida and Louisiana will reach or exceed fifty percent (Klauke, 1989). In many of the remaining states at least one-fourth of the children will also be of African, Hispanic or Asian American descent (Schwartz and Exeter, 1989; Klauke, 1989).

Despite the ethnic diversification race remains the most powerful and controversial means of categorizing and dividing people in the U.S. (Padilla, 1980). As such, Americans' attitudes toward ethnic minority groups remain a great concern, especially for those who hold to ideals of a pluralistic society (Morse, and Ludovina, 1999). According to Morse and Ludovina's (1999) report, thirty percent of native-born Americans hold strong anti-immigrant attitudes. Another forty percent characterize themselves as being "on the fence" or unsure as to whether immigrants constitute a positive or negative presence in American society. 
The notion that America has always existed as a nation of immigrants remains far from the mind of the native born American. Therefore, attitudes toward West Indians and Haitians and their reception in the U.S have not always reflected the historical image of the U.S. as a "melting pot" (Miles, 1996; Muller, 1996; Portes, 2000). Caribbean immigrants have not tended to be welcomed by U.S. citizens because they often fear the loss of jobs or reduction in wages due to competition from immigrants willing to work for low wages (Takaki, 1993; Miles, 1996). In urban areas such as Miami where many immigrant families settle, there is a tendency toward intensification of anti-immigrant sentiments. Compounding the issue is the problem that U.S. complex race relations pose for immigrant minority families. Anti-immigrant attitudes and discrimination based on race persist as two powerfully negative factors relating to the educational and adaptation experiences of immigrant minority children (Roper and Ponce, 1995; Du Bois, 1961; Waters, 1994).

In contrast, to earlier research that attempted to find general adaptation patterns for all groups (see Gordon, 1964) current studies reflect more multi-disciplinary attempts to understand the barriers affecting specific immigrant groups (Delgado-Gaitan, 1988; Gans, 1992; Portes, and Zhou, 1993; Fordham and Ogbu, 1987; Portes and Rumbaut, 1996; Solomon, 1992). Studies have shown that the education and adaptation experiences of West Indian and Haitian immigrants are further complicated by not only skin color but languages that set them apart from the majority group (Vernay, 1990; Waters, 1994; National Coalition of Advocates for Students, 1988). In fact, for many skin color and language is used as primary elements to characterize them as "unmeltable" immigrants (Novak, 1971). 
Comparing West Indian and Haitian students' educational experiences to those of other ethnic minorities such as the African American. It was found that over time both groups experience the same types of barriers in U.S. educational systems (DelgadoGaitan, 1988; Gans, 1992; Portes and Zhou, 1993; Fordham and Ogbu 1987). Both groups possess phenotypic characteristics that are used to identify and marginalize them as minority members within the social structure (Delgado-Gaitan, 1988).

Association Between Length of Stay on West Indian and Haitian Students' Perceptions

Waters $(1994 ; 1999)$ and others have done much to dispel long held beliefs that West Indian and Haitian children adapt easily to the changes that take place in their family, school, racial, and cultural environments (Garcia-Zamor 1998; Gil and Vega, 1998). New findings suggest that many do not adapt well and over time are severely affected particularly by the length of time they are exposed to practices of racism and discrimination in the U.S. (Igoa, 1995; James, 1997, Waters, 1999). Length of stay has been gaining much attention as a crucial factor associated with the educational experiences of immigrant students (Portes and MacLeod, 1996; Vega and Gil, 1998; Waters 1994, 1999). Bearing in mind that people are complex products comprised of not only ethnicity but also individuality it is important to understand how the immigrant student's length of stay might be associated with his or her educational experience.

Length of stay often refers to the number of years immigrant children are exposed to the new culture. Herr (1999) describes minority children' exposure to negative elements in the U.S. as periods of cultural alienation. The argument is that in many cases where children of color are singled out (i.e. in classrooms) repeatedly as underachievers they 
experience what is called cultural alienation. In a study examining a sample of 5,266 second-generation high school students, including Haitians in Miami, Portes and MacLeod (1996) reported that when students experience cultural alienation their academic performance is affected by the experience.

Multiple studies identify length of stay or exposure to prejudice and racism as a factor influencing immigrant students' overall perceptions or attitudes toward education (Portes and Macleod, 1996; Waters, 1994; 1999). Evidence is mounting to show West Indians and Haitians who live in the U.S. for shorter periods tend to be more motivated to do well in school than those who have been here longer. In addition, school failures and dropout rates increase among immigrant minority students as length of stay increases (Gans, 1992; Portes and Zhou, 1993, Portes and Rumbaut, 1996; Suarez-Orozco, 1995). Immigrant minority students' motivation levels decrease as they become aware of disparities in economic opportunity for Blacks (National Immigration Forum, 1994). Some researchers explain that unlike African-Americans who are socialized early to expect historically rooted discriminatory practices in schools and society immigrant children's awareness of racial barriers comes later and at a less gradual pace (Ogbu, 1991; Solomon, 1992; Waters, 1994). The adjustment process for West Indians and Haitians involves a blending of old cultures with new race relations. Changes in cultural awareness relate to a broadening of understanding of their social position in a different worldview from that of the Caribbean Black experience (Rond and Preissle; Gainor and Forrest, 1991). 
Role of Self-concept Theory in the Understanding of

West Indian and Haitian Students' Perceptions

In addition to length of stay, self-concept was identified as a crucial personal-factor influencing minority student' perceptions of education and race relations (Gainor and Forrest, 1991). Despite common usage of the term self-concept is often a poorly defined construct. In defining self-concept Purkey (1988), a key proponent of the theory, makes a very important distinction between self-concept and self-esteem. In general, selfconcept theory refers to the totality of a complex, organized, and dynamic system of learned beliefs, attitudes and opinions that each person holds to be true about his or her personal existence.

Conversely, self-esteem refers to feeling of personal worth and level of satisfaction regarding one's self or self-report (Purkey, 1988). Streins (1993) points out that, there are at least fifteen different "self" terms used by authors of various disciplines, which relate to self-concept. Researchers have used terms such as "self-esteem", "self-worth", "self-acceptance," and "self-concept" interchangeably and inconsistently to differentiate ideas about how people view themselves. Some have relied on various instruments to measure or scale self-concept. For example, three scales that are widely accepted and used to measure self-concept are Rosenberg (1965) scale self-esteem scale and selfconcept scale, the Piers-Harris' children self-concept scale (Piers, 1984) and Tennessee's self-concept scale (Fitts, 1991).

The experiences that a child has in school environments have significant impact on the child's self-concept. In a study of minority children's self-concept Silberman (1971) 
showed eighty percent of young Black children entering schools with positive selfconcepts and by the fifth grade eighty-percent of the children had negative self-concepts. By their senior year in high school, ninety percent presented negative self-concepts. Purkey emphasizes three major qualities of self-concept that are applicable to students' adjustment. The first is that self-concept is learned. Secondly, it is organized and finally it is dynamic (Purkey, 1988).

Those descriptions of self-concept also relate to Waters (1994) study of West Indians and Haitians in that she describes negative changes or erosions that take place in the organization of second-generation immigrants' self-concept during their acculturation process. Silberman's (1971) work also relates to Waters' $(1994,1999)$, which indicates that West Indian and Haitian adolescents are required to adapt in order to fit into schools and society's race construct. Immigrant's adjustment is accomplished through the contacts they establish in the new environments. Whether they fail or succeed in school has much to do with the way they perceive themselves, their family, and the social status of people in their racial-ethnic groups and economic opportunities in their communities.

Self-concept theory is therefore very crucial to the understanding of school failures among West Indian and Haitians. Vega and Gil (1993) explain that minority students who possess positive self-concepts experience greater school success, more positive social interaction with others, and more emotional, social and intellectual growth. Swanson et al. link minority students' self-concept to the ways in which they view themselves in relationship to others within their own minority group, other minority groups and those of the majority group. The use of self-concept theory is very useful to the study of specific 
groups such as West Indian and Haitian adolescents in Miami school in that the theory lends itself to the examination of the students' personal perceptions.

In line with self-concept theorist, each individual regardless of race or ethnicity has a tendency toward self-actualization and development as long as it is permitted and encouraged within inviting learning environments (Purkey, 1988; Purkey and Schmitdt, 1987). This is an area where possibilities exist for schools to fail minority students. Although an individual's self-concept possesses relatively boundless potential for development and actualization any experience that is inconsistent with one's self-concept could be perceived as a threat (Purkey and Schmitdt, 1987). Supposedly the more threatening experiences there are for the individual in society the more rigidly the selfconcept is expected to be organized to maintain and protect itself. However, if the person is unable to get rid of perceived inconsistency adjustment problems will arise (Purkey, 1988).

Purkey (1988) also explains that an individual's self-concept is organized in that it generally possesses a stable quality that is characterized by orderliness and harmony. Further, each person maintains countless perceptions regarding his or her personal existence and each perception are orchestrated with all others. If the person's selfconcept therefore requires consistency, stability and tends to resist change as Purkey (1988) indicates, a central question that remains is whether immigrants' self-concept serves as a shield to protect against the negative aspects of race relations. In addition, to what extent does these students' acculturation experiences involving racism or discriminatory practices threaten self-actualization and overwhelm them? The notion that one's self-concept is capable of organizing to maintain and protect itself will be 
expounded on further when these students's perception of race-related mistrust is discussed. However, Purkey's point is well taken in expecting individuals to possess some personal ability to protect themselves against negative elements.

Gilmore and Gilmore (1982) point out that while praise and acceptance strengthen self-concept derogation and disapproval lower it. In the case of the West Indians and Haitians, increased awareness of the limited access to opportunities for Blacks may affect their self-concepts (Waters, 1999; Gil and Vega, 1993; Purkey, 1988). According to Waters (1994), West Indian and Haitian children whose self-concept involves an African American or black identity tend to perceive more racial discrimination and less opportunity for themselves as well as for other Blacks in the U.S. In contrast, those who perceive themselves as Caribbean or immigrants tend to see more opportunities and rewards for individual effort and initiative (Waters 1994). This suggests that there are some inherent dangers in the acculturation process for West Indian and Haitian children and the classroom may be the most ideal place to explore the process as it relates to immigrant minorities' perceptions of education and race relations.

Teacher derogation and Race-related Mistrust: West Indian and Haitian Students' Perceptions

Bearing in mind that neither teachers nor school environments are isolated from the wider society, it is important to understand the role each may play in communicating societal norms and values to minority students during the acculturation process. Also of importance are the new perceptions that immigrant minorities may form concerning their status and role in society. According to Mitchell and Conn (1985) teachers' attitudes are 
the most decisive factors in classrooms. In all situations in the classroom teachers choose whether to humanize or dehumanize a student. Their personal approach sets the tone and creates the learning environment for minorities. A teacher can be a tool of torture or an instrument of inspiration.

Teachers who are familiar with the diverse cultures represented in their classrooms promote a better environment conducive to acceptance, cooperation and learning. Teachers possessing intercultural competence have the ability to relate and communicate effectively in the classroom with students who do not share their culture, ethnicity, language or other salient variables (Hains, Lynch and Winton, 1997). On the other hand, students who encounter racism and discrimination in classrooms may develop negative perceptions about their social status as it relates to the different ethnic-racial groups in society (Swanson et al.).

Swanson et al. further explains that educational successes and failures minority among students are closely related to interactions taking place between teachers and students. Teachers who are more intra-culturally competent tend to appreciate the differences that exist between and among the diverse populations they work with, thus serving diverse families more effectively (Lynch \& Hanson, 1998). Fernandez-Kelly (1994) explains that when racial or ethnic conflict or conflicting expectations between students and teachers exist each interferes with or redirects minority students' natural curiosity and innate love of learning.

Alarmingly, thirty percent of Black students in the U.S. report feelings of mistrust toward Whites in general and more specifically of White teachers (Taylor, Biafora and Warheit, 1994). Racial mistrust is identified as a phenomenon not uncommon among 
native and various immigrant minority groups in the U.S. (Gil and Vega, 1993). Some researchers describe racial mistrust as a necessary and protective mechanism associated with African Americans and other Black children (Biafora, Taylor, Warheit, Zimmerman, and Vega, 1993; Taylor, Biafora and Warheit, 1994).

Kailin (1999) completed a study that analyzed White teachers' understanding of racism in schools. The findings indicate that most White teachers in the U.S. posses impaired consciousness of racism. Many tend to "blame the victims" in assigning the causality of racist treatment to minorities. In addition, when teachers observed racist behaviors of other teachers most do not challenge their colleagues. Another phenomenon, which relates to racial mistrust in school on the part of teachers, is the disproportionate number of minority students that teachers refer for remedial and psychological services. Many minority students' behaviors are misinterpreted and labeled as adjustment or achievement problems (Sugai and Maheady, 1988; Trueba, 1983).

Rubovits and Maehr's (1973) explains that Black students, regardless of their actual intelligence or gifted labels, are given far less attention and are ignored more often by teachers than their white counterparts in classroom settings. Irvine (1985) supports these findings in her work that showed Black students receiving more negative behavior comments and more mixed messages from White teachers than white students. In a retrospective study of reasons high school students dropped out of school, Olsen, Gary and Moore (1982) found that most students described interactions with teachers who were unhappy with their jobs, disgruntled, unfair and sometime humiliating toward students. 
Fine (1986) in a study that focused on urban adolescents identified teachers' attitudes as the biggest school-related factor for students quitting high school. In fact, teachers also played a role in the erosion of students' confidence. Many at-risk adolescents reported going to great length to disengage from teachers who put them down or put them in uncomfortable or humiliating situations. Studies show that when ethnic minority students observe teachers that are committed to providing a fair and representative environment the students experience a greater sense of school ownership. The result is that those students' involvement in the educational process increases, resulting in greater school success rates (Klauke, 1989; "School Focusing”, 1989; Grant, 1988).

Using Acculturation and Segmented Assimilation Theories to Understand Influences on West Indian and Haitian Students' Perceptions

In light of the associations that have been suggested between immigrant students' lengths of stay and self-concepts, it is important to also take an in- depth look at the acculturation processes. Similar to self-concept, acculturation is a complex construct used by theorists to describe the experience of immigrants in a new society (Walcott 1997). Although some researchers use the term acculturation interchangeably with the term assimilation, it is important to distinguish between them when studying immigrant adolescents' perceptions of race relation and chances of upward social mobility. Gordon (1964) who is a major proponent of the theory broke the assimilation process into several sub-processes that include acculturation, as a component of behavioral assimilation. He also included structural assimilation, which pertains to access to societal institutions; amalgamation or marital assimilation; identificational assimilation; attitude receptional 
assimilation, involving the absence of discrimination; and civic assimilation, or the absence of values and power conflict.

The 1990s were periods of considerable strides in immigrant research that contributed to deeper understandings of Caribbean immigrants' acculturation processes. Some researchers describe second-generation immigrants' acculturation process as that which involves a cultural modification of immigrants' behaviors, social activities, thinking patterns, values, and self-identifications (Lambert, and Taylor, 1990;

D'Innocenzo and Sirefman, 1992; Olsen, 1997). Wolcott (1997) describes acculturation as a process that allows immigrant students for example to participate in the mainstream culture without necessarily abandoning values and traditions of their country of origin. As such, immigrant-children are portrayed as having the option of negotiating their movement toward becoming acculturated to the new society and development of new values and orientation (Wolcott, 1997; Igoa, 1995). Others refer to traditional assimilation theory when describing pressures immigrant adolescents face to acculturate. The immigrants attempt to adapt and blend in to be more like their peers, thereby assuming new ethnic and personal identity based on norms within U.S. (James, 1997; Waters, 1994).

When immigrant children adapt, their goal is usually to survive in schools and among their American-born peers as dually cultured individuals. However, as indicated earlier, for West Indian and Haitian students the process involves the additional pressure to take on African-American behaviors (Woldemikael, 1989; Rumbaut, 1994; Waters, 1999). Strict assimilation theorists propose that the immigrant and American culture are bound together and that immigrants benefit only by giving up their ethnic identities. 
Thus, traditional assimilation requires full acceptance on the part of the host society of the immigrant (Gordon, 1964). This of course is not always the case for groups such as West Indians and Haitians. As Waters $(1994,1999)$ argues, for these groups the process is much more complex given the race-related barriers embedded within society.

Increasingly, studies are focusing on immigrants' relocation from native country with its social network, familiar institutions and customs to understand adjustment and economic problems in the new country with unfamiliar ways and confusing networks. Many are challenging notions that immigrant groups simply move toward traditional or straight-line assimilation as described by Warner and Srole (1945) and later by Glazer (1993). Glazer (1993) links the direction of immigrants' social mobility both downward and upward strictly to traditional or straight-line assimilation. Portes and Zhou (1993) looking at social mobility movements argue that the process is more representative of a segmented-assimilation process. Some immigrants however may never be assimilated or be fully accepted by the host society because of prejudices against their particular racial or ethnic group (Zhou, 1997).

In Zhou's (1997) view, the whole premise of segmented assimilation theory is that immigrant families may be dispersed over various segments of society, spreading from the most affluent to the most impoverished sectors. Therefore, certain immigrant groups may be confined either to permanent underclass status or by preserving the values of the immigrant community and solidarity, they move toward rapid economic advancement. Thus, the factors that influence immigrant students in Miami vary across the various socioeconomic strata. For immigrant minorities the path to social mobility may lead 
upward or spiral downward depending not solely on ethnicity or race but also on their ability to successfully gain access to educational opportunities.

Educational qualifications for example are linked to the immigrants' occupational status and social mobility. Therefore disparities in educational achievement, dropout rates and access to higher education may be viewed as indicators of disparity in future opportunities for social mobility (Collins, 1979; Jaschik, 1979). In addition to educational qualifications, immigrants' perceptions of opportunities for social mobility are linked to their social conditions. When studying West Indians and Haitians in an urban area such as Miami, it is important to consider not only the school but also the social environment in which the school is located.

Miami has been called a lightening rod for those who attack immigrants and even U.S. immigration policies. Although some describe Miami as a microcosm of U.S urban areas of the future, it is also a place where many immigrants are reluctant to speak English or assimilate into mainstream American life. Miami is a place of great cultural diversity, yet it is fill with racial and ethnic tension (Beck, 1996)..

In assessing the social conditions of the city, Warheit (1998) describes Miami as a place that lacks defining social cohesion, with widespread personal alienation and social anomie. Many policy makers and educators whose opinions contribute to Miami's image emphasize that the city faces a great challenge in meeting immigrants' demands for education and other social services. Miami's politicians are often calling for increases in federal resources, arguing that the presence of large numbers of ethnic minority immigrants increase the city's cost of providing social services, particularly in the area of education (Warheit, 1999; Morse and Ludovina, 1999). 
Indeed, many West Indian and Haitian immigrant families who settle in Miami do find themselves among one of the fastest growing segment of the immigrant population in the United States, the urban underclass (Walker, 1993). Many live in social conditions that accentuate an already problematic social adjustment process (Garcia-Zamor 1998). However, that is not to say West Indians and Haitians are the only groups to struggle in their adaptation to the new environment. In fact, each immigrant group in the U.S. faces some sort of obstacles in its adjustment. It is worthwhile however to look at West Indian and Haitian students in Miami given the amount of immigrants who settle here (National Coalition of Advocates for Students, 1988; Trueba, 1983; Harris, 1993).

The literature offers many empirical findings that support an examination of a relationship between length of stay, self-concept and racial mistrust, teacher derogation and social mobility. The literature indicates that that as groups of African descent, West Indian and Haitian students encounter problems in school that are clearly related to U.S. race relations. Self-concept theory, acculturation theory and segmented assimilation theory undergrids the conceptual framework of this study. Each theory informs about the educational experience and perception of West Indian and Haitian students. 


\section{Chapter 3}

\section{Methodology}

This chapter elucidates the methodology used in this study. The chapter includes discussions of the research design, subject, data collection, and instruments and data analysis. In addition to those topics, the six research hypotheses of the study are presented.

\section{Research Design}

This research used a longitudinal, questionnaire design that allowed students and their parents to answer questions relating to six specific research hypotheses. The study utilizes secondary data from an ongoing research project that examines sixth, seventh, eighth and ninth graders in Miami County middle schools (Vega and 1998). Survey questionnaire research was chosen because it represents the primary means of obtaining social science data (Rubin and Babbie, 1997). The aim of the study was to analyze variables and indicators that may explain relationships between length of stay, selfconcept and perception of racial mistrust, teacher derogation and opportunities for social mobility among West Indian and Haitians adolescents in Miami.

As a correlation study, it did not focus on causation relating to the development of perceptions about racial mistrust, teacher derogation or social. Instead, the study sought to understand the relationship between those dependent variables and some specific independent variables- length of stay in the U.S. and self-concept. The decision to use 
secondary data was based on the availability and the appropriateness of data that were collected as part the larger study (Vega and Gil, 1998).

The data were collected in three waves. The first set of data was collected during the fall of 1990 as the students were entering the sixth and seventh grades; the second set of data was collected during the eighth grade. The final set of data was collected during the ninth grade, as the students were transitioning to high school (Vega and Gil, 1998).

\section{Sample}

A sub-sample of 173 West Indian and 191 Haitian students was taken from the larger study, which included 7,386 students in early to late stages of adolescence from all 48 middle schools in Miami Dade-County (Vega and Gil, 1998)). Although the larger study focused primarily on substance uses, attitudes, beliefs, and behaviors of a multiethnic cohort of adolescents much of the data had relevance to the issues of the current project. There was the availability of cross-sectional as well as longitudinal data on the sample.

The data were representative of the great ethnic diversity that resulted from recent demographic changes in Miami Schools. The larger study included nativity data on students from the United States, Cuba, Colombia Puerto, Rico Dominican Republic Honduras, El Salvador, Mexico, other countries in South and Central America, Haiti, the other Caribbean Islands, Asia, and Europe. All the data on students from the "Other Caribbean Islands" and Haiti were extrapolated for the analysis of the current study. The questionnaires were designed so that each participant could identify his or her country of origin and if such country was excluded from the questionnaires (see Vega and Gil 1998).

The data were obtained from students, parents and teachers represented in the two 
cohort groups of West Indian and Haitian students. Trained members of the project staff were engaged in the larger study and administered the questionnaires at Time 1 (T-1), Time 2 (T-2) and again at Time 3, (T-3). The first source of data collection derived from the students in 1990-1993. The second source was obtained from parents of students in the samples as well as a non-probability sample of teachers involved with the same cohort from whom the parent and family data were secured (Warheit, 1998).

Data from the students and parents were collected in 1990, 1992 and 1993. The teacher-data were collected at year one only however school records were available at T-1, T-2 and T-3 Vega et al. (1998:p30).

\section{Instrumentation}

During the larger study, the students' self-appraisal responses were collected using a total of 113 survey questions at $\mathrm{T}-1$ and $\mathrm{T}-2$ and 131 survey questions at $\mathrm{T}-3$ representing the three sets of data. All questions and responses from T-1, T-2 and T-3 of the larger sample were reviewed and only questions relevant to the research questions of the present study were selected (See Appendix for the list of all items.) The questionnaires of the larger study, which focused mostly on Hispanic students, were not designed to permit West Indian and Haitian students to qualify their ethnic identity. Therefore, two questions, "where were you born?" and "where was your mother born?" were used in combination to operationalize each student's ethnic background. In cases where students were born in the U.S. but their mothers were born in the Caribbean, the mothers' places of birth were used as indicators of those students' ethnicity. If both the mother and 
student were born in the Caribbean then the respective country was used as the indicator for the student's ethnicity.

The questionnaires allowed each respondent to respond to questions concerning selfconcepts, racial mistrust, teacher derogation and social mobility using Likert-type scales. Ten items were selected from the larger questionnaire and used as indicators to measure the self-concept levels of the two cohort groups. The items were as follows: a)"I am not liked by other kids," (b)“I don't like myself as much as I use to," (c) "At times I think I am not good at all," (d)"I wish I could have more respect for myself," (e)"On a whole I am satisfied with myself," (f)"My parents do not like me very much," (g)"I am a better person now than I used to be," (h)"I use to be a better person than I am now," (i)"I like myself a lot better now than I used to," (j) "I feel I do not have much to be proud of" and (k)"I take a positive attitude toward myself."

Seven items from the original questionnaire were used as indicators to measure students' perceptions of racial mistrust: a) "White teachers ask Black student hard question on purpose so that they can fail," (b) "When a white teacher talks to a Black student, it is usually to get information that can be used against him or her," (c) "Members of my family have talked to me about dealing with racism and prejudice," (d) "Blacks should be suspicious of a white person who tries to be friendly," (e) "I always defend the rights of Blacks,"(f) "Black parents should teach their children not to trust white teachers" and (g) "Members of my family have told me about problems they have because they are black".

The racial mistrust scale used in this study was adopted from McAdoo's (1983) Racial Awareness Scale and Terrell's (1981) Cultural Mistrust Scale. All responses for 
racial mistrust were scored using a four-point scale:(1) "Agree a lot," (2) "Sort of agree," (3) "Sort of agree," (4) "Disagree a lot, except item" (c) "Which was measured on a fourpoint scale: (1) "Very true for me," (2) "Pretty true for me," (3) "Not true for me" and (4) "Not at all true for me". Scores were totaled and grouped, resulting in a scale of racial mistrust from low to moderate to high. Descriptive statistics of the racial mistrust scores are presented on Table 5 in chapter 4.

Four items were used to indicate and measure perception of teacher derogation: (a) "Some of my teachers are usually not interested in what I say or do," (b) "My teachers feel that I am a failure," (c) "My teachers do not like me very much," and (d) "My teachers usually put me down". The teacher derogation scale that was used was adopted from Kaplan's (1984; 1986) Teacher Derogation Scale. All the responses were scored using a four-point scale: (1) "Very true" to (4) "Not true at all". The Totals were then ranged from low to moderate to high. The descriptive results for teacher derogation are presented on Table 6 in Chapter 4.

Finally, perception of opportunity for social mobility was defined as the student's expectation that he or she had the same chance of doing well or becoming rich in the U.S. as others. Four items from the questionnaires were used to measure generalized, as opposed to specific perception of social mobility. In essence, the items measured West Indian and Haitian students' perceptions of their chances of "making it". In terms of assessing perceptions of future opportunity for social mobility the developmental level of the students and their ability to formulate responses about an abstract construct such as the chances of "making it" or social mobility must be taken into consideration. 
These are the items utilized for perceptions of social mobility: (a) "In the United States, everyone has the same chance of getting rich," (b) "I have the same chance of doing well in life as everyone else," (c) "It is very important to me to get good grades" and (d) "I want to know more about how Black people have overcome problems in America". All the responses were scored using a four-point scale: (1) "Very true," to (4) "Not true at all". Totals were then used to develop a ranking from low to moderate to high levels of optimism for social mobility. The results are shown in Table 6.

\section{Research Hypotheses}

The analysis tested an overarching hypothesis that certain background factors would be found to have a relationship with West Indian and Haitian students' perceptions of racial mistrust, teacher derogation and social mobility. Those factors included mother's level of education, father's level of education, socioeconomic status, student's level of English proficiency and academic performance as indicated by cumulative grade point average. Those factors in combination with the immigrants' length of stay and selfconcept were expected to constitute profiles important to the understanding of both West Indian and Haitian students' social and educational adjustment.

To that end, the following research hypotheses were addressed:

\section{Hypothesis 1.}

The longer the student has lived in the U.S. the more likely it is for he or she to report racial mistrust.

The study anticipated specific differences in the student's perceptions of racial mistrust based on time in the country. It was expected that students living here longer 
would respond more often in the affirmative to the following statements:

a) White teachers ask Black students hard question on purpose so that they can fail.

b) When a white teacher talks to a Black student, it is usually to get information that can be used against him or her.

c) Members of my family have talked to me about dealing with racism and prejudice.

d) Blacks should be suspicious of a white person who tries to be friendly.

e) I always defend the rights of Blacks.

f) Black parents should teach their children not to trust white teachers.

g) Members of my family have told me about problems that they have because they are black.

The study hypothesized that student who lived here longer would display a profile of moderate to high levels of race-related mistrust. Therefore, length of stay would be considered a crucial factor associated with perceptions of racial mistrust.

\section{Hypothesis 2.}

The longer the student has lived in the U.S. the more likely it is for he or she to perceive teacher derogation.

The study anticipated specific differences in the student's levels of teacher derogation according to time in the country. It was expected that students' who lived here for longer periods would respond more often in the affirmative to the following statements: 
a) Some of my teachers are usually not interested in what I say or do.

b) My teachers feel that I am a failure.

c) My teachers do not like me very much.

d) My teachers usually put me down.

The study hypothesized that students living here longer would display a profile of higher levels of teacher derogation.

\section{Hypothesis 3.}

The less favorable the student's self-concept the more likely, it is for he or she to perceive racial mistrust.

The study anticipated an association between higher levels of racial mistrust and lower levels of self-concepts. It was expected that students who had less favorable self-concept scores would respond more often in the affirmative to the following statements:

a) White teachers ask Black students hard questions on purpose so that they can fail.

b) When a white teacher talks to a Black student, it is usually to get information that can be used against him or her.

c) Members of my family have talked to me about dealing with racism and prejudice.

d) Blacks should be suspicious of a white person who tries to be friendly.

e) I always defend the rights of Blacks. 
f) Black parents should teach their children not to trust white teachers.

g) Members of my family have told me about problems that they have because they are black.

Based on those expectations, the study hypothesized that students with lower self-concept scores would be more likely to report high levels of race-related mistrust levels.

\section{Hypotheses 4.}

The less favorable the student's self-concept, the more likely it is for he or she to perceive teacher derogation.

The study anticipated specific differences in student's perceptions of teacher derogation associated with levels of self-concept. It was expected that students revealing less favorable self-concepts would be more likely to perceive teacher derogation indicated by affirmative responses to the following statements:
a) Some of my teachers are usually not interested in what I say or do.
b) My teachers feel that I am a failure.
c) My teachers do not like me very much.
d) My teachers usually put me down.

\section{Hypothesis 5.}

The longer the student lived in the U.S. the more likely for he or she to perceive less chance for social mobility.

The study anticipated specific differences in student's perceptions of social mobility associated with length of stay. It was expected that students who had been here longer would respond negatively more often to items (a) and (b) and affirmatively to items (c) 
and (d): a) In the United States, everyone has the same chance of getting rich

b) I have the same chance of doing well in life as everyone else.

c) It is very important to me to get good grades.

d) I want to know more about how Black people have overcome problems in America.

Hypothesis 6a. and 6b.

(6a) Students who had self-concepts that are more favorable would perceive greater chances for social mobility than those with less favorable self-concepts.

(6b) Students who had less favorable perceptions of racial mistrust and teacher derogation would be more pessimistic in terms of their perceptions of chances for social mobility.

It was expected that students with less favorable self-concepts more often would respond negatively to item (a) and (b) and affirmatively to item (c) and (d) below:

a) In the United States, everyone has the same chance of getting rich.

b) I have the same chance of doing well in life as everyone else.

c) It is very important to me to get good grades.

d) I want to know more about how Black people have overcome problems in America.

In addition to these six hypotheses, two assumptions guided this study. The first was that U.S. race relations affect the school environment and subsequently West Indian and Haitian students' academic experiences are affected on personal levels by the school 
environment. Specifically the students' perceptions are associated with the quality of teacher-student interaction they experience.

\section{Data Analysis}

A quantitative approach was used to analyze West Indian and Haitian students' perceptions respectively and to determine whether any relationship existed between (1) student's length of stay in the U.S. and (2) self-concept and perception of (a) racial mistrust, (b) teacher derogation and (c) chances for social mobility. First, frequency distributions were computed for each of the demographic variables in order to provide a profile of the population sample under study. A chi-square test was also performed for each ethnic group to compare the mean score differences for length of stay by country of birth (including U.S. born versus non-U.S. born) and to complete the profile of the sample.

The analysis included West Indian and Haitian students' responses to specific questions that measured students' length of stay in the U.S. and identified country of birth. Each was coded and chi-square test was used to determine whether there were statistically significant differences between the two ethnic groups using significant alpha levels set at less than .01 .

Second, reliability analyses were performed using Cronbach's (1951) alpha coefficients. The purpose of the analyses was to facilitate discovery of dimensions of the scales used in the study. Then, depending on which dependent variable and or hypothesis were being analyzed correlation tests and or regression tests were performed. Again, the 
dependent variables were racial mistrust, teacher derogation and social mobility. The independent variables were length of stay in the U.S and self-concept.

Using regression models and correlation statistical procedures the relationships and strength of the relationships between the variables and a number of background factors such as parents' level of education, socioeconomic status were tested.

\section{Chapter 4}

\section{Results}

This chapter is presented in two sections. The first section is a descriptive presentation of the findings utilizing frequency distributions and measures of central tendency, including mean scores of responses where appropriate. Statistical tests of demographic comparisons are presented in the second section. Descriptive results are also provided reflecting the tests used for each of the hypotheses proposed. In order to test the hypotheses in the study various statistical techniques were utilized.

The quantitative descriptive presentation of the study consists of the demographic summary of the study's population as well as summary data for the independent and dependent variables that were examined. As mentioned in chapter 1, the work sought new information on West Indians and Haitians two racial minority groups that share African ancestry yet are ethnically and culturally different. Hence, the study's hypotheses involving the relationship of independent variables on dependent variables seldom compare the two ethnic groups. Instead, the findings are presented in a manner that facilitates an examination of changes and relationships between the variables looking at the two cohort groups respectively across $\mathrm{T}-1, \mathrm{~T}-2$ and $\mathrm{T}-3$. However, when necessary 
profiles for both cohort groups are discussed comparatively as in the case of the descriptive presentation of length of stay and ethnicity (see Table 1 on page 50).

In using three separate periods of data collection the study's findings are presented in a manner that indicate changes that occur across T-1, T-2 and T-3. For example, the percent changes in correlation relationships between the students' perceptions of racial mistrust, teacher derogation and social mobility on the independent variables are provided across each period.

\section{Demographic Characteristics}

This section reports findings on the demographic characteristics of the study's respondents. It includes salient findings on students' country of birth, age, parents' levels of education, socioeconomic status, grade point average and the level of English proficiency among Haitian students. Table 1 presents the results of the chi-square test showing a breakdown of the ethnic groups according to the students' length of stay in the U.S.

\section{Country of Birth}

The question, "where were you born?" was used as the indicator for each student's country of birth. Analysis of this item demonstrated that there are statistically significant differences between the two ethnic groups relating to students who were born in the U.S. versus those born in the Caribbean. Descriptive data collected at T-1 is provided below in Table 1. The results indicate that West Indian students represented slightly over $49 \%$ of the cohort samples with Haitian students representing slightly fewer than $50 \%$. 
However, Chi-square test shows that significantly more of the Haitian students in the sample were born in the U.S. (45.7\%) than were West Indian students (29.6\%)(see Table 1). The remainder of the sample represents West Indian as well as Haitian students who were born in Caribbean islands such as Haiti, Jamaica, Trinidad, Barbados, Antigua, Cayman Islands, Grenada, Guyana, St Lucia, St Vincent and Bahamas. 
Table 1.

Chi-Square Test Length of Stay by Ethnicity at T-1

\begin{tabular}{lccc} 
Value & df & Asymp. Sig. (2sided) \\
\hline 6.5 & 2 & \multicolumn{3}{c}{$.03^{\mathrm{a}}$} \\
& \multicolumn{3}{c}{ Number of years in U.S. } \\
Group & $0-5$ & $6-11$ & U.S. Born \\
West Indians & $33.90 \%$ & $36.50 \%$ & $29.60 \%$ \\
Haitians* & $24.10 \%$ & $30.20 \%$ & $45.70 \%$ \\
\hline
\end{tabular}

a. 0 cells $(.0 \%)$ have expected count less than 5 . The minimum expected count is 33.35

*Haitians were significantly different at <. 01 from West Indians. 
Table 2 below provides further comparative data on the two cohort samples such as ages, parents' levels of education, socioeconomic status, grade point average and English proficiency for Haitians.

Age

Starting with age as a background factor at T-1 data reveal that students' ages ranged from 10 to 17 years. Only one student in the sample had already reached the age of 17 years. As expected, there were no statistically significant differences in the mean age between the two groups. Results for West Indian students show a mean of 11.51 years (SD .98) and Haitian students having a mean of 11.70 years (SD .93). 
Table 2.

Descriptive Statistics of the Sample's Demographics Characteristics at T-1

\section{Length of Stay}

U.S. Born

6 to 11 years

0 to 5 years

Ages (years)

10

11

12

13

14

17

Mean Age

\begin{tabular}{c} 
West Indians \\
\hline \% \\
29.6 \\
36.5 \\
33.9
\end{tabular}

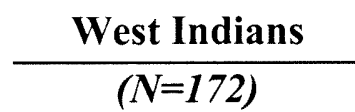

$\mathrm{N}$

22

67

61

20

1

1

11.51

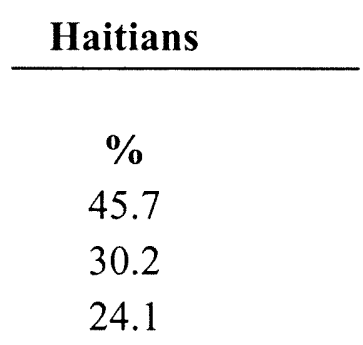

\begin{tabular}{cc} 
Haitians \\
\hline \multicolumn{2}{c}{$(\boldsymbol{N}=\mathbf{1 8 7})$} \\
$\mathrm{N}$ & $\%$ \\
19 & 10.2 \\
55 & 29.4 \\
80 & 42.8 \\
29 & 15.5 \\
4 & 2.1 \\
0 & 0.0 \\
11.7 &
\end{tabular}

Mother's Education

Below H.S.

Some H.S.

$\begin{array}{ll}4 & 2.6\end{array}$

11

6.7

H.S. Grad.

21

13.8

20

12.3

Some Coll.

43

28.3

43

26.4

Coll. Grad

36

37

22.7

48

52

31.9

Father's Education

Below H.S.

$\begin{array}{cccc}4 & 2.8 & 8 & 4.9 \\ 9 & 6.3 & 18 & 11 \\ 38 & 26.8 & 43 & 26.1 \\ 41 & 28.9 & 36 & 22 \\ 50 & 35.2 & 59 & 36\end{array}$




\section{Parents' Level of Education}

Looking at the parents' level of education as a background factor, results indicate that the mother and father's levels of education were very similar for both cohort groups. $28.3 \%$ of the West Indian mothers and $26.8 \%$ of the West Indian fathers were high school graduates. The proportions were very similar for the Haitians mothers showing $26.4 \%$ and fathers $26.2 \%$ as high school graduates. The percentages of parents with college degrees were also very similar. $31.6 \%$ of the West Indian mothers and $31.9 \%$ of the Haitian mothers were college graduates. $35.2 \%$ of the West Indian fathers and $36 \%$ of the Haitian fathers were college graduates.

Those results may be surprising given the level of poverty in Haiti as compared to the other island and the specific nature of Haitian immigration into the U.S. However, it is important to note that the similarities in levels of parental education makes other comparisons between these two ethnic groups in the study less likely to be influenced by socioeconomic status differences.

\section{$\underline{\text { Socioeconomic Status }}$}

The socioeconomic statuses (SES) of the students in the cohort sample were determined using a formula developed for the larger study. This SES formula involved calculating the mean of both parents' levels of education plus their house size (measured by number of bedrooms and bathrooms as well as the number of occupants living in the house). Overall, socioeconomic statuses of the students in the larger sample were very low. Data indicated that $57 \%$ of the sixth graders and $48 \%$ of the seventh graders in the larger study 
were enrolled in the free or reduced lunch-cost program (Vega and Gil, 1998: p.26-27). In addition to SES, the analysis includes the students' academic performances. Table 3 below provides descriptive data on the academic performances of both groups at $\mathrm{T}-1$ and $\mathrm{T}-3$. 
Table 3.

Grade point average by Ethnicity

West Indians

$(\mathrm{N}=121)$

\section{Haitians}

$(\mathrm{N}=121)$

\begin{tabular}{ccc} 
& \multicolumn{2}{c}{ Time 1} \\
\cline { 2 - 3 } GPA* & N & Percent \\
$A$ & 0 & $0.0 \%$ \\
$B$ & 14 & $11.6 \%$ \\
$C$ & 53 & $43.8 \%$ \\
$D$ & 40 & $33.1 \%$ \\
$F$ & 14 & $11.6 \%$
\end{tabular}

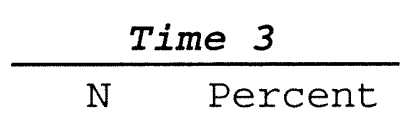

$\begin{array}{cc}0 & 0.0 \% \\ 14 & 11.6 \% \\ 49 & 40.5 \% \\ 42 & 34.7 \% \\ 16 & 13.2 \%\end{array}$

TOTAL

$121 \quad 100.0 \%$

$121 \quad 100.0 \%$

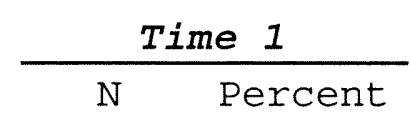

$\begin{array}{cc}0 & 0.0 \% \\ 8 & 6.6 \% \\ 51 & 42.1 \% \\ 45 & 37.2 \% \\ 17 & 14.0 \%\end{array}$

$121 \quad 100.0 \%$
Time 3

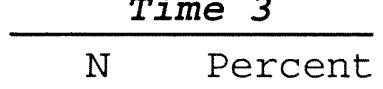

$\begin{array}{cc}0 & 0.0 \% \\ 8 & 6.7 \% \\ 46 & 38.3 \% \\ 51 & 42.5 \% \\ 15 & 12.5 \%\end{array}$

$120 \quad 100.0 \%$ 


\section{Academic Performance}

The mean GPA for West Indian students represented 1.88 on the four-point scale indicating a low "C" average. The students' cumulative grade point average (GPA) was measured at $\mathrm{T}-1,(\mathrm{~N}=121)$ and again at $\mathrm{T}-3(\mathrm{~N}=121)$. At $\mathrm{T}-1,11.6 \%$ of the West Indian students had an overall "B" GPA, 54.9\% had a "C" GPA, 33.9\% had a "D" and 11.6 had an "F" GPA. The cumulative GPA among the West Indian students at T-3, reflected only slight changes from that of $\mathrm{T}-1$ showing $11.6 \%$ of the students with an overall " $\mathrm{B}$ " GPA. 40.9\% had a "C" GPA, 34.7\% had a "D" and 13.2 had an "F" GPA.

The students' cumulative GPAs were also measured for Haitian students at T-1 $(\mathrm{N}=121)$ and again at $\mathrm{T}-3(\mathrm{~N}=120)$. The mean GPA for Haitian students represented 1.81 on the four-point scale or a high "D" average. At T-1, $6.6 \%$ of the students had an overall "B" GPA, 42.2\% had a "C" GPA, 37.2\% had a "D" and 14.0\% had an "F" GPA. The cumulative GPA was measured again at T-3 when $6.7 \%$ of the Haitian students had an overall "B" GPA, 42.5\% had a "C" GPA, 42.5\% had a "D" and 12.5 had an "F" GPA.

The academic profile shows that no West Indian or Haitian student in the cohort sample $(\mathrm{N}=243)$ had a cumulative "A" GPA. In addition to this fact the 'B' GPA for West Indians was almost double that of Haitians.

\section{English Proficiency}

As a background factor, English proficiency was considered an important factor only for Haitian students born in Haiti. English proficiency was not considered a relevant 
factor for West Indian students since they are native English speakers. Using a subsample of Haitian students $(\mathrm{N}=144)$, English proficiency was determined at $\mathrm{T}-1$ and again at T-3 by identifying the number of Haitian students who were enrolled in English as a Second Language classes or Functional Skill Classes. The results indicated that more than $97 \%$ of the Haitian students in the sample did not require English as a Second Language or Functional Skill Classes ${ }^{1}$. In addition to the data on English proficiency classes taken from school records students were asked the following question: "how many items on the questionnaire were hard to understand?" That question was used to determine the Haitian students' level of English proficiency at the time they completed the questionnaires. Each student was asked to respond by selecting one of the following responses: "None", "1 or 2 questions," "A few questions," and "A lot of the questions." All the Haitian students' responses to that question reflected the "None" category.

\section{The 'Time' Factor}

In addition to the background factors mentioned above 'time' was also used as a factor to measure changes that occurred in students' perceptions over the three periods of data collection, (T-1, T-2 and T-3). Time not only reflected the different periods of data collection it also facilitated the observation of developmental changes as the students proceeded through the middle schools.

${ }^{1}$ Over $50 \%$ of the Haitian students in the sample were born in the U.S. Thus, they were considered native English speakers. $30.2 \%$ of the Haitian students had lived in the U.S. for at least $6-11$ years. The other $24.1 \%$ were in the U.S. less than one year to five years. Only three out of 144 Haitian students in the sample were enrolled in ESOL classes. 


\section{Descriptive of Self-concept Scores}

Table 4 presents the self-concept scores for West Indian and Haitian students respectively at $\mathrm{T}-1, \mathrm{~T}-2$ and $\mathrm{T}-3$. The students' responded to the eleven items mentioned in chapter 3, which were used collectively as the indicator of self-concept level. When necessary the scores were reversed to reflect the direction of the response. The Cronbach's (1951) alpha coefficients for self-concept obtained at T-1 is .7 and obtained at $\mathrm{T}-3$ is .8 .

\section{$\underline{\text { West Indians' Profile }}$}

Scores for each question were totaled and a ranking of low, moderate and high was assigned to each student. Table 4 provides the resulting descriptive statistics for each group. At T-1, T-2 and T-3 the majority of West Indian students scored in the moderate to high ranges for self-concept. A change was observed between T-1 and T-2 indicating a $14 \%$ increase in the number of students scoring in the moderate and high ranges. At T-3 there was a slight movement toward the low self-concept range indicating a return to the ranges for self-concept observed at $\mathrm{T}-1$.

\section{Haitians' Profile}

Measured at T-1, T-2 and T-3 the majority of Haitian students scored in the moderate to high ranges for self-concept. At T-2 there was a slight increase in the percentage of students scoring in the low range. Between $\mathrm{T}-2$ and $\mathrm{T}-3$ there was also an increase in the percentage of students scoring in the high ranges. At T-3 scores increased from the 
moderate toward high levels indicating that over time the majority of Haitian students' scored in the moderate and high ranges for self-concept.

Although the majority of the students in both ethnic groups scored in the moderate to high ranges for self-concept across the three periods of data collection, more West Indians scored in the high range at T-1 and T-2 than did Haitians. However at T-3 Haitian students' scores also increased indicating movements toward the high range. The results of moderate to high self-concept scores among West Indian and Haitian students suggest that both groups presented with favorable views of themselves throughout middle school. 
Table 4.

Self-concept Descriptive Statistics by Ethnic Group at T-1, 2 and 3

West Indian students' self-concept

\begin{tabular}{|c|c|c|c|c|c|c|c|c|c|}
\hline \multirow{3}{*}{ Time } & \multicolumn{6}{|c|}{ Ranges } & & & \multirow[b]{2}{*}{ Total } \\
\hline & Low & or $<1$ & Mode & $e(28-35)$ & & $(35>)$ & & sing & \\
\hline & $\mathrm{N}$ & Percent & $\mathrm{N}$ & Percent & $\mathrm{N}$ & Percent & $\mathrm{N}$ & Percent & $\mathrm{N}$ \\
\hline$T-1$ & 34 & 19.7 & 45 & 26.0 & 86 & 49.7 & 8 & 4.6 & 173 \\
\hline$T-2$ & 33 & 19.1 & 56 & 32.4 & 82 & 47.4 & 2 & 1.2 & 173 \\
\hline $\mathrm{T}-3$ & 37 & 21.4 & 49 & 28.3 & 86 & 49.7 & 1 & 0.6 & 173 \\
\hline
\end{tabular}

Haitian students' self-concept

\begin{tabular}{|c|c|c|c|c|c|c|c|c|c|}
\hline \multirow{3}{*}{ Time } & \multicolumn{6}{|c|}{ Ranges } & & & \multirow[b]{2}{*}{ Total } \\
\hline & \multirow{2}{*}{$\begin{array}{c}\text { Low }(2 \\
N\end{array}$} & \multirow{2}{*}{$\begin{array}{l}3 \text { or }<\text { ) } \\
\text { Percent }\end{array}$} & \multicolumn{2}{|c|}{ Moderate $(28-35)$} & \multicolumn{2}{|c|}{$\operatorname{High}(35>)$} & \multicolumn{2}{|c|}{ Missing } & \\
\hline & & & $\mathrm{N}$ & Percent & $\mathrm{N}$ & Percent & $\mathrm{N}$ & Percent & $\mathrm{N}$ \\
\hline$T-1$ & 49 & 25.7 & 72 & 37.7 & 61 & 31.9 & 9 & 4.7 & 191 \\
\hline $\mathrm{T}-2$ & 53 & 27.7 & 55 & 28.8 & 74 & 38.7 & 9 & 4.7 & 191 \\
\hline$T-3$ & 46 & 24.1 & 56 & 29.3 & 84 & 44.0 & 5 & 2.6 & 191 \\
\hline
\end{tabular}

Note: Item responses ranged from 1-4, a total score lower than 28 indicated less favorable levels for self-concept, scores of 28-35 indicated moderate levels of self-concept and scores of 36 or higher indicated high levels of self-concept were more favorable levels of Self-concept. 


\section{Dependent Variables}

This section presents scores and ranges of the dependent variables that were examined among West Indians and Haitians respectively. The presentation of these scores and ranges reflect the students' perceptions of racial mistrust, teacher derogation and social mobility and provide important information on the profiles of the two groups. After testing each hypothesis, the results of the analyses are reported indicating the presence or lack of a presence of statistically significance relationships between the independent and dependent variables.

\section{$\underline{\text { Racial Mistrust }}$}

Table 5 shows the descriptive statistics of the items for racial mistrust from $\mathrm{T}-1$ to T-3. The Cronbach's (1951) alpha coefficients for racial mistrust of .6 was obtained at $\mathrm{T}-1$ and .8 at $\mathrm{T}-3$ (Also see appendix 1).

\section{West Indians' Profile for Racial Mistrust}

Most West Indian students scored in the moderate to high ranges for racial mistrust across all three periods of data collection. At T-1 $52 \%$ of the students scored in the moderate to high ranges. At T-2 47\% scored in the moderate and high ranges. At T-3 $63 \%$ scored in the moderate and high ranges (See Table 5). 
$\underline{\text { Haitians' Profile for Racial Mistrust }}$

The Haitian students' scores revealed moderate to high ranges for racial mistrust across all three periods. At T-1 over 55\% of the students scored in the moderate to high ranges. At $\mathrm{T}-2$ over $57 \%$ scored in the moderate and high ranges and at $\mathrm{T}-3$ over $63 \%$ scored in the moderate and high ranges. 
Table 5

Racial Mistrust Descriptive Statistics

by Ethnic Group

West Indian students' Racial Mistrust

\begin{tabular}{|c|c|c|c|c|c|c|c|c|c|}
\hline \multirow{3}{*}{ Time } & \multicolumn{6}{|c|}{ Ranges } & & & \multirow[b]{2}{*}{ Total } \\
\hline & \multicolumn{2}{|c|}{ Low $(14$ or $<)$} & \multicolumn{2}{|c|}{ Moderate $(15-20)$} & \multicolumn{2}{|c|}{ High (21-28) } & \multicolumn{2}{|c|}{ Missing } & \\
\hline & $\mathrm{N}$ & Percent & $\mathrm{N}$ & Percent & $\mathrm{N}$ & Percent & $\mathrm{N}$ & Percent & $\mathrm{N}$ \\
\hline $\mathrm{T}-1$ & 60 & $34.7 \%$ & 49 & $28.3 \%$ & 15 & $8.7 \%$ & 49 & $28.3 \%$ & 173 \\
\hline $\mathrm{T}-2$ & 67 & $38.7 \%$ & 48 & $27.7 \%$ & 12 & $6.9 \%$ & 46 & $26.6 \%$ & 173 \\
\hline $\mathrm{T}-3$ & 46 & $26.6 \%$ & 60 & $34.7 \%$ & 21 & $12.1 \%$ & 46 & $26.6 \%$ & 173 \\
\hline
\end{tabular}

Haitian students' Racial Mistrust

\begin{tabular}{cccccccccc} 
& \multicolumn{1}{l}{ Ranges } & & & & \\
Time & \multicolumn{2}{l}{ Low (14 } & or $<)$ & \multicolumn{2}{c}{ Moderate(15-20) } & \multicolumn{2}{c}{ High(21-28) } & & \multicolumn{2}{c}{ Missing } & Total \\
& $\mathrm{N}$ & Percent & $\mathrm{N}$ & Percent & $\mathrm{N}$ & Percent & $\mathrm{N}$ & Percent & $\mathrm{N}$ \\
$\mathrm{T}-1$ & 66 & $34.6 \%$ & 66 & $34.6 \%$ & 27 & $14.1 \%$ & 32 & $16.8 \%$ & 191 \\
$\mathrm{~T}-2$ & 66 & $34.6 \%$ & 79 & $41.4 \%$ & 11 & $5.8 \%$ & 35 & $18.3 \%$ & 191 \\
$\mathrm{~T}-3$ & 58 & $30.4 \%$ & 77 & $40.3 \%$ & 21 & $11.0 \%$ & 35 & $18.3 \%$ & 191
\end{tabular}

Note. Item responses ranged from 1-4, a total score of 14 or lower indicated more favorable levels of racial mistrust. Scores 15-20 indicated moderate levels of racial mistrust and scores 21-28 indicated high levels of racial mistrust that were less favorable. 


\section{Perceptions of Teacher Derogation}

Table 6 shows the descriptive statistics for the items that indicate perceptions of teacher derogation among West Indian and Haitian students. The Cronbach's (1951) alpha coefficients for teacher derogation obtained at both T-1 and T-3 were .8 (also see appendix 2).

West Indians' Perceptions of Teacher Derogation

Most West Indian students scored in the low range for teacher derogation across all three periods of data collection. At T-1, almost $80 \%$ of the students scored in the low range. At T-2 almost $74 \%$ scored in the low range and at T-3 over $79 \%$ scored in the low range.

\section{Haitians' Perceptions of Teacher Derogation}

Most Haitian students scored in the low range for teacher derogation across the three periods of data collection. At T-1,72\% scored in the low range. At T-2 almost $75 \%$ scored in the low range and at $\mathrm{T}-3$ over $73 \%$ scored in the low range. 
Table 6.

Teacher Derogation Descriptive Statistics

\section{By Ethnic Group \\ West Indian students' Teacher Derogation}

\begin{tabular}{|c|c|c|c|c|c|c|c|c|c|}
\hline \multirow{3}{*}{ Time } & \multicolumn{9}{|c|}{ Ranges } \\
\hline & Low & or $<1$ & \multicolumn{2}{|c|}{ Moderate $(9-11)$} & \multicolumn{2}{|c|}{ High (12-16) } & \multicolumn{2}{|c|}{ Missing } & Total \\
\hline & $\mathrm{N}$ & Percent & $N$ & Percent & $\mathrm{N}$ & Percent & $\mathrm{N}$ & Percent & $\mathrm{N}$ \\
\hline$T-1$ & 130 & $75.1 \%$ & 21 & $12.1 \%$ & 12 & $6.9 \%$ & 10 & $5.8 \%$ & 173 \\
\hline $\mathrm{T}-2$ & 128 & $74.0 \%$ & 34 & $19.7 \%$ & 9 & $5.2 \%$ & 2 & $1.2 \%$ & 173 \\
\hline $\mathrm{T}-3$ & 119 & $68.8 \%$ & 37 & $21.4 \%$ & 14 & $8.1 \%$ & 3 & $1.7 \%$ & 173 \\
\hline
\end{tabular}

Haitian students' Teacher Derogation

\begin{tabular}{|c|c|c|c|c|c|c|c|c|c|}
\hline \multirow{3}{*}{ Time } & \multicolumn{9}{|c|}{ Ranges } \\
\hline & Low & or $<1$ & \multicolumn{2}{|c|}{ Moderate $(9-11)$} & \multicolumn{2}{|c|}{$\operatorname{High}(12-16)$} & \multicolumn{2}{|c|}{ Missing } & Total \\
\hline & $\mathrm{N}$ & Percent & $\mathrm{N}$ & Percent & $\mathrm{N}$ & Percent & $\mathrm{N}$ & Percent & $\mathrm{N}$ \\
\hline $\mathrm{T}-1$ & 130 & $68.1 \%$ & 33 & $17.3 \%$ & 17 & $8.9 \%$ & 11 & $5.8 \%$ & 191 \\
\hline $\mathrm{T}-2$ & 136 & $71.2 \%$ & 32 & $16.8 \%$ & 14 & $7.3 \%$ & 9 & $4.7 \%$ & 191 \\
\hline$T-3$ & 136 & $71.2 \%$ & 33 & $17.3 \%$ & 16 & $8.4 \%$ & 6 & $3.1 \%$ & 191 \\
\hline
\end{tabular}

Note. Item responses ranged from 1-4, a total score of lower 8 or lower indicated more favorable levels of teacher derogation, scores of 9-11 indicated moderate levels of teacher derogation and scores of 12-16 indicated high levels of teacher derogation that were less favorable 


\section{Perceptions of Social mobility}

Table 7 shows the descriptive statistics perceptions of social mobility scores for West Indian and Haitian Students respectively at T-1,2 and 3. It is important to note that the Cronbach's (1951) alpha coefficients for social mobility tested at T-1 and T-3 were relatively low however the items had face validity therefore the measures were retained for the purpose of this study. The Cronbach's (1951) alpha coefficients for social mobility obtained at T-1 was .3 and .5 at T-3. Given these alpha levels the analyses and findings specific to social mobility are considered very conservative.

\section{West Indians' Profile}

There were fluctuations in the levels of optimism for social mobility across all three periods of data collection among West Indians. At T-1 over $58 \%$ of West Indian students scored in the high optimism range. Over $26 \%$ in the moderate range and a little over $14 \%$ scored in the low optimism range. At T-2 almost 53\% scored in the high range, over $36 \%$ scored in the moderate range and slightly under $10 \%$ in the low range. At T-3, over $54 \%$ of West Indian students scored in the high optimism range, over $28 \%$ scored in the moderate range and slightly more than $11 \%$ scored in low optimism range for social mobility (see Table 7). 
Haitians' Profile

There were fluctuations also in Haitian students' perceptions of optimism for social mobility scores across the three periods of data collection. Most of the fluctuations were found between the moderate to high ranges therefore the scores remained within favorable levels of optimism toward social mobility. At T-1 over $54 \%$ of Haitian students scored in the high range for optimism toward social mobility, over $28 \%$ scored in the moderate range and a little under $18 \%$ scored in the low range. At T-2 over $54 \%$ scored in the high range, over $34 \%$ scored in the moderate range and slightly under $11 \%$ scored in the low range. At T-3 only a little over $37 \%$ of Haitian students scored in the high range, over $45 \%$ in the moderate range and slightly under $17 \%$ scored in low range reflecting a drop towards the moderate levels. 
Table 7.

Optimism for Social Mobility Descriptive Statistics

By Ethnic Group

West Indians' Optimism Toward Social Mobility

\begin{tabular}{|c|c|c|c|c|c|c|c|c|c|}
\hline \multirow{3}{*}{ Time } & \multicolumn{6}{|c|}{ Ranges } & & & \multirow{3}{*}{$\begin{array}{c}\text { Total } \\
N\end{array}$} \\
\hline & \multirow{2}{*}{$\begin{array}{l}\text { Low }(\varepsilon \\
\mathrm{N}\end{array}$} & \multirow{2}{*}{$\begin{array}{l}\text { or }<) \\
\text { Percent }\end{array}$} & \multicolumn{2}{|c|}{ Moderate $(9-11)$} & \multicolumn{2}{|c|}{$\operatorname{High}(12-16)$} & \multicolumn{2}{|c|}{ Missing } & \\
\hline & & & $\mathrm{N}$ & Percent & $\mathrm{N}$ & Percent & $\mathrm{N}$ & Percent & \\
\hline$T-1$ & 25 & $14.5 \%$ & 46 & $26.6 \%$ & 102 & $59.0 \%$ & 0 & $0.0 \%$ & 173 \\
\hline $\mathrm{T}-2$ & 17 & $9.8 \%$ & 64 & $37.0 \%$ & 92 & $53.2 \%$ & 0 & $0.0 \%$ & 173 \\
\hline$T-3$ & 19 & $11.0 \%$ & 98 & $56.6 \%$ & 56 & $32.4 \%$ & 0 & $0.0 \%$ & 173 \\
\hline
\end{tabular}

\section{Haitians' Optimism Toward Social Mobility}

\begin{tabular}{|c|c|c|c|c|c|c|c|c|c|}
\hline \multirow{3}{*}{ Time } & \multicolumn{8}{|c|}{ Ranges } & \multirow{3}{*}{$\begin{array}{c}\text { Total } \\
\mathrm{N}\end{array}$} \\
\hline & \multirow{2}{*}{$\begin{array}{l}\text { Low }(\varepsilon \\
\mathrm{N}\end{array}$} & \multirow{2}{*}{$\begin{array}{l}\text { or }<) \\
\text { Percent }\end{array}$} & \multicolumn{2}{|c|}{ Moderate (9-11) } & \multicolumn{2}{|c|}{$\operatorname{High}(12-16)$} & \multicolumn{2}{|c|}{ Missing } & \\
\hline & & & $\mathrm{N}$ & Percent & $\mathrm{N}$ & Percent & $\mathrm{N}$ & Percent & \\
\hline$T-1$ & 33 & $17.3 \%$ & 54 & $28.3 \%$ & 104 & $54.5 \%$ & 0 & $0.0 \%$ & 191 \\
\hline $\mathrm{T}-2$ & 21 & $11.0 \%$ & 66 & $34.6 \%$ & 104 & $54.5 \%$ & 0 & $0.0 \%$ & 191 \\
\hline $\mathrm{T}-3$ & 32 & $16.8 \%$ & 86 & $45.0 \%$ & 72 & $37.7 \%$ & 1 & $0.5 \%$ & 191 \\
\hline
\end{tabular}

Note. Item responses ranged from 1-4, a total score of lower 8 or lower indicated less favorable levels of optimism toward social mobility, scores of 9-11 indicated moderate of optimism toward social mobility and scores of 12-16 indicated high levels of optimism towards social mobility that more less favorable. 


\section{Hypotheses Testing and Multivariate Analyses}

This section presents the result of the analyses that tested hypotheses \#1-6. In testing each hypothesis consideration was given to the age and developmental stage of the respondents. For example, with each analysis involving examination of the correlation it is important to bear in mind that adolescents tend to respond in the extreme ends of scales. Therefore, for correlation analyses the focus was placed not only on linear correlations since those correlations alone may not be sufficient to detect nonlinear relationships that may be present.

This section also presents the multivariate analyses results. Focus is placed on the relationships between the identified dependent variables and independent variables, which the study introduced for hypotheses testing. Pearson correlation tests were conducted to determine existence and the degree of relationships between length of stay and perceptions of racial mistrust, teacher derogation and social mobility across T-1, T-2 and T-3. The results are presented in Tables 8,9 and 10. Pearson correlation tests were also conducted to determine the degree of relationships between self-concept and perceptions of racial mistrust and teacher derogation at $\mathrm{T}-1, \mathrm{~T}-2$ and $\mathrm{T}-3$. The results are also presented in Tables 8,9 and 10, with profile information presented in Charts 3 and $4)$. 


\section{Testing Hypothesis \#1}

Hypothesis \#1 proposes that the longer the student has lived in the U.S. the more likely it is for he or she to report racial mistrust.

Hypothesis \#1 required an examination of the relationship between the independent variable length of stay and the dependent variable perceptions of racial mistrust using correlation analysis.

$\underline{\text { West Indians }}$

At T-1 West Indian students living in the U.S. for 5 years or less scored mostly in the moderate range for racial mistrust. Those who living here for 6-10 years scored mostly in the low range while those with 11 or more years (most of the U.S. born) scored in the moderate range for racial mistrust. At T-2 students who lived in the U.S. for 5 years or less scored mostly in the low range for racial mistrust and those here 6-10 years scored mostly in the low range. Those with 11 or more years and mostly U.S. born scored in the moderate range for racial mistrust. Similarly at T-3 West Indian students living here for 5 years or less scored mostly in the low range. Those here 6-10 years scored mostly in the moderate range, and those with 11 or more years (mostly U.S. borns) scored in the moderate range for racial mistrust (Chart 3 also Tables 8, 9 and 10 and appendix 1). 


\section{Haitians' Results}

At $\mathrm{T}-1$ regardless of the number of years lived in the U.S., most Haitian students scored the moderate range for racial mistrust. At T-2 those in the U.S. for 5 years or less scored in the low range. Those here for 6-10 years scored mostly in the moderate range and those with 11 or more years (U.S. born) scored in the moderate range for racial mistrust. At T-3 Haitian students here for 5 years or less scored mostly in the moderate range. Those here for 6-10 years in the low range, and those with 11 or more years (mostly U.S. borns) scored in the moderate range for racial mistrust.

\section{Correlation Results for Hypotheses \#1}

Overall, correlation tests results indicate that there were few statistically significant relationships between variable length of stay and racial mistrust for both ethnic groups (See Tables 8, 9 and 10.)

\section{$\underline{\text { West Indians }}$}

Among West Indian students at T-1 and T-2 no statistically significant relationships between length of stay and perceptions of racial mistrust was indicated. Only T-3 was a positive relationship indicated between that between length of stay and perceptions racerelated mistrust was statistically significant at $p<.01$ level. 


\section{$\underline{\text { Haitians }}$}

Among Haitians no statistically significant relationships was indicated between length of stay and perceptions of racial mistrust at $\mathrm{T}-1, \mathrm{~T}-2$ or $\mathrm{T}-3$. 
Influence of Length of stay on Perceptions of Racial Mistrust

by Ethnicity

West Indians'

Perception of Racial Mistrust

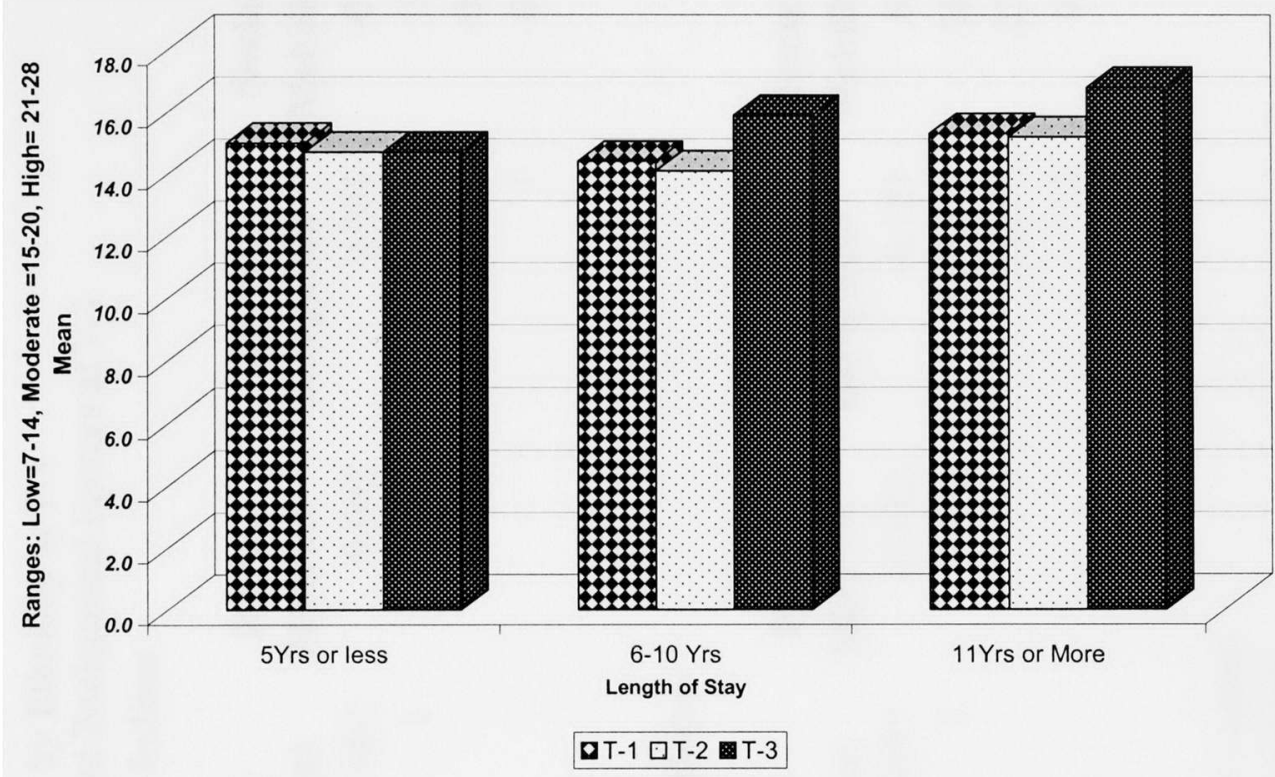

Haitians'

Perception of Racial Mistrust

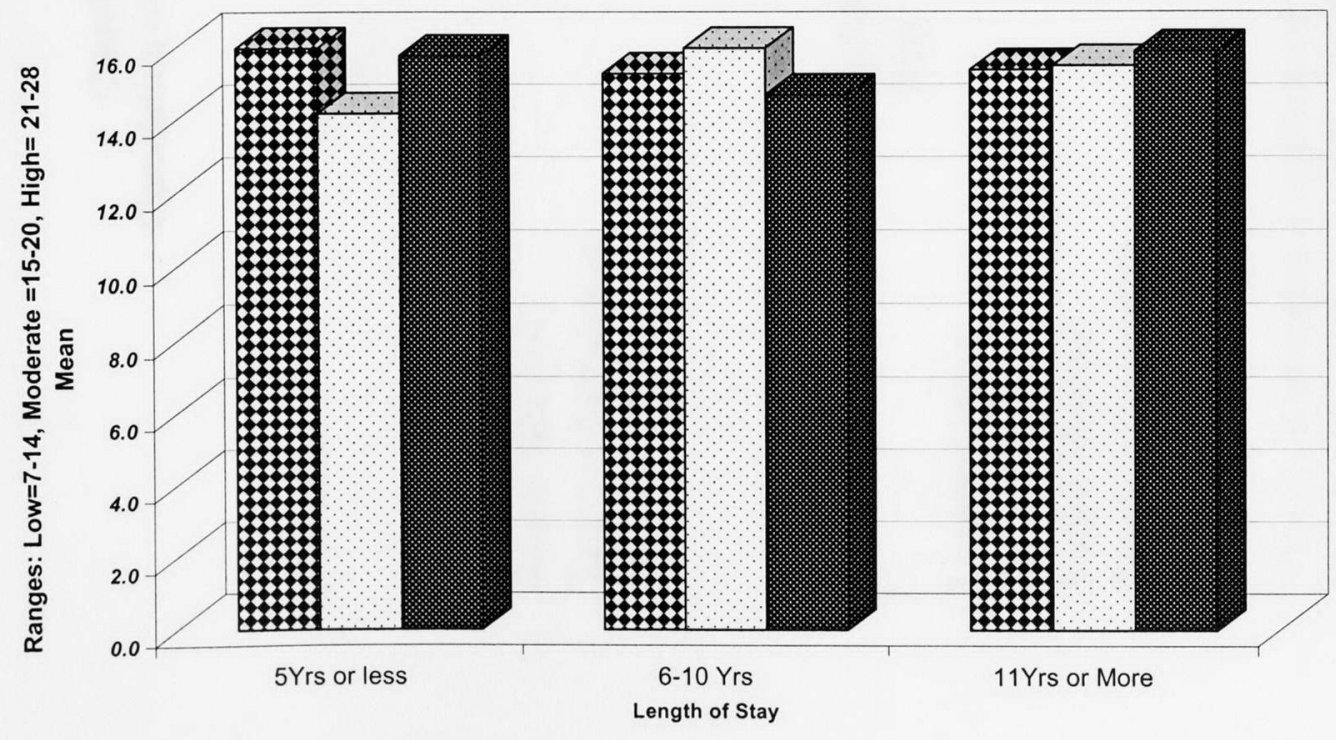

[T-1 T-2 숭 T-3 
Table 8.

Correlation Matrix by Ethnicity at T-1

Correlation of Variables and Background Factors at T-1

West Indians

\begin{tabular}{|c|c|c|c|c|c|}
\hline Variables & $\begin{array}{l}\text { Length of } \\
\text { Stay }\end{array}$ & $\begin{array}{c}\text { Self- } \\
\text { concept }\end{array}$ & $\begin{array}{c}\text { Racial } \\
\text { Mistrust }\end{array}$ & $\begin{array}{c}\text { Teacher } \\
\text { Derogation }\end{array}$ & $\begin{array}{c}\text { Social } \\
\text { Mobility }\end{array}$ \\
\hline Length of Stay & 1 & 0.062 & 0.063 & 0.033 & -0.001 \\
\hline Self-concept & & 1 & $-.281 * *$ & $-.403 * *$ & $.174^{*}$ \\
\hline Racial Mistrust & & & 1 & $.410^{* *}$ & -0.052 \\
\hline $\begin{array}{l}\text { Teacher Derogation } \\
\text { Social Mobility }\end{array}$ & & & & 1 & -0.129 \\
\hline
\end{tabular}

\section{Haitians}

Variables

Length of
Stay

Self-

Racial

Teacher

Social

Length of Stay

Self-concept concept

Mistrust

Derogation

Mobility

Racial Mistrust

$.234 * *$
1

$-0.082$

$-0.12$

0.099

$-.297 * *$

$-.420 * *$

$.180 * *$

Teacher Derogation

1

$.417 * *$

$277 * *$

Social Mobility

1

0.086

${ }^{* *} \mathrm{P}<.01$. (Correlation is significant at the 0.01 level (1-tailed).

$* \mathrm{P}<.05$. (Correlation is significant at the 0.05 level (1-tailed). 
Table 9

Correlation Matrix by Ethnicity at T-2

Correlation of Variables and Background Factors at T-2

West Indians

Variables

Length of Stay

Self-concept

Racial Mistrust

Teacher Derogation

Social Mobility

Variables

Length of Stay

Self-concept

Racial Mistrust

Teacher Derogation

Social Mobility

\begin{tabular}{|c|c|c|c|c|}
\hline \multirow[t]{5}{*}{$\begin{array}{c}\text { Length of } \\
\text { Stay }\end{array}$} & $\begin{array}{c}\text { Self- } \\
\text { concept }\end{array}$ & $\begin{array}{c}\text { Racial } \\
\text { Mistrust }\end{array}$ & $\begin{array}{c}\text { Teacher } \\
\text { Derogation }\end{array}$ & $\begin{array}{c}\text { Social } \\
\text { Mobility }\end{array}$ \\
\hline & 0.01 & 0.125 & 0.025 & -0.019 \\
\hline & 1 & -0.088 & $-.279 * *$ & $.284^{* *}$ \\
\hline & & 1 & $.439 * *$ & -0.041 \\
\hline & & & 1 & -0.11 \\
\hline
\end{tabular}

Haitians

Length of
Stay

Self-
concep
.165

\begin{tabular}{c}
\multicolumn{1}{c}{ Racial } \\
Mistrust \\
0.084 \\
0.017 \\
1
\end{tabular}

Teacher

Social

Derogation

0.049

$-.248 * *$

$.297 * *$

1

\section{Mobility}

$-0.038$

$.370 * *$

0.077

$-0.102$

${ }^{* *} \mathrm{P}<.01$. (Correlation is significant at the 0.01 level ( 1 -tailed).

$* \mathrm{P}<.05$. (Correlation is significant at the 0.05 level (1-tailed). 
Table 10

Correlation Matrix by Ethnicity at T-3

Correlation of Variables and Background Factors at T-3

West Indians

\begin{tabular}{|c|c|c|c|c|c|}
\hline Variables & $\begin{array}{c}\text { Length of } \\
\text { Stay }\end{array}$ & $\begin{array}{c}\text { Self- } \\
\text { concept }\end{array}$ & $\begin{array}{c}\text { Racial } \\
\text { Mistrust }\end{array}$ & $\begin{array}{c}\text { Teacher } \\
\text { Derogation }\end{array}$ & $\begin{array}{c}\text { Social } \\
\text { Mobility }\end{array}$ \\
\hline Length of Stay & 1 & 0.123 & $.175^{*}$ & -0.025 & $.161 *$ \\
\hline Self-concept & & 1 & -0.058 & $-416^{* *}$ & $.189^{* *}$ \\
\hline Racial Mistrust & & & 1 & $.415^{* *}$ & -0.037 \\
\hline Teacher Derogation & & & & 1 & -0.042 \\
\hline Social Mobility & & & & & 1 \\
\hline
\end{tabular}

Haitians

Variables

Length of Stay

Self-concept

Racial Mistrust

Teacher Derogation

Social Mobility

\begin{tabular}{|c|c|c|c|c|c|}
\hline \multirow{5}{*}{$\begin{array}{l}\text { Length of } \\
\text { Stay }\end{array}$} & & $\begin{array}{c}\text { Self- } \\
\text { concept }\end{array}$ & $\begin{array}{c}\text { Racial } \\
\text { Mistrust }\end{array}$ & $\begin{array}{c}\text { Teacher } \\
\text { Derogation }\end{array}$ & $\begin{array}{c}\text { Social } \\
\text { Mobility }\end{array}$ \\
\hline & 1 & 0.111 & 0.057 & -0.019 & 0.021 \\
\hline & & 1 & -0.037 & $-.310^{* *}$ & $.408^{* *}$ \\
\hline & & & 1 & $.285^{* *}$ & 0.026 \\
\hline & & & & 1 & -0.099 \\
\hline
\end{tabular}

$* * \mathrm{P}<.01$. (Correlation is significant at the 0.01 level (1-tailed).

${ }^{*} \mathrm{P}<.05$. (Correlation is significant at the 0.05 level ( 1 -tailed). 


\section{Testing Hypothesis \#2}

Hypothesis \#2 proposes that the longer the student has lived in the U.S. the more likely it is for he or she to perceive teacher derogation.

Hypothesis \#2 required the examination of the association between length of stay and the dependent variable and perceptions of teacher derogation using correlation analysis.

$\underline{\text { West Indians' Profile }}$

Across all three periods of data collection regardless of the number of years living in the U.S. all West Indian students' scores for teacher derogation remained in the low ranges (See Tables 8, 9 and 10 and Chart 4).

\section{Haitians' Profile}

Regardless of the number of years lived in the U.S. all Haitian students' scores for teacher derogation remained in the low ranges at $\mathrm{T}-1$ and $\mathrm{T}-2$. However at $\mathrm{T}-3$, the scores did increase to the moderate range. 
Chart 2.

Relationship between Lengths of Stay and Perceptions of Teacher Derogation West Indians'

Perception of Teacher Derogation

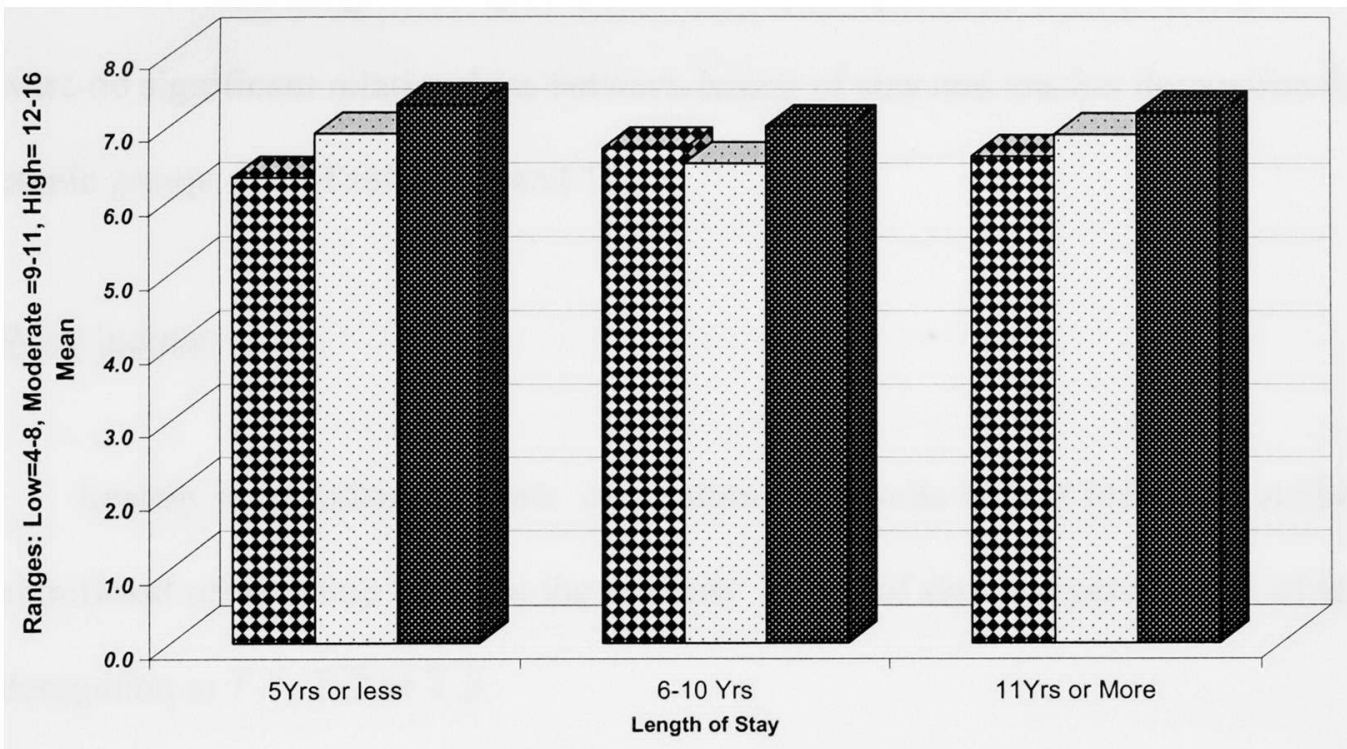

凶T-1 T-2 중-3

Haitians'

Perception of Teacher Derogation

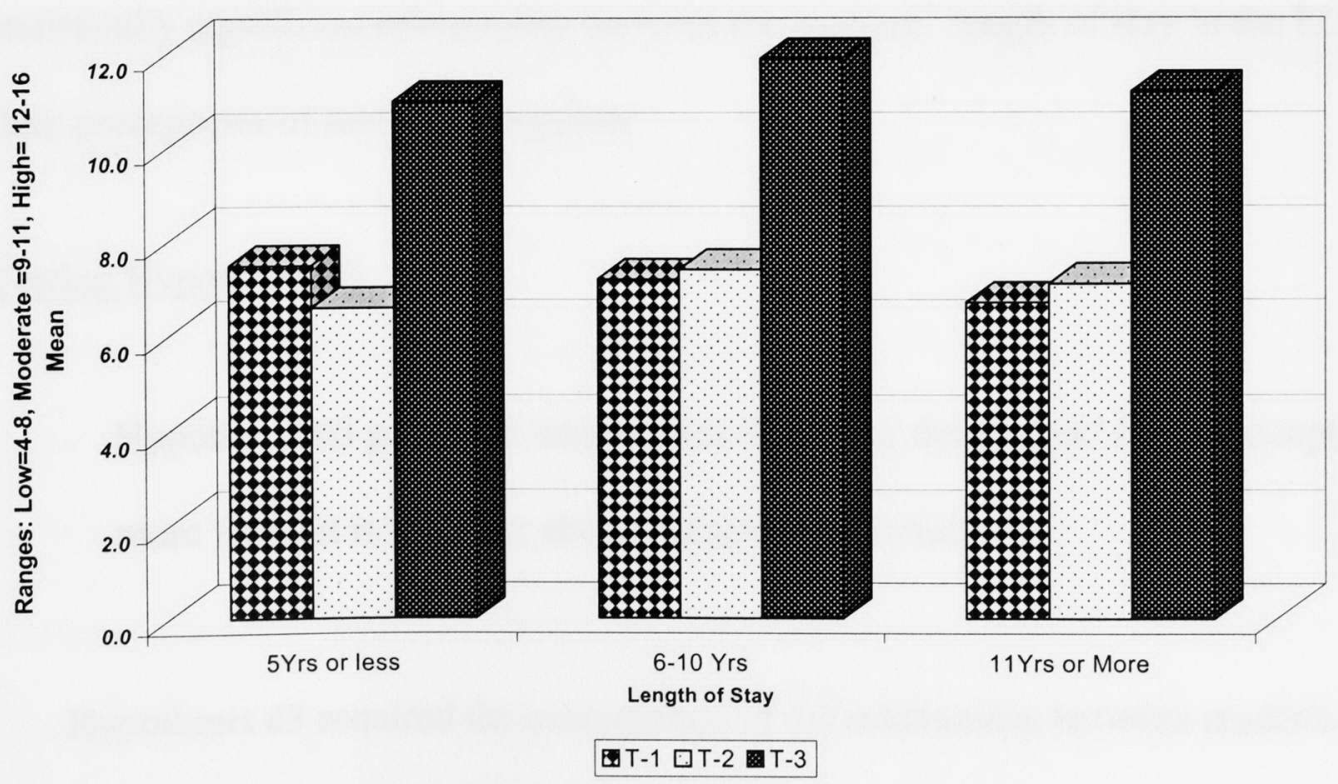


Correlation tests were used to examine the relationship between West Indian and Haitian students' length of stay in the U.S. and perceptions of teacher derogation. There were no significant relationships between length of stay and teacher derogation for either ethnic groups (See Tables 8, 9 and 10).

\section{West Indians}

Among West Indian students' correlation test results did not indicate a statistically significant relationship between the students' length of stay and perceptions of teacher derogation at $\mathrm{T}-1, \mathrm{~T}-2$ or $\mathrm{T}-3$.

\section{Haitians}

Among Haitians at T-1, T-2 and T-3 correlation tests results did not indicate a statistically significant relationship between the students' length of stay in the U.S. and their perceptions of teacher derogation

\section{Testing Hypothesis \#3}

Hypothesis \#3 proposed that the less favorable the student's self-concept the more likely it is for he or she to perceive racial mistrust.

Hypothesis \#3 required the examination of the relationship between students' selfconcept and perception of racial mistrust (See Tables 8, 9 and 10). 


\section{West Indians' Profile}

At T-1 most West Indian students scored in the high range for self-concept and reported low levels of racial mistrust. Students scoring in the moderate range for selfconcept reported moderate level for racial mistrust. However, those with scores in the low range also reported moderate levels of racial mistrust. At T-2 most students' with self-concept scores in the high range reported low level of racial mistrust. Those with self-concept scores in the moderate range reported moderate levels of racial mistrust. Those with self-concept scores in the low range reported moderate levels of racial mistrust. T-3 reflected some changes in racial mistrust levels indicating that all West Indian students regardless of self-concept scores reported moderate levels of racial mistrust (See Table 10 and chart 3; also see appendix 3).

\section{Haitians' Profile}

At T-1 the majority of Haitian students scored in the moderate range for self-concept and reported low levels of racial mistrust. Those with self-concept scores in the high range reported low levels of racial mistrust while those with low self-concept scores reported moderate levels. At T-2 more of the Haitian students' self-concept scores were in the high range (higher than at T-1) and they reported moderate levels of racial mistrust. At T-2 fewer students had self-concept scores in the moderate ranges and they reported low levels of racial mistrust. Those with self-concept scores in the low range reported moderate levels of racial mistrust. At T-3, which reflected an increase the number of 
students scoring in the high range for self-concept those students also reported moderate levels of racial mistrust (See Table 10 and chart 3). 
Chart 3

Relationship between students' self-concept and Perception of Racial Mistrust

West Indians'

Students' Self-concept and Perception of Racial Mistrust

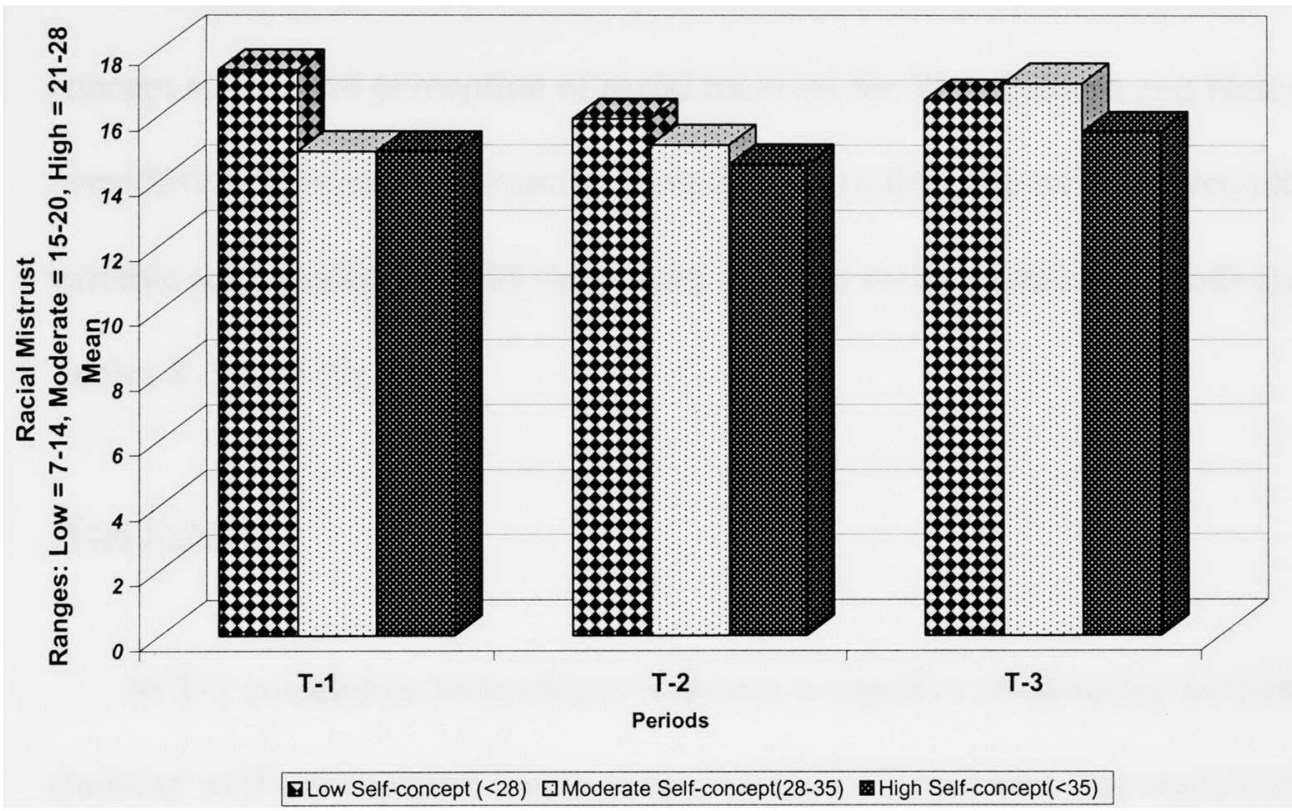

Haitians'

Students' Self-concept and Perception of Racial Mistrust

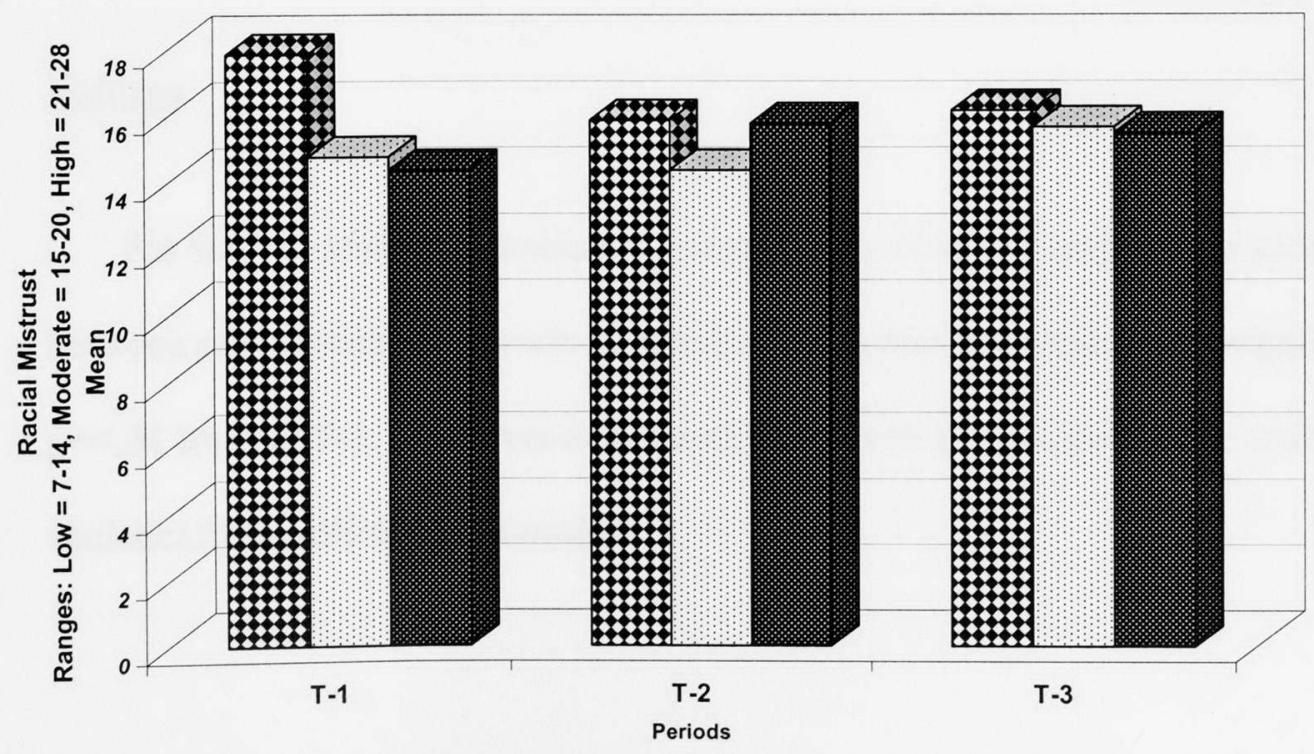

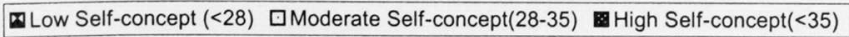


Correlation Results for Hypotheses \#3

Correlation tests were used to examine the relationship between students' selfconcept scores and perception of racial mistrust for West Indians and Haitians respectively. Some significant relationships were found to exist between the independent variable self-concept and the dependent variable racial mistrust for both groups (See Tables 8,9 and 10$)$.

$\underline{\text { West Indians }}$

At $\mathrm{T}-1$ correlation tests results indicates a negative relationship between West Indian students' self-concept and levels of race-related mistrust that was statistically at $\mathrm{p}=<.01$ level. However, correlation results did not indicate a statistically significant relationship at $\mathrm{T}-2$ or $\mathrm{T}-3$.

$\underline{\text { Haitians }}$

For Haitian students correlation tests results indicates a negative relationship between self-concept and levels of racial mistrust that was statistically significant at $\mathrm{p}=<.01$ level at $\mathrm{T}-1$. However at $\mathrm{T}-2$ and $\mathrm{T}-3$ correlation results not did indicate a statistically significant relationship. 
Hypothesis \#4 proposed that the less favorable the student's self-concept, the more likely it is for he or she to perceive teacher derogation.

Hypothesis \#4 required the examination of the relationship between self-concept and teacher derogation (See Tables 8, 9 and 10).

\section{West Indians'}

At T-1 and T-2 most West Indian students scored in the high range for self-concept. The majority of the students reported low level of teacher derogation. At T-3, which reflected some changes in teacher derogation levels more students reported moderate levels of teacher derogation (see chart 4.; also see appendix 4.).

\section{Haitians'}

At $\mathrm{T}-1$ the majority of the Haitian students scored in the moderate to high ranges for selfconcept with the majority reporting low levels of teacher derogation. At T-2 the majority of students scored in the moderate to high ranges for self-concept with an increase toward the high range. At T-3, which also reflected an increase in the number of Haitian students scoring in the high range for self-concept the majority of the students reported low levels of teacher derogation. 
Chart 4.

Relationship between self-concept and Perceptions of Teacher Derogation

West Indians'

Students' Self-concept and Perception of Teacher Derogation

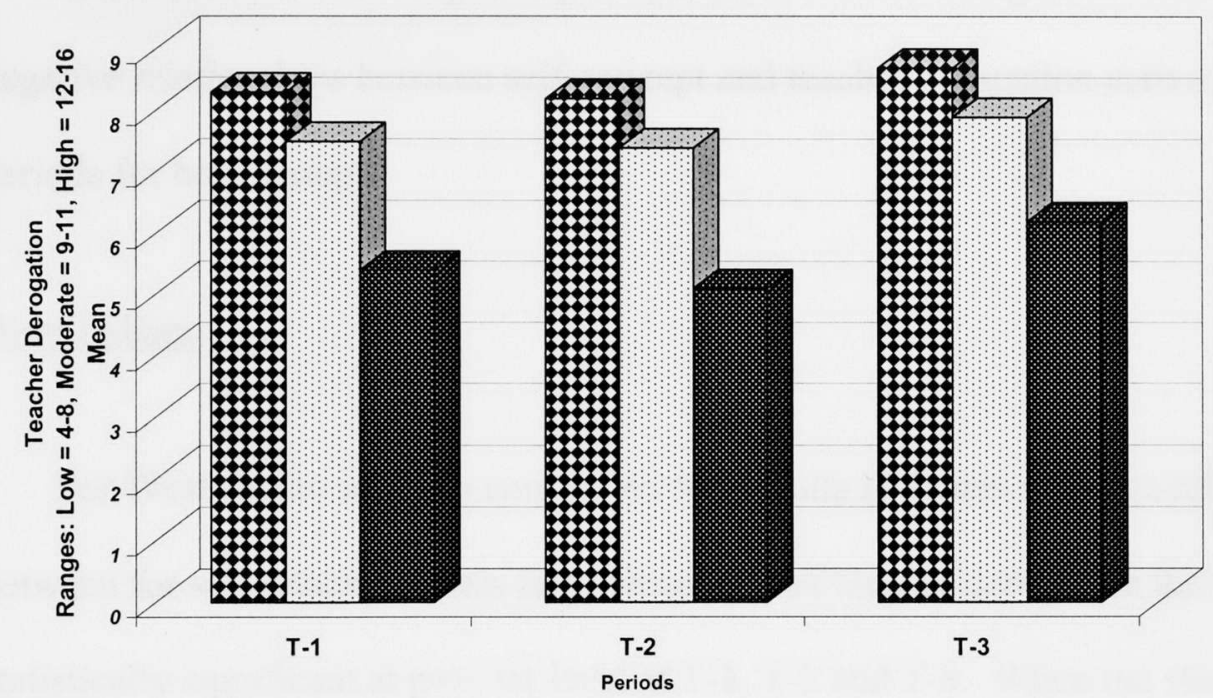

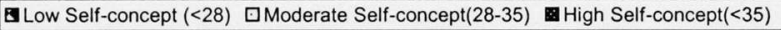

Haitians'

Students' Self-concept and Perception of Teacher Derogation



Low Self-concept (<28) घModerate Self-concept(28-35) 


\section{Correlation Results for Hypothesis \#4}

Correlation tests were used to examine the relationship between West Indian and Haitian students' self-concept and perceptions of teacher derogation. Overall, there were negative relationships between self-concept and teacher derogation across the three periods for both groups.

\section{$\underline{\text { West Indians }}$}

For West Indian students correlation test results indicates negative relationships between for self-concept scores and perceptions of teacher derogation that were statistically significant at $\mathrm{p}=<.01$ level at $\mathrm{T}-1, \mathrm{~T}-2$ and $\mathrm{T}-3$. When the students' selfconcept scores increased their perceptions of teacher derogation decreased.

\section{$\underline{\text { Haitians }}$}

Among Haitian students correlation test results indicates negative relationships between for self-concept scores and perceptions of teacher derogation that were statistically significant at $\mathrm{p}=<.01$ level at $\mathrm{T}-1, \mathrm{~T}-2$ and $\mathrm{T}-3$. For Haitians when selfconcept scores increased perceptions of teacher derogation decreased.

\section{Testing Hypothesis \#5}

Hypothesis \#5 proposed that the longer the student lived in the U.S. the more likely it is for the student to perceive less chances for social mobility. 
West Indians' Profile

Across the three periods of data collection regardless of their length of stay in the U.S. (5yrs or less, 6-10yrs or $11 \mathrm{yrs}$ or more) most of the West Indian students reported moderate levels of optimism toward social mobility (See appendix 5 also Tables 8, 9 and $10)$.

Haitians' Profile

Across the three periods of data collection regardless of their length of stay in the U.S. (5yrs or less, 6-10yrs or 11 yrs or more) most of the Haitian students reported moderate levels of social mobility. 
Chart 5.

Relationship between Length of Stay and Perceived Chance for Social Mobility

West Indians'

Perception of Social Mobilty by Length of Stay

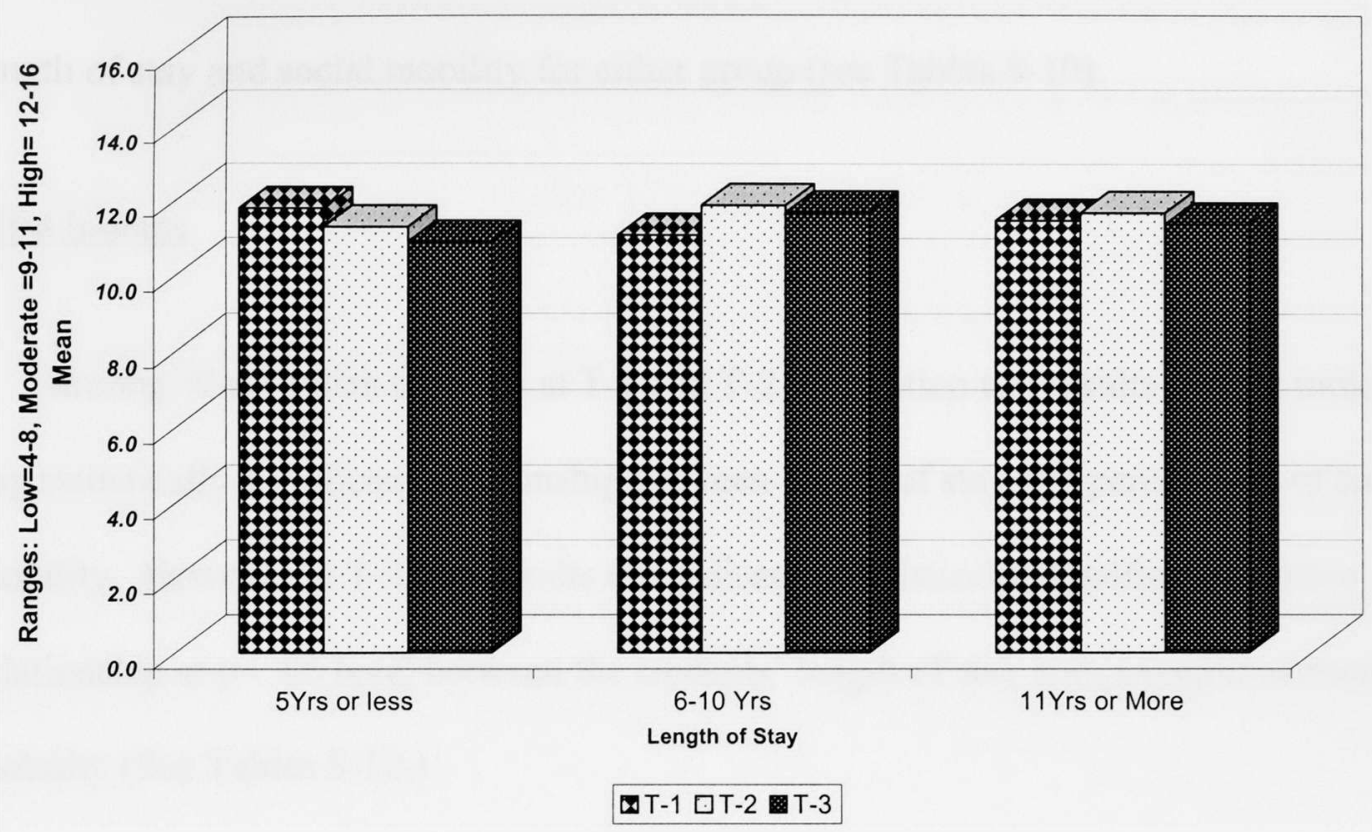

Haitians'

Perception of Social Mobilty by Length of Stay

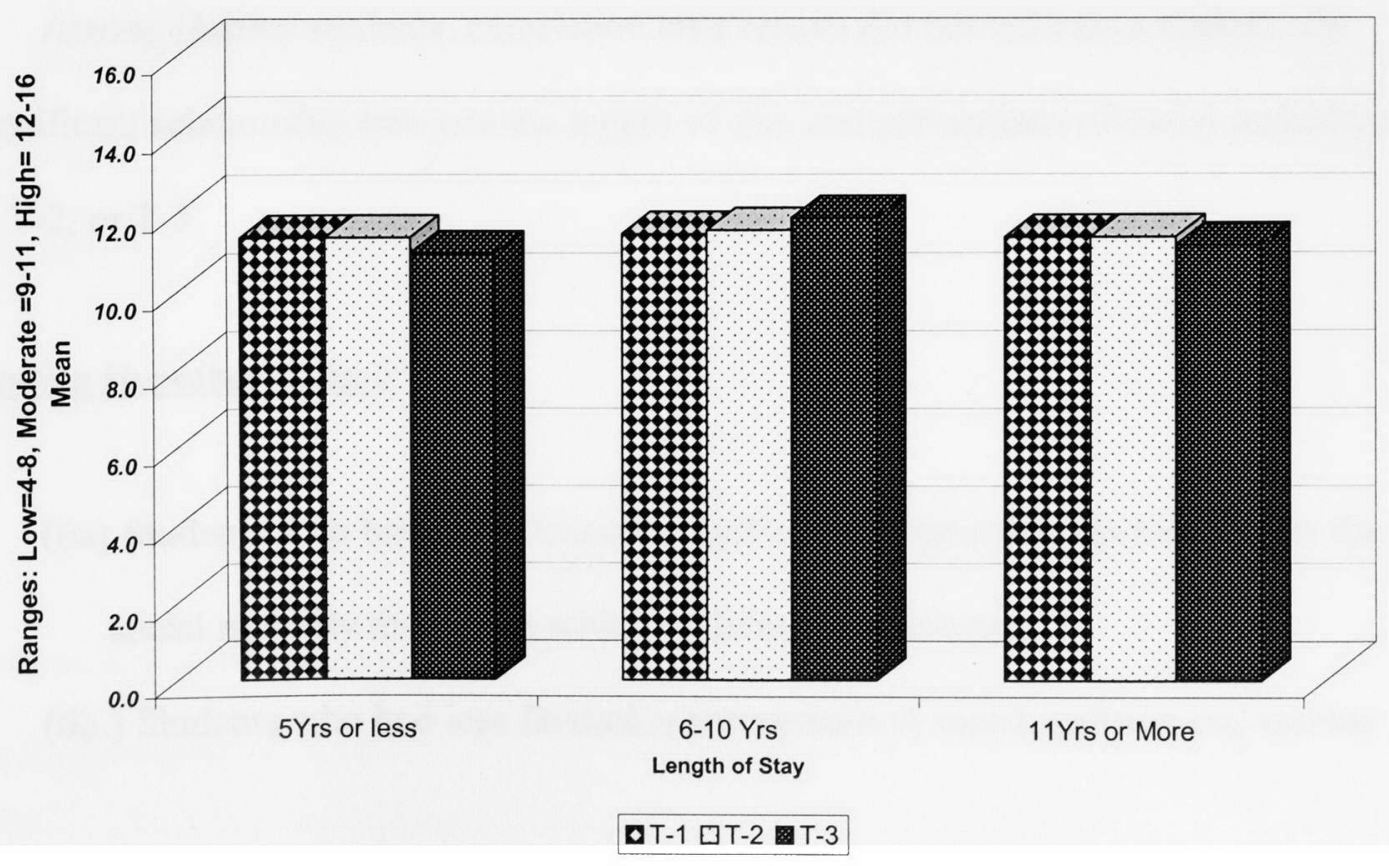




\section{Correlation result for Hypothesis 5}

Hypothesis \#5 required the examination of the relationship between length of stay and social mobility. Overall, there were very few significant relationships between length of stay and social mobility for either group (see Tables 8-10).

\section{$\underline{\text { West Indians }}$}

Among West Indian students at T-1 and T-2 correlation test results did not indicate any statistically significant relationship between length of stay and perceptions of social mobility. However at $\mathrm{T}-3$, the results did indicate a statistically significant positive relationship at $\mathrm{p}<.05$ level between the students' length of stay and perceptions social mobility (See Tables 8-10.)

\section{$\underline{\text { Haitians }}$}

Among Haitian students, correlation tests results did not indicate a statistically significant relationship between the length of stay and perceptions of social mobility at T$1, \mathrm{~T}-2$, or $\mathrm{T}-3$.

\section{Testing Hypothesis \#6a-b}

(6a) Students who had more favorable self-concept perceived more chances for social mobility than those with less favorable self-concepts.

(6b.) Students who had less favorable perceptions of racial mistrust and teacher 
derogation would be more pessimistic in terms of their perceptions of chances for social mobility.

Hypothesis \#6a involved an examination of not only the relationships between self-concept and social mobility but also the percent changes in the relationships that occurred across T-1, T-2 and T-3 (See Table 11 and chart 6).

\section{Correlation Results for Hypothesis 6a}

For Hypotheses $6 \mathrm{a}$, correlation tests were used to examine the relationship between students' self-concept and perceptions of social mobility. Overall, there were positive relationships between self-concept and social mobility across the three periods for both groups.

\section{West Indians}

Among West Indian students at T-1 and T-3 correlation test results indicates positive relationships between the students' self-concept and social mobility that were statistically significant at $\mathrm{p}=<.01$ level and at $\mathrm{p}=<.05$ level at $\mathrm{T}-3$.

\section{Haitians}

Among Haitian students at T-1, T-2 and T-3 correlation test results also indicated a statistically significant positive relationship between the students' self-concept and social mobility at $\mathrm{p}=<.01$ level. 


\section{Tracking Percent Changes across $\mathrm{T}-1, \mathrm{~T}-2$ and $\mathrm{T}-3$}

In calculating the percent changes in the relationship between self-concept and social mobility across $\mathrm{T}-1$ and $\mathrm{T}-3$ results reveal some positive as well as negative variances in the relationships for the groups (see chart 6).

\section{West Indians}

Analysis results indicate that for West Indians there was a positive percent change revealing a $63.2 \%$ increase in the strength of the relationship between self-concept and social mobility across $\mathrm{T}-1$ and $\mathrm{T}-2$. However, from $\mathrm{T}-2$ to $\mathrm{T}-3$ results indicated a negative percent change that revealing a $33.5 \%$ decrease in the strength of the relationship between self-concept and social mobility across T-2 and T-3. Looking across from $\mathrm{T}-1$ to $\mathrm{T}-3$ there was a slight increase of $8.6 \%$ in the percent change indicating that there was longitudinally a positive change.

\section{Haitians}

Analysis results indicates that for Haitians there was a positive percent change that revealing a $105.6 \%$ increase in the strength of the relationship between self-concept and social mobility across $\mathrm{T}-1$ and $\mathrm{T}-2$. From $\mathrm{T}-2$ to $\mathrm{T}-3$ the results indicate a positive percent change of $10.30 \%$ as well as a continuation in the strength of the relationship between self-concept and social mobility across T-2 and T-3. Looking across from T-1 to $\mathrm{T}-3$ there was a strong increase of $126.7 \%$ in the percent change indicating that there was longitudinally a strong and positive relationship between self-concept and social mobility. 
Percent Changes:

Self-concept on Social Mobility T-1, T-2 and T-3

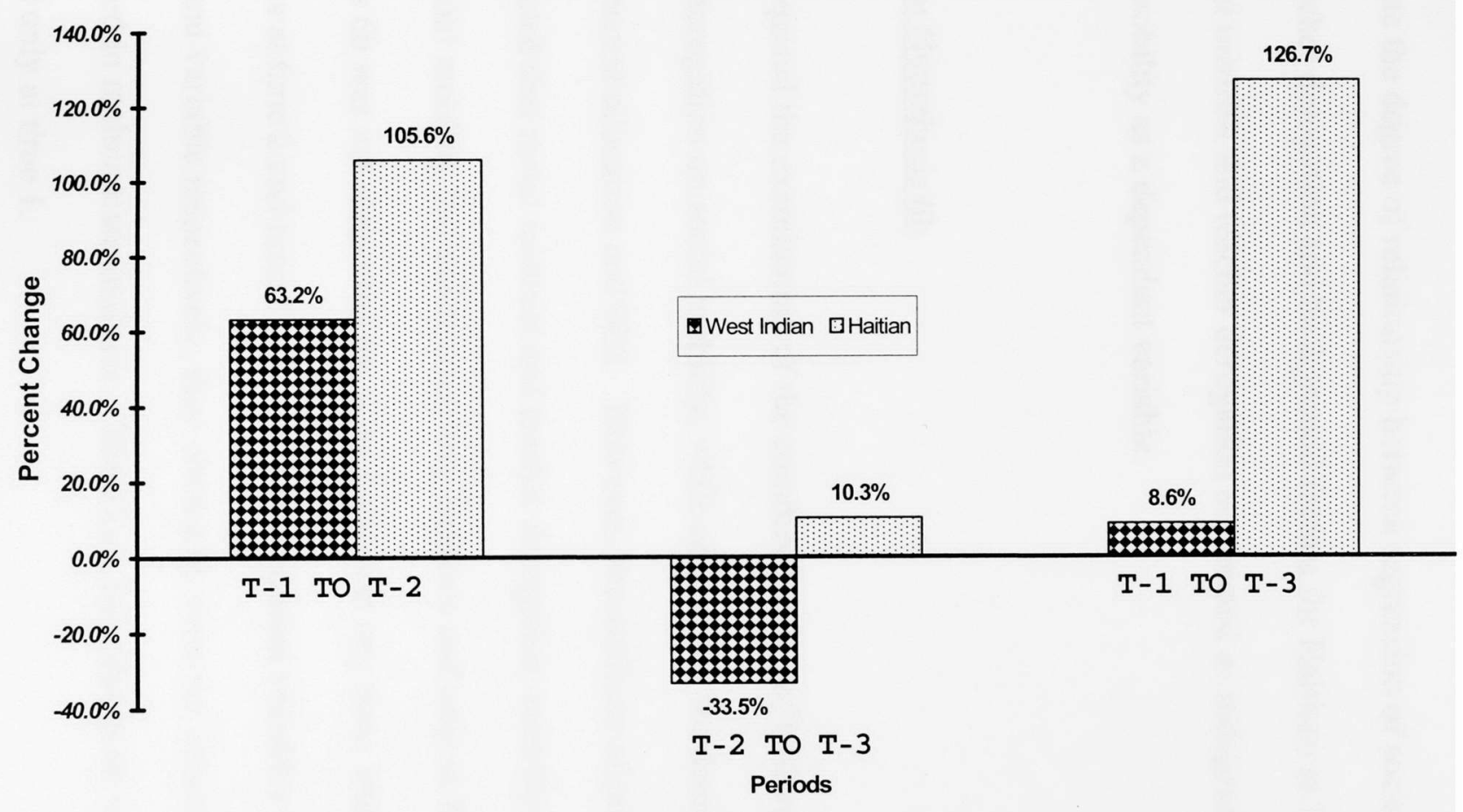


Regression

This section focuses on the expectation that for hypothesis \#6b, the independent variables predict the dependent variables in the study. Regression tests were therefore conducted to determine the degree of relationship between regression of social mobility on racial mistrust, teacher derogation and background factors for Haitians at T-1 (see Table 11). Here racial mistrust and teacher derogation are treated as independent variables and social mobility as a dependent variable.

$\underline{\text { Regression Results for Hypothesis } 6 \mathrm{~b}}$

Hypothesis $6 \mathrm{~b}$ required the examination of the combined effect of both racial mistrust and teacher derogation on social mobility, while controlling for demographic factors consisting of parent education and SES. However, the analyses of prior hypotheses demonstrated that racial mistrust and teacher derogation were the only variable related to social mobility this occurred among Haitians and only at T-1. Therefore, hypothesis $6 \mathrm{~b}$ was not supported for West Indians at any time, and was not supported for Haitians at time 2 and time 3. Since the independent variables were not related to the dependent variable respectively, they obviously were not expected to be related when combined in multivariate analyses. Therefore, hypothesis $6 \mathrm{~b}$ was tested only for Haitians and only at time 1. 
Table 11 below presents the results of the regressions testing for hypothesis $6 \mathrm{~b}$.

Racial mistrust had more influence on perceptions of social mobility among West Indians than for Haitian in the sample T-1. 
Table 11

Regression of Social Mobility on Racial Mistrust, Teacher Derogation and Background Factors for Haitians at Time 1
EQ 1
EQ 2
EQ 3

Unstandardized Regression Coefficients

Background

Factors

Mother Education

.277

$-.090$

$-.076$

Father Education

$-.246$

.288

.297

SES

$-.197$

$-.223$

$-.222$

Racial Mistrust

$.175^{* * *}$

$.167^{* * *}$

Teacher Derogation

$-.028$

$\mathrm{R}^{2}$

.019

.203

.204

$\mathrm{R}^{2}$ Change

$.184 * * *$

.001

F.

.461

$4.50 *$ *

$3.54 * *$ 
This section presents a succinct summary of the hypotheses results discussed in chapter 5 .

Hypothesis \#1 involving the testing of the relationship between length of stay and race-related mistrust is only partially supported. For this sample length of stay has hardly any association with West Indian and Haitian students' perception of racial mistrust. The only instance in which the hypothesis is supported, indicating that length of stay and racial mistrust are related, is at T-3 and only for West Indians. Hypothesis \#2, involving testing of the relationship between length of stay and teacher derogation is not supported. However, hypothesis \#3 involving testing of the relationship between self-concept and race-related mistrust is partially supported.

These results indicate an association between students' levels of race-related mistrust and self-concept. At T-1 self-concept scores increase when racial mistrust levels decrease for both Haitian and West Indian students. Hypothesis \#4 is also supported showing an association between teacher derogation and self-concept. Although the students' mean scores for teacher derogation are mostly in the low range there are statistically significant relationships between self-concept and teacher derogation at T-1, $\mathrm{T}-2$ and $\mathrm{T}-3$. When self-concept scores decrease perceptions of teacher derogation scores increases for both West Indian and Haitian students. Hypothesis \# 5 involving testing of the relationship between length of stay and social mobility is only partially supported. Length of stay is associated with perceptions of social mobility only at T-3 for West 
Indians. Hypothesis \# 6a is supported indicating self-concept was highly correlated with perceptions of social mobility. However, hypothesis \# $6 \mathrm{~b}$ is only partially supported.

After controlling for parents' education, and SES only racial mistrust correlates with social mobility. This occurs only among Haitians and at T-1 only. In controlling for parents' level of education, SES and racial mistrust teacher derogation is not related to social mobility. The first regression equation (EQ1) consists of the control variables, mother and father education, and SES. As shown on Table 11, the proportion of variance explained by these variables is minimal (2\%), and the equation is not significant $(f=.461)$.

The second equation (EQ2) consists of the addition of racial mistrust. Racial mistrust is statistically significant, $(b=.175, p<.001)$, and it produced a significant $R 2$ change of $18.4 \%$, indicating a strong relationship between racial mistrust and social mobility after controlling for parental education and SES. The third and final equation (EQ3) consisted of the addition of teacher derogation. Teacher derogation is statistically significant, however it produced a minimal R2 change of .001, which is not statistically significant. Finally, these results indicate that in the context of parental education, SES and teacher derogation racial mistrust is the strongest predictor of social mobility. 


\section{Chapter 5}

\section{Discussion of Findings}

The aim of this study was to identify correlate relationships that exist between West Indian and Haitian students' perceptions concerning variables such as race-related mistrust, teacher derogation and social mobility and students' length of stay in the U.S. and self-concept. In interpreting the analyses results the dissertation cautions against forming hasty conclusions about these students' perceptions based on racial and ethnic classification or even socioeconomic status. Given these caveats, the findings of the study's variables offers some clear and interesting patterns about the students' perceptions focusing specifically White teachers' attitudes and behaviors toward them and the other students of African descent.

Several interesting correlations emerged from the analyses. A few of the important ones were presented in the preceding summary of the findings. However, of equal importance is the discovery of the absence of statistically significant correlation between some of the variables suggested by the literature. For example, it seemed unusual to find that despite the fact that most students in this sample were born here, length of stay is not highly correlated with racial mistrust, teacher derogation or social mobility.

It seemed logical to reason that since most students had lived here 6-11 years or more and were well exposed to U.S. race relations that their perceptions particularly of racial mistrust and social mobility would be highly correlated to length of stay as indicated by other studies (Waters, 1994, 1999). However, this is not the case for this sample of West Indian and Haitian students. One variable contributing to a possible 
explanation for these findings is the lack of variability in length of stay, particularly among the Haitian students. The cohort samples were not adequately distributed based on number of years students had lived here therefore the hypotheses concerning length of stay could not be confirmed statistically. Therefore, it is suggested that future researcher who use length of stay, as an independent variable seek to include greater variability than was available in this study's sample.

In addition to lengths of stay, several other salient patterns emerged from the data. One pattern that is alarming and raises some concerns about the future outlook for West Indian and Haitian students in Miami is the one representing the students' academic achievements. The mean GPA of the West Indian students remained surprisingly low (1.88) throughout middle school. The mean GPAs for the Haitians were equally low (1.81). This was of particular concern given the literature's linking of educational qualifications to future occupational status and opportunities for social mobility (Collins, 1979; Jaschik, 1979).

School performance in middle school years is inextricably linked to high school years and subsequently to higher education and future social mobility. These findings, concerning the GPAs indicate that the majority of these students will encounter academically imposed barriers to social mobility regardless of their perceptions or levels of optimism about opportunities for social mobility. The other background factor relating to the students' academic performance is the parents' level of education. It was surprising to discover that despite the presence of relatively high educational achievements among the parents in both cohort samples that this background factor did 
not contribute to higher academic performance among the students. This suggests that there are other variables that are stronger contributors to students' GPAs.

As was the case with parental education, SES did not emerge as a salient factor in terms of having an association with the students' perception of race-related mistrust, teacher derogation or social mobility. Here again, the sample lacked variability in terms of the students' SES and therefore it could not be statistically confirmed whether there are associations between SES and the students' perceptions. The cohort samples are not adequately distributed in terms of SES because the SES of the students in the sample is generally very low.

In interpreting the results pertaining to the hypotheses, the findings show some hypotheses are supported while others are not supported. As in other studies of students of African descent, racial mistrust surfaced in this dissertation as a very crucial educational concern (Taylor, Biafora and Warheit, 1994; Gil and Vega, 1993). In finding a consistent pattern of students reporting high levels of race-related mistrust of teachers in Miami schools it suggests the possibility that these students are not receiving adequate social and academic encouragement from their teacher. Roper and Pence (1995) also raised this issue as a matter of national concern.

Focusing specifically on the finding concerning parental education, SES and perceptions of teacher derogation the question surfaces as to why racial mistrust stands out also as a strong predictor of students' level of optimism and pessimism about social mobility, particularly for Haitians. The research by Waters (1994) holds a possible answer to the question. She explains that West Indian and Haitian students whose selfidentity involves an African American or Black-American identity tend to perceive more 
racial discrimination and less opportunity for themselves as well as for other Blacks in the U.S. In contrast, those who perceive themselves as "Caribbeans" tend to see more opportunities and rewards for individual efforts.

This current study did not incorporate the students' appraisal of their ethnic-identity however in keeping with Waters' premise, and given that the majority of the students in this sample were born here, it is probably safe to assume that most of the students are identifying as African Americans (Waters, 1994; 1999). Most West Indian and Haitian immigrants in Miami settle in communities that are heavily populated by African Americans. Therefore, it is conceivable that the students in this study are acculturating into an African American social structure.

Portes and Zhou (1993) offer a similar explanation for the high levels of racial mistrust. They describe the immigrants' assimilation process as one involving the development of an African American ethos. When West Indian and Haitian students assimilate into African American groups they do so not simply because of institutional pressures, but also because they live in communities populated predominantly by African American.

Living in an African American environment the students learn ways of interpreting and coping with barriers that historically have affected African Americans that are different from those of their Caribbean parents. Zhou (1997) provides yet another explanation relating to associations that exist between the students' perception of racial mistrust and social mobility. Certain immigrant groups may be confined either to permanent underclass status or by preserving the values of the immigrant community and solidarity, they move toward rapid economic advancement. Thus, the students' 
perceptions of social mobility are associated with their school environment as well the communities in which they live.

Another major concern that surfaced as a crucial issue in this current study relates to the quality of the teacher-student interactions in classrooms. Swanson et al. explain that educational successes and failures of minority students are closely related to interactions taking place between them and their teachers. Fernandez-Kelly (1994) suggests that the interaction between students and their teachers determined to a great extent the students' level of curiosity and love of learning. When students observe teachers that are committed to providing fair and representative environments the students experience a greater sense of school ownership resulting in greater student- involvement in the educational process and increases in academic success (Klauke, 1989; "School Focusing”, 1989; Grant, 1988).

Most of the West Indian and Haitian students in the Miami sample are on a path to social mobility that has already been set to spiral downward. The path is not determined solely by ethnicity or race but by their level of academic preparedness to face the social and economic challenges that are inherent within U.S. race relations.

\section{Limitations of the Study}

Several intrinsic factors that contribute to limitations in the field of social research confront this current study. The first limitation lies in the utilization of survey questionnaires, which, as a non-experimental research design, does not allow for the manipulation of independent variable and therefore removes the potential for exploring causality. Therefore, a determination could not be made as to whether West Indian and 
Haitian students' perceptions of racial mistrust, teacher derogation or social mobility were antecedents or a consequence of other variables in the study.

Another limitation is that the current study remained susceptible to potential internal and external validity problems given that there were little or no controls or manipulations for independent or intervening variables, a procedure that is available in true experimental designs. Finally, the samples of the study were small and were drawn from a geographically distinct area. This raises questions about the study's generalizability. Thus, the study should be replicated using a sample from various parts of the country.

Despite these limitations, the study's findings offer some valuable information with implications for immigrant research and education policy evaluation. Future research needs to expand the variables beyond the context of the classroom and to incorporate more of the family factors relating to parents and immigration history.

Implication for Research and policy evaluation

Research of West Indian and Haitian students has only recently begun to explore the importance of self-concept theory and acculturation theory to the understanding of immigrant students' school adjustment. This study offers an innovative approach by using the immigrant minority students' self-appraisal to measure their perceptions of racial mistrust, teacher derogation and optimism toward social mobility. This study also offers empirical data and findings that support further development and implementation of culturally sensitive curricula and educational policies in schools heavily populated by immigrant students. 
The effectiveness of education policies that takes into account diverse backgrounds will determine the success in school and future adaptation of West Indian and Haitian students. The expectations are that for generations to come, immigrant minority groups will continue to use schooling as the means for attaining social mobility and stability. Therefore, the development and implementation of culturally relevant education policies and curricula is not only pivotal to positive identity development during adolescence but also critical for navigating immigrant students through the difficult transition to gainful employment in adulthood. 


\section{REFERENCES}

Baker, D. (1983). Race, ethnicity, and power: A comparative study. Boston: Routledge and Kegan Paul.

Beck, R. (1996). The case against immigration. New York: W.W. Norton.

Bell, D. (1996). Racism is the cause of problems for Blacks. In Bender and Leone, Series Eds. and Winters Ed., Race Relations: Opposing Views. San Diago Cailf., Greenhaven Press.

Benedict, R. and Ellis, M. (1942). Race and culture relations: America's answer to the Myth of a master race. Menash, WI: Banta Publishing.

Biafora, F. A., Taylor, D. L., Warheit, G. J., Zimmerman, R. S., and Vega, W. A. (1993). Cultural mistrust and racial awareness among ethnically diverse black adolescents boys. Journal of Black Psychology, 19, 266-282.

Brown v. Board of Education. 347 U.S. 483 (1954).

Bryce-Laporte, R.S. (1972). "Black Immigrants: The Experience of Invisibility and Inequality”. Journal of Black Studies 3: 29-56.

Collins, R. (1979). The credential society: A historical sociology of education and stratification. New York: Academic Press.

Delgado-Gaitan, C. (1988). Socio-cultural Adjustment to School and Academic Achievement. Journal of Earlier Adolescence 8, 1, 63-82.

Dentler, R. and Hafner, A. L (1997). Hosting newcomers: structuring educational opportunities for immigrant children. Sociology of Education Series. 177 155-161. New York Teachers College Press.

D'Innocenzo,M., and Sirefman, J.P., (1992). Immigration and ethnicity: American Society "melting pot" or "salad bowl"? Contributions in Sociology, 0084-9278;no.97. Westport, Conn.:Greenwood Press.

Dodoo, F. Nil-Amoo (1997). "Assimilation Differences among Africans in America". Social Forces: 76 (2) 527-46.

DuBois, W.E.B. (1961). The Souls of Black Folk. New York: Fawett.

Fernandez-Kelly, M. P. (1994). Divided fates: immigrant children in a restructured U.S. economy. (Special Issue: The New Generation). International Migration Review; 
Winter, v28, n4, p662 (28).

Fine, M. (1986) Why urban adolescents drop into and out of public schools Teachers College Board, Spring.

Fitts, W. H.(1984). Tennessee self-concept manual. Los Angeles: Western Psychological Services.

Fix, M. and Zimmermann, W. (1993). Educating immigrant children: Chapter One in the changing city. Urban Institute Report. 93 Washington, D.C.:Urban Institute Press.

Foner, N., (1987). The Jamaicans: race and ethnicity among migrants in New York. City In Nancy Foner (ed.), New Immigrants in New York. N.Y.: Columbia University Press.

Fordham S. and J. U. Ogbu (1987). Black students success: coping with the burden of acting white, Urban Review, 18 (3) 176-206.

Frazier, F. (1957). Race and cultural contacts in the modern world. NY. Knopf.

Freeman, F. (1924). Sorting the students: Education Review.

Gainor, K. A. and Forrest, L.(1991). African American Women's self-concept. Career Development Quarterly 39, no. 3 March (EJ 428 194) 261-272.

Gans, H. J. (1992). Second generation decline: scenarios for the economic and ethnic futures of the Post-1965 American immigrants, Ethnic and Racial Studies, 15 (2): 172-192.

Garcia-Zamor, J (1998). Social service delivery for immigrants in Southeastern Florida. In Becker, F., Dluhy, M. and Clark, T. Solving Urban Problems in Urban Areas Characterized by Fragmentation and Divisiveness. Vol.7 185-200.

Gibson, M. A. (1995). Additive Acculturation as a Strategy for School Improvement. In California Children: theory, Research, and Implication for Educational Policy. R. Rumbaut and W. A Cornelius. San Diego: Center for U.S. Mexico Studies, University California.

(1989). Accommodation without assimilation: Sikh immigrants in an American high school. Ithaca, New York: Cornell University Press.

Gilmore, J., and E. (1982). Give your child a future. Englewood Cliffs, New Jersey: Prentice-Hall, Inc.

Glazer, N. (1993). Is Assimilation Dead? The Annals of the American Academy of 
Gollnick, D. M. (1995). National and state initiatives for multicultural education. In J. A. Banks and C.A.M. Banks (eds), Handbook of research and multicultural education (44-64). New York: Macmillan.

Gordon, M. (1964). Assimilation in American Life: The Role of Race, Religion and National Origin. Oxford University Press, New York.

Grant, C., and Tate, W.F. (1995). Multicultural education through the lens of multicultural education research literature. In J. A. Banks and C.A.M. Banks (eds), Handbook of research and multicultural education (145-166). New York: Macmillan.

Grant, C. A., (1988). The persistent significance of race in schooling. The Elementary School Journal, 88 (5), 561-569.

Grenier, G. (1999). Triadic Politics: Ethnicity, Race and Politics in Miami, 19591998. Pacific Historical Review; v. 68, 2, 273.

Hacker, A. (1995, November). Who they are. New York Times Magazine, 70-71.

Hains, A. H., Lynch, E. W., and Winton, P.J. (1997). Cultural competence: A review of the literature. Unpublished manuscript, CLAS Early Childhood Research Institute, Champaign, IL.

Harris, C. (1993). Identifying and serving recent immigrant children who are gifted. ERIC Clearing house on Disabilities and Gifted: ED358676. Education Reston VA.

Herr, K., (1999). Unearthing the unspeakable: when teacher research and political agenda collide (teacher research discovers institutional racism). Language Arts; Sept., v. $77,1,10(6)$.

Hirshman, C. (1993). Problem and prospects of studying immigrant adaptation from the 1990 census: from generational comparisons to process of "becoming American". (Special Issue in: The new Generation) International Migration Review, v. 28, n4, p. $690(24)$.

Hodgekinson, H. (1989). The same client: The demographics of education and service delivery systems. Washington D.C.: Center for Demographic Policy, Institute for Educational Leadership.

Hovey, J. (1996). Acculturation stress, depression and suicidal ideation among immigrant and second-generation Latino adolescent. Journal of the American Academy of Child and Adolescent Psychiatry. V. 35, n9, 183. 
Igoa, C. (1995). The inner world of the immigrant child. New York, N.Y. St. Martin's Press.

Irvine, J. (1985). Teachers communicating patterns as related to the race and sex of the student. Journal of Educational Research, July/ August.

James, D. (1997). Coping with a new society: the unique psychosocial problems of immigrant youth. Journal of School Health. (3) 98-101.

Jaschik, S. (1986, January 21). Black enrollment rate drops. Colorado Daily, University of Colorado, pp.1,8.

Kailin, J., (1999). How white teachers perceive the problem of racism in their schools: a case study in 'liberal' Lakeview. Teachers College Record Summer, v 100, 4. $\underline{724(4)}$.

Kalmijn, M. and Kraaykamp, G. (1996). "Race, Cultural Capital, and Schooling: An Analysis of Trends in the United States." Sociology of Education 69:22-34.

Kaplan, H.B. (1984). Pathways to adolescent drug use: Self-derogation, peer influence, weakening of social controls and early substance use. Journal of Health and Social Behavior 25:270-289.

Kaplan, H.B., Johnson, R. J., Bailey, C.A. (1986). Self-rejection and the explanation of deviance: Refinement and elaboration of latent structure. Social Psychology Quarterly 49:110-128.

Kasinitz, P., (1992). Caribbean New York: Black immigrants and the politics of race. Anthropology of Contemporary Issues. xv, 280 257-273. Ithaca: Cornell University Press.

Kinder, D.R. (1986). The continuing American dilemma: White resistance to racial change 40 years after Myrdal. Journal of Social Issues, 42 (2), 151-171.

Kluauke, A. (1989). Coping with changing demographics. ERIC Clearinghouse on Educational Management: Eugene OR.

Ladson-Billings, G. (1995). Butthat's just good teaching: the case for culturally relevant 165 .

Lambert, W.E., and Taylor, D. M. (1990). Coping with cultural and racial diversity in urban America. NY:Praeger.

Larkin; J. and Sleeter, C. E.(1995). Developing multicultural teacher education curricula. Albany: State Univ. of NY Press. 
Lawrence, S. (1997). Beyond race awareness: White racial identity and Multicultural teaching. Journal of Teachers Education, March-April, v48, n2, (10) 108.

Lawrence, S. M. and Tatum, B. D. (1997). Teachers in transition: the impact of antiracist professional development on classroom practice. Teachers College Record; Fall, v99, n1, p162 (17).

Lynch, J. (1987). Prejudice reduction and the schools. New York: Nichols.

Lynch, E. W., and Hanson, M. J. (Eds.).(1998). Developing cross-cultural competence: A guide for working with children and their families (2nd ED.). Baltimore, MD: Paul Brookes. ED 346190.

MacAdoo H. (1983). Extended family support of single Black mothers. Final report for the National Institute of Mental Health

Maehr, M. L. and Midgley, (1996). Transforming school culture, Boulder, Colo.: Westview Press.

McGinnis, J. (1984). Educating for peace and justice: Global dimensions. St. Louis: Institute for Peace and Justice

Miles, J. (1996). Immigrants take jobs from Blacks. In Bender and Leone, Series Eds. and Winters Ed., Race Relations: Opposing Views. San Diago Cailf., Greenhaven Press.

Mitchell, V. (1990). Curriculum and instruction to reduce racial conflict. ERIC Clearinghouse on Urban Education, (n 64).:New York, N.Y.

Mitchell, W, and Conn, C. P. (1985). Power of Positive Students. New York, N.Y.: Morrow Publishing Co.

Morse, S. and Ludovina, F. S., (1999). Responding to undocumented children in the schools. ERIC Clearinghouse on Rural Education and Small Schools, (ED433172) Charleston WV.

Moultry, M. (1988) Multicultural education among seniors in the College of Education at Ohio State University. Paper presented at the Annual Meeting of the American Education Research Association, New Orleans, LA. (ED 296 634).

Muller, T. (1996). ). Immigrants do not take jobs from Blacks. In Bender and Leone, Series Eds. and Winters Ed., Race Relations: Opposing Views. San Diago Cailf., Greenhaven Press.

National Coalition of Advocates for Children, (1988, April). New voices, immigrants in U.S. public schools (Research Rep. No 1988-1). Boston, MA: 
National Immigration Forum. (1994). A guide to immigration facts and figures. Washington, DC: Author.

Novak, M. (1971). The rise of the unmeltable ethnics. New York: Macmillian.

Ogbu, J. U., (1987). Variability in Minority School Performance: A Problem in search of explanation. Anthropology and Education Quarterly 18 (4): 312-334.

(1991). Immigrant and involuntary minorities in comparative perspective. In M. Gibson and J. Ogbu (Eds.). Minorities status and schooling: A comparative study of immigrant and involuntary minorities. New York: Garland Press. (ED340 810).

Olneck, M. R. (1990) The recurring dream: Symbolism and ideology in intercultural and multicultural education. American Journal of Education, 98 (2), 147-174.

Olsen, L.(1997). Made in America: Immigrant students in our public schools. New York, N.Y.: The New Press.

Olsen, G. and Moore, M. (1982). Voices from the classroom. Oakland, California: Citizens Policy Center.

Padilla, A. M. (1980). Acculturation theory, models and some new findings. Boulder, CO: Westview.

Patterson, O. (2000). TRB from Washington. In the New Republic.

Perlmann, J. and Waldinger R. (1997). Second generation decline? Children if immigrants, past and present-a reconsideration. (Special Issue in Immigration Adaptation and Native-Born Response in the Making of Americas). International Migration Review, Winter, v31, n4, (30) 893.

Phillips, T., (1998). Why is the face of exclusion so often black? (institutional racism). Educational Supplement; Oct. 23 n 4295, p15 (1).

Piers, E. V. (1984). Piers-Harris children's self-concept scale: Revised Manual. Los Angles, CA: Western Psychological Services.

Portes, A. (1995). Children of immigrants: Segmented Assimilation and its determinants. In The Economics Sociology of Immigration: Essay on Network, Ethnicity and Entrepreneurship. New York: Russell Sage Foundation.

Portes, A., (2000). An enduring vision: The melting pot that did happen. $\underline{\text { In }}$ International Migration Review; Spring, v34, (1) 243. 
(1997). Immigration theory for a new century: some problems and opportunities. (Special Issue: Immigration adaptation and Native-Born responses in the Making of Americas) In International Migration Review; Winter, v31, n4 (27) 799.

Portes, A. and MacLeod, D. (1996). Educational Progress of children of immigrants: the roles of class, ethnicity, and school context. Sociology of Education; Oct, v69, n4, p255 (21).

Portes A. and Rumbaut R. G. (1996). Immigrant America: a portrait. 2nd ed. Berkley, Calif.: University of Calif. Press.

Portes, A. and Stepick, A. (1993). City on the Edge: Transformation of Miami. Berkley, CA.: Univ. Calif. Press.

Portes, A., M. Zhou (1993). The new second generation: segmented assimilation and its variants. The Annuals of the American Academy of Political and Social Science, 530: 74-96.

Sanders, M. (2000). Schooling students placed at risk: research, policy, and practice in the education of poor and minority adolescents. Mahwah, NJ: Erlbaum Associates.

Pryor, C. (1992). Integrating immigrants into American schools. Social Work in Education Vol. 14, No. 3.

Purkey, W. W., (1988). An overview of Self-concept theory for counselors: Highlights. ERIC Clearinghouse on Counseling and Personnel Services Ann Arbor MI.

Purkey, W.W. and Schmitdt, J., (1987). The inviting relationship: An expanded perspective for professional counseling. Englewood Cliffs, N.J.: Prentice-Hall, Inc.

Reid, Ira de A. (1939). The Negro Immigrant. AMS Press.

Rivera-Batiz, F., (1996). The education of immigrant children in New York City. ERIC Clearinghouse on Urban Education; (ED402399) New York N.Y.

Rong, X.L. and Preissle, J. (1998). Educating immigrant students: what we need to know to meet the challenges. Thousand Oaks, Calif.: Corwin Press.

Ropers, R. and Pence, D. J. (1995). American Prejudice: with liberty and justice for some. Insight Books Plenum Press. New York

Rosenberg, M. (1965). Society and adolescents self-image. Princet0on, N.J.: Princeton University Press.

Rubin, A. and Babbie, E.(1997). Research methods for social work 3ed. 
Brooks/Cole Publishing co.: Pacific Grove Calif.

Rubovits, P. C., and Maehr, M. L. (1973). Pygmalion black and white. Journal of Personality and Social Psychology, February.

Rumbaut, R. G. (1994). The crucible within: Ethnic identity, self-esteem, and segmented assimilation among immigrant children. International Migration Review, 28 (4): 748-796.

(1990). Immigrant Students in California Public Schools: A Summary of Current Knowledge. CDS Report No. 11. Baltimore, MD: Center for Research on Effective Schooling for Disadvantaged Students. John Hopkins University.

(1997). Ties that bind: Immigration and immigrant families in the United States: In Immigration and the family: Research and Policy on U.S. Immigration, edited by Alan Booth, Ann C. Crouter, and Nancy S. Landale. Mahwah, N.J.: Lawrence Erlbaum Associates.

(1988). The Adaptation of Southeast Asian refugee youth: A comparative perspective. Washington, DC: U.S. Office of Refugee Resettlement.

School Focusing on Integration Not Desegregation. (1989). The San Diego Union: Monday, November 27, 1989: A 1, B 6-7.

Schwartz, J. and Exeter, T. (1989). All our children. The American Demographics 1, 5 (May) 34-34.

Silberman, C. (1971). Crisis in the classroom. New York, N.Y. Vintage Books.

Solomon, P. R. (1992). Black resistance in high school: Forging a separatist culture. Albany: State University of New York Press. (ED 346 189).

Streins, W. (1993). Advances in research on academic self-concept: Implications for school psychology. School Psychology Review, 22, 273-284.

Suarez-Orozco, M. (1989). Central American refugees and U.S. high schools: a psychological study of motivation achievement. Stanford, Calif.: Stanford University Press.

(1995). Transformations: Migration, family life, and achievement among Latino adolescents. Stanford, CA: Stanford University Press.

Sugai, G. and Maheady, L.(1998) Cultural diversity and individual assessment for behavior disorders. Teaching Exceptional Children, 21, 28-31 (1). 
Survey Research Center. (1986). Changes in ethnic, religious and race-related attitudes in Maryland-Survey II: Report to the Governor's task force on violence and extremism. College Park: University of Maryland.

Swanson, D. P., Spenser, M. B., A. Peterson (1998). Identity formation in adolescence. In Borman, K., Schneider B. The adolescent years: Social Influences and educational challenges. University of Chicago Press. Chicago, Illinois.

Takaki, R. (1993). A different mirror: A history of multicultural America. Boston: Little, Brown.

Tatum, B.D. (1992). Talking about race, learning about racism: The application of racial identity development theory in the classroom. Harvard Education Review, 62(1), $1-24$.

Taylor, D., Biafora, F., Warheit, G. and Gil, A.. (1994). Racial mistrust and attitudes towards the law among African-American, Haitian, and other Caribbean Island boys. Law and Human Behavior, 18, 291-303.

Terrell, F. (1981). Effects of race on examiner and cultural mistrust on the WAIS performance of black students. Journal of Consulting Clinical Psychology, 49, 750-751.

Trueba, H. T. (1983). Adjustment problem of Mexican and Mexican-American students: an anthropological study. Learning Disability Quarterly, 6(4), 395-415.

U.S. Bureau of Census. (1996). U.S. Census Bureau: The Official Statistics [Online]. Available: http://www.census.gov/[1998, October 28].

Usdansky, M. (1993), September 16. College doesn't close blacks' pay gap. USA Today. p.A3.

Vega, W. A. (1993). Acculturation and delinquent behavior among Cuban American adolescents: Towards and empirical model. American Journal of Community Psychology, February, v21, n1, (13) 113.

Vega, W.A. and Gil A. (1998). Drug Use and Ethnicity in Early Adolescence. Plenum Press, New York.

Vernay, M. (1990). Curriculum and Instruction to Reduce Racial Conflict (Eric/Cue Digest, n 64), ERIC Clearinghouse on Urban Education New York NY.

Walcott, H. (1997). The teacher as an enemy. In Spindler, G.D. Education and cultural processes: Anthropological Approaches. Waveland Press Inc. Prospect Heights, Illinois. 
Walker, D.C. (1993). The role of the mass media in the adaptation of Haitian immigrants in Miami. UMI: Ann Arbor MI.

Warner W. L., Srole L. (1945). The social system of American ethnicgroups. New Haven: Yale University Press.

Warheit, G. J. (1998) In Gil, A.G., Vega, W.A. Drug Use and Ethnicity in Early Adolescence. Plenum Press, New York.

Waters, M. (1994a). Differing perceptions of racism: West Indians, African Americans, and Whites in the workplace. Paper presented at the annual meeting of the American sociologist association, Los Angeles, Calif.

(1994b). Ethnic and racial identities of second-generation black immigrants in New York City. International Migration Review 28:795-820.

(1999). "Black Identities: West Indian Immigrant Dreams and American Realities". Cambridge, Mass.: Harvard University Press.

Weissglass, J. (1997). Deepening our dialogue about equity. Educational Leadership; April, v54, n7, p78 (4).

Wellman, D. (1993). Portraits of white racism (2nd ed.). New York: Cambridge University Press.

Williams, C., Berry J. (1991) Primary prevention of acculturation stress among refugees: application of psychological theory and practice. American Psychology.46: $\underline{632-641 .}$

Wilson, M. (1980). Evaluating mental health status in adults. Paper presented at the Fifth Conference on Empirical Research in Black Psychology. Howard University, Washington, DC.

Woldemikael, T. M. (1989). Becoming Black American: Haitians and American Institutions in Evanston, Illinois. New York: AMS Press, p114.

Zastrow, C., Kirst-Ashman, K. (1994). Understanding human behavior and the social environment. $3^{\text {rd }}$ Ed. Nelson-Hall Publishing. Chicago Illinois.

Zhou, (1997). Growing up American: the challenges confronting immigrant children and children of immigrants. Annual Review of Sociology. v.23. P. 63-95. 
Appendix 1

Influence of Length of stay on Perceptions of Racial Mistrust across T-1, 2 and 3

West Indians

\begin{tabular}{lcccccr} 
& \multicolumn{2}{c}{ T-1 } & \multicolumn{2}{c}{ T-2 } & \multicolumn{2}{c}{ T-3 } \\
Years in U.S. & N=118 & Mean* & N=121 & Mean* & N=120 & Mean* \\
5Yrs or less & 36 & 15.0 & 28 & 14.7 & 28 & 14.7 \\
6-10 Yrs & 30 & 14.4 & 32 & 14.1 & 32 & 15.9 \\
11Yrs or More & 52 & 15.3 & 61 & 15.2 & 60 & 16.8
\end{tabular}

Haitians

\begin{tabular}{lcccccc} 
& \multicolumn{2}{c}{ T-1 } & \multicolumn{2}{c}{ T-2 } & \multicolumn{2}{c}{ T-3 } \\
Years in U.S. & N=156 & Mean* & N=150 & Mean* & N=150 & Mean* \\
5Yrs or less & 33 & 16.0 & 30 & 14.2 & 25 & 15.8 \\
$6-10$ Yrs & 30 & 15.3 & 24 & 16.0 & 27 & 14.7 \\
11Yrs or More & 93 & 15.4 & 96 & 15.5 & 98 & 15.9
\end{tabular}

Racial Mistrust Range: Low $=7-14$, Moderate $=15-20$, High $=21-28$

* Means of Racial Mistrust Score 


\section{Appendix 2}

Relationship between Lengths of Stay and Perceptions of Teacher Derogation at T-1, 2, and 3

\section{West Indians}

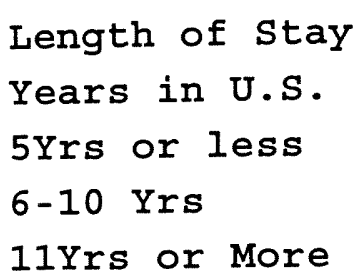

IIYrs or More

\begin{tabular}{cc}
\multicolumn{2}{c}{$T-1$} \\
$N=155$ & Mean* \\
51 & 6.3 \\
38 & 6.7 \\
66 & 6.6
\end{tabular}

\section{Haitians}

\begin{tabular}{cc}
\multicolumn{2}{c}{ T-1 } \\
N=174 & Mean* \\
37 & 7.5 \\
35 & 7.2 \\
102 & 6.7
\end{tabular}

\begin{tabular}{cc}
\multicolumn{2}{c}{$\mathrm{T}-2$} \\
$\mathrm{~N}=164$ & Mean* \\
45 & 6.9 \\
40 & 6.5 \\
79 & 6.9
\end{tabular}

\begin{tabular}{cc}
\multicolumn{2}{c}{ T-3 } \\
$N=164$ & Mean* \\
45 & 7.3 \\
41 & 7.0 \\
78 & 7.2
\end{tabular}

Years in U.S.
5 Yrs or less
$6-10$ Yrs
11Yrs or More

Teacher Derogation Range: Low $=4-8$, Moderate $=9-11$, High=12-16

* Means of Teacher Derogation Scores

\begin{tabular}{cccc}
\multicolumn{2}{c}{ T-2 } & \multicolumn{2}{c}{ T-3 } \\
N=174 & Mean* & N=178 & Mean* \\
35 & 6.6 & 37 & 11.0 \\
30 & 7.4 & 32 & 11.9 \\
109 & 7.1 & 113 & 11.2
\end{tabular}


Appendix 3

Relationship between students' self-concept and Perception of Racial Mistrust at T-1, 2, and 3

\section{West Indians}

Self-Concept Range

High (>35)

Moderate (28-35)

Low $(<28)$

Self-Concept Range

High (>35)

Moderate $(28-35)$

Low $(<28)$

\begin{tabular}{cc}
\multicolumn{2}{c}{ T-1 } \\
$\mathrm{N}$ & Mean* \\
61 & 14.9 \\
34 & 14.9 \\
26 & 17.4
\end{tabular}

\section{Haitians}

\begin{tabular}{cc}
\multicolumn{2}{c}{$\mathrm{T}-1$} \\
$\mathrm{~N}$ & Mean* \\
52 & 14.4 \\
64 & 14.8 \\
41 & 17.9
\end{tabular}

T-2

N Mean*

$58 \quad 14.5$

$41 \quad 15.1$

$27 \quad 15.9$

$\mathrm{N}$ Mean*

$63 \quad 15.8$

$46 \quad 14.4$

$45 \quad 15.9$
$\mathrm{T}-3$

Mean*

$66 \quad 15.5$

$34 \quad 17.0$

$27 \quad 16.5$

Racial Mistrust Range: Low $=7-14$, Moderate $=15-20$, High 21-28

* Means of Racial Mistrust Scores 
Appendix 4

Relationship between self-concept and

Perception of Teacher Derogation at T-1, 2, and 3

West Indians

\section{Self-Concept}

High (<35)

Moderate $(28-35)$

Low $(<28)$

\section{Self-Concept}

High (<35)

Moderate (28-35)

Low $(<28)$

\begin{tabular}{cc}
\multicolumn{2}{c}{ T-1 } \\
N & Mean* \\
86 & 5.4 \\
45 & 7.5 \\
32 & 8.3
\end{tabular}

\section{Haitians}

\begin{tabular}{cc}
\multicolumn{2}{c}{ T-1 } \\
N & Mean* \\
61 & 5.7 \\
72 & 7.1 \\
47 & 8.5
\end{tabular}

\begin{tabular}{cc}
\multicolumn{2}{c}{ T-2 } \\
$\mathrm{N}$ & Mean* \\
8.2 & 5.1 \\
56 & 7.4 \\
33 & 8.2
\end{tabular}

$T-2$

N Mean*

$74 \quad 6.4$

$55 \quad 6.1$

$53 \quad 8.3$
$T-3$ Mean*

$86 \quad 6.2$

$\begin{array}{ll}49 & 7.9\end{array}$

$35 \quad 8.7$

\begin{tabular}{cc}
\multicolumn{2}{c}{ T-3 } \\
$N$ & Mean* \\
84 & 6.0 \\
56 & 7.5 \\
45 & 8.6
\end{tabular}

Teacher Derogation Range: Low $=4-8$, Moderate=9-11, High=12-16

* Means of Teacher Derogation Scores 
Appendix 5

Relationship between Length of Stay and Perceived Chance for Social Mobility at T-1, 2, and 3

\section{West Indians}

\begin{tabular}{lcccccc} 
& \multicolumn{2}{c}{$\mathrm{T}-1$} & \multicolumn{2}{c}{$\mathrm{T}-2$} & \multicolumn{2}{c}{$\mathrm{T}-3$} \\
Years in U.S. & $\mathrm{N}=165$ & Mean* & $\mathrm{N}=166$ & Mean* & $\mathrm{N}=166$ & Mean* \\
5 Yrs or less & 54 & 11.8 & 45 & 11.3 & 45 & 10.9 \\
$6-10$ Yrs & 39 & 11.1 & 41 & 11.9 & 41 & 11.7 \\
11Yrs or More & 72 & 11.5 & 80 & 11.7 & 80 & 11.4
\end{tabular}

Haitians

T-1 T-2 T-3

$\begin{array}{lcccccc}\text { Years in U.S. } & \text { N=184 } & \text { Mean* } & \mathrm{N}=183 & \text { Mean* } & \mathrm{N}=182 & \text { Mean* } \\ \text { 5Yrs or less } & 38 & 11.4 & 37 & 11.4 & 37 & 11.0 \\ 6-10 \text { Yrs } & 35 & 11.5 & 32 & 11.6 & 31 & 11.9 \\ \text { 11Yrs or More } & 103 & 11.4 & 114 & 11.4 & 111 & 11.2 \\ & & & & \end{array}$


Appendix 6.

Questionnaires $^{2}$

YOUTH DEVELOPMENT QUESTIONNAIRE T-1, 2 AND 3

For Each Question, Please circle the number of your answer.

1) How old were you on your last birthday?

\begin{tabular}{|l|l|l|l|l|l|l|l|l|}
\hline & 10 & 11 & 12 & 13 & 14 & 15 & 16 & 17 \\
\hline
\end{tabular}

2) (a) In what month were you born?

\begin{tabular}{|l|l|l|l|l|l|l|l|l|l|l|l|}
\hline Jan & Feb. & Mar & Apr & May & Jun & Jul & Aug & Sept & Oct & Nov & Dec \\
\hline 1. & 2. & 3. & 4. & 5. & 6. & 7. & 8. & 9. & 10. & 11. & 12. \\
\hline
\end{tabular}

(b) On which day of the month were you born?

\begin{tabular}{|l|l|l|l|l|l|l|l|l|l|}
\hline 1. & 2. & 3. & 4. & 5. & 6. & 7. & 8. & 9. & 10. \\
\hline 11. & 12. & 13. & 14. & 15. & 16. & 17. & 18. & 19. & 20. \\
\hline 21. & 22. & 23. & 24. & 25. & 26. & 27. & 28. & 29. & 30. \\
\hline 31. & \multicolumn{10}{|l}{} \\
\cline { 1 - 5 } &
\end{tabular}

3) Are you a: Boy Girl

1. 2 .

4) What grade are you in? $\quad 6^{\text {th }} \quad 7^{\text {th }} \quad 8^{\text {th }}$

5) What school did you attend last year? (please print neatly)

6) Where was you mother born?

\begin{tabular}{|c|c|c|c|c|c|}
\hline U.S. & Haiti & $\begin{array}{c}\text { Jamaic } \\
a\end{array}$ & $\begin{array}{c}\text { Trinida } \\
d\end{array}$ & $\begin{array}{c}\text { Barbado } \\
s\end{array}$ & Antiqua \\
\hline 1. & 2. & 3. & 4. & 5. & 6. \\
\hline Cayman Is & $\begin{array}{l}\text { Grenad } \\
a\end{array}$ & Guyana & St Lucia & $\begin{array}{l}\text { St } \\
\text { Vincent }\end{array}$ & $\begin{array}{l}\text { Bahama } \\
\text { s. }\end{array}$ \\
\hline 7. & 8. & 9. & 10. & 11. & 12. \\
\hline
\end{tabular}

${ }^{2}$ This survey instrument, which was utilized at T-1,2 and 3 is a partial representation the survey instrument that was developed for the original study conducted (Vega and Gil, 1998). 
Where was your father born?

\begin{tabular}{|c|c|c|c|c|c|}
\hline U.S. & Haiti & $\begin{array}{c}\text { Jamaic } \\
a\end{array}$ & $\begin{array}{c}\text { Trinida } \\
d\end{array}$ & $\begin{array}{c}\text { Barbado } \\
s\end{array}$ & Antigua \\
\hline 13. & 14. & 15. & 16. & 17. & 18. \\
\hline $\begin{array}{c}\text { Cayman } \\
\text { IS }\end{array}$ & $\begin{array}{c}\text { Grenad } \\
a\end{array}$ & Guyana & St Lucia & St & Bahama \\
Vincent & $s$ \\
\hline 19. & 20. & 21. & 22. & 23. & 24. \\
\hline
\end{tabular}

9) Where were you born?

\begin{tabular}{|c|c|c|c|c|c|}
\hline U.S. & Haiti & $\begin{array}{c}\text { Jamaic } \\
a\end{array}$ & $\begin{array}{c}\text { Trinida } \\
d\end{array}$ & $\begin{array}{c}\text { Barbado } \\
s\end{array}$ & Antigua \\
\hline 1. & 2. & 3. & 4. & 5. & 6. \\
\hline $\begin{array}{c}\text { Cayman } \\
\text { IS }\end{array}$ & $\begin{array}{c}\text { Grenad } \\
a\end{array}$ & Guyana & St Lucia & $\begin{array}{c}\text { St } \\
\text { Vincent }\end{array}$ & $\begin{array}{c}\text { Bahama } \\
s\end{array}$ \\
\hline 7. & 8. & 9. & 10. & 11. & 12. \\
\hline
\end{tabular}

10) Which of the following adults live with you all or most of the time?

(Circle one answer only)
1. Your mother and father
4. Your mother only
2. Your mother and other
5. Your father only adults
3. Your father and other adults
6. Not with parents, but other adults

11) How many years of school has your mother (or other woman you live with) had?
1. Less than High School
4. Some Junior College or University
2. Some High School
5. College or University
Degree or More

3. High School Graduate

12) How many years of school has your father (or other man you live with) had?
1. Less than High School
4. Some Junior College or
2. Some High School
5. College or University

\section{Degree or More}

3. High School Graduate 
13) How long have you lived in the U.S.?
1. Less than 1 Year
4. 6-11 Years
2. 1-2 Years
5. 11 or more Years
3. $3-5$ Years

14) How true do you think the following sentence is:

In the United States, everyone has the same chance of getting rich.

Very true Pretty true Not very true Not true at all

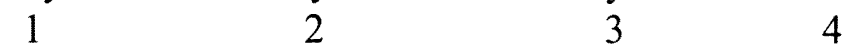

Below is a list that describes kids. Answer how true each statement is for you.

15) I have the same chance of doing well in life as everyone else.

Very true Pretty true Not very true Not true at all

$\begin{array}{llll}1 & 2 & 3 & 4\end{array}$

16) Members of my family have told me about problems they have had because they are black.

Very true Pretty true Not very true Not true at all

$\begin{array}{llll}1 & 2 & 3 & 4\end{array}$

17) I want to know more about how black people have overcome problems in America.

Very true Pretty true Not very true Not true at all
1
2
3
4

18) Members of my family have talked to me about dealing with racism and prejudice.

$\begin{array}{cccc}\text { Very true } & \text { Pretty true } & \text { Not very true } & \text { Not true at all } \\ 1 & 2 & 3 & 4\end{array}$


19) My family spends time teaching me about the right way to live.

Very true Pretty true Not very true Not true at all

$\begin{array}{llll}1 & 2 & 3 & 4\end{array}$

20) Black parents should teach their children not to trust white teachers.

Very true Pretty true Not very true Not true at all

$\begin{array}{llll}1 & 2 & 3 & 4\end{array}$

21) I always defend the rights of blacks.

Very true Pretty true Not very true Not true at all
1
2
3
4

22) Black should be suspicious of a white person who tries to be friendly.

Very true Pretty true Not very true Not true at all
1
2
3
4

23) When a white teacher talks to a black student, it is usually to get information that can be used against him or her.

Very true Pretty true Not very true Not true at all

$\begin{array}{llll}1 & 2 & 3 & 4\end{array}$

24) White teachers ask black student hard question on purpose so that they can fail.

Very true Pretty true Not very true Not true at all

$\begin{array}{llll}1 & 2 & 3 & 4\end{array}$

25) I feel that all blacks are my brothers and sisters.

Very true Pretty true Not very true Not true at all
1
2
3
4 
26) Some of my teachers are usually not interested in what I say or do.

Very true Pretty true Not very true Not true at all $\begin{array}{llll}1 & 2 & 3 & 4\end{array}$

27) I don't like myself as much as I use to.

Very true Pretty true Not very true Not true at all $\begin{array}{llll}1 & 2 & 3 & 4\end{array}$

28) At times I think that I am no good at all.

Very true Pretty true Not very true Not true at all $\begin{array}{llll}1 & 2 & 3 & 4\end{array}$

29) I wish I could have more respect for my self.

Very true Pretty true Not very true Not true at all $\begin{array}{llll}1 & 2 & 3 & 4\end{array}$

30) On the whole, I am satisfied with myself.

Very true Pretty true Not very true Not true at all $\begin{array}{llll}1 & 2 & 3 & 4\end{array}$

31) My life is a lot more satisfying than it use to be.

Very true Pretty true Not very true Not true at all $\begin{array}{llll}1 & 2 & 3 & 4\end{array}$

32) My teachers feel that I am a failure.

Very true Pretty true Not very true Not true at all $\begin{array}{llll}1 & 2 & 3 & 4\end{array}$

33) I am better now than I use to be.

Very true Pretty true Not very true Not true at all $\begin{array}{llll}1 & 2 & 3 & 4\end{array}$ 
34) My teachers do not like me very much.

Very true Pretty true Not very true Not true at all $\begin{array}{lllll}1 & 2 & 3 & 4\end{array}$

I feel I do not have much to be proud of.

Very true Pretty true Not very true Not true at all $\begin{array}{llll}1 & 2 & 3 & 4\end{array}$

36) My parents are usually not very interested in what I say.

Very true Pretty true Not very true Not true at all $\begin{array}{llll}1 & 2 & 3 & 4\end{array}$

37) In general I feel like a failure.

Very true Pretty true Not very true Not true at all $\begin{array}{llll}1 & 2 & 3 & 4\end{array}$

38) I certainly feel useless at times

Very true Pretty true Not very true Not true at all $\begin{array}{llll}1 & 2 & 3 & 4\end{array}$

39) I use to be a better person than I am now.

Very true Pretty true Not very true Not true at all $\begin{array}{llll}1 & 2 & 3 & 4\end{array}$

40) My parents have put me down for a long time.

Very true Pretty true Not very true Not true at all $\begin{array}{llll}1 & 2 & 3 & 4\end{array}$

41) I like myself a lot more than I use to.

Very true Pretty true Not very true Not true at all
1
2
3
4 
42) I take a positive attitude toward my self.

$\begin{array}{cccc}\text { Very true } & \text { Pretty true } & \text { Not very true } & \text { Not true at all } \\ 1 & 2 & 3 & 4\end{array}$

43) My teachers usually put me down.

Very true Pretty true Not very true Not true at all $\begin{array}{llll}1 & 2 & 3 & 4\end{array}$

44) It is very important to me to get good grades.

Very true Pretty true Not very true Not true at all $\begin{array}{llll}1 & 2 & 3 & 4\end{array}$

45) It is very important to me to get good grades.

Very true Pretty true Not very true Not true at all
$1 \quad 2$

46) My parents do not like me very much

Very true Pretty true Not very true Not true at all $\begin{array}{llll}1 & 2 & 3 & 4\end{array}$

47) How important is it to talk to your parents or family about your feelings?

Very important Pretty important Not very important Not important at all $\begin{array}{llll}1 & 2 & 3 & 4\end{array}$

48) How important do you think it is to avoid doing something to embarrass your family?

Very important Pretty important Not very important Not important at all $1 \quad 2 \quad 3 \quad 4$

49) How much do you agree with each of the following statements about your immediate family (the people you live with)?

Family members respect each other.

Agree a lot Sort of agree Sort of disagreeDisagree a lot 
51) We share similar values and beliefs as a family.
Agree a lot
1
Sort of agree Sort of disagree
Disagree a lot 2 3 4

52) Things work out well for us as a family.
Agree a lot 1 Sort of agree Sort of disagree 2 3
Disagree a lot 4

53) We really do trust and confide in each other.

Agree a lot

1
Sort of agree Sort of disagree

2
3
Disagree a lot 4

54) Family members feel loyal to the family.

Agree a lot 1
Sort of agreeSort of disagree 2 3

Disagree a lot 4

55) We are proud of our family.

Agree a lot Sort of agree Sort of disagree Disagree a lot 1

3

4

56) We can express our feelings with our family.

Agree a lot Sort of agree Sort of disagree Disagree a lot
1
2
3
4

How often is the following true about your immediate family (the people you live with)?

57) Family members like spending free time together.

$\begin{array}{ccccc}\text { Never } & \text { Once in a while } & \text { Sometimes } & \text { Often } & \text { Always } \\ 1 & 2 & 3 & 4 & 5\end{array}$

58) Family members feel very close to each other. 
$\begin{array}{ccccc}\text { Never } & \text { Once in a while } & \text { Sometimes } & \text { Often } & \text { Always } \\ 1 & 2 & 3 & 4 & 5\end{array}$

59) Family togetherness is very important.

$\begin{array}{ccccc}\text { Never } & \text { Once in a while } & \text { Sometimes } & \text { Often } & \text { Always } \\ 1 & 2 & 3 & 4 & 5\end{array}$

60) How much of your private thoughts and feeling do you think you can share with your:

\begin{tabular}{|c|c|c|c|c|c|}
\hline & $\begin{array}{l}\text { Don't } \\
\text { have } \\
\text { one }\end{array}$ & None & Some & Most & Everything \\
\hline $\begin{array}{c}A . \\
\text { Mother }\end{array}$ & 0 & 1 & 2 & 3 & 4 \\
\hline $\begin{array}{r}B . \\
\text { Father }\end{array}$ & 0 & 1 & 2 & 3 & 4 \\
\hline $\begin{array}{c}C . \\
\text { Sister(s) }\end{array}$ & 0 & 1 & 2 & 3 & 4 \\
\hline $\begin{array}{c}D . \\
\text { Brother(s) }\end{array}$ & 0 & 1 & 2 & 3 & 4 \\
\hline $\begin{array}{l}\quad \text { E. } \\
\text { Very best } \\
\text { Friend }\end{array}$ & 0 & 1 & 2 & 3 & 4 \\
\hline
\end{tabular}

61) Over all how honest would you say you were in answering this questionnaire?

Completely honest Very honest Pretty honest Not very honest Not honest at all 1 2 3 4

62) How many questions were hard to understand?

None $\quad 1$ or 2 questions A few questions A lot of the questions
0
1
2
3

63) How much privacy do you feel you had when filling out the questionnaire?
A lot of privacy
1
Some privacy
2
No privacy
3 
1994.

M.S.W. Social Work

Florida International University

1989

B.A. Psychology

College of New Rochelle,

Academic Positions

New York, 1989

1994-1996

Visiting Instructor and Coordinator of Student Services, Florida International University

1996-1998

Acting Coordinator, MSW Program, Florida International University,

1996-Present

Instructor and Coordinator of Student, Florida International University,

Scholarly Activities:

Albertini, V.L., Kosberg, J. and Fredrick G., (2000). "The Needs of Caribbean Male Immigrants: Implication for Social Work Research and Practice," Manuscript in Preparation.

Albertini, V.L. (2000) "Racial Mistrust and Teacher Derogation the Double Bind Confronting Immigrant Students: Implication for Research and Practice," Manuscript in preparation.

Albertini, V.L., (1999). "Jamaican Family Forms" in Charles B. Hennon and Timothy H. Brubaker Diversity in Families: A Global Perspective. Wadsworth, Publishing Co. Manuscript under review. 
Conference Presentations:

Albertini, V.L., "The Needs of Caribbean Male Immigrants: Implication for Social Work Research and Practice," Co-presented with Fredrick G. at: The Fourth Caribbean and International Social Work Educators Conference on Caribbean Peoples on the World Stage-Mobilizing Social Workers for Action in the New Millennium. University of the West Indies, Mona Kingston Jamaica. (June 2-5, 1999).

Albertini, V.L., "Matrifocality and Child-shifting: Implications for Social Work Practice" a paper presented at the CSWE APM/International Symposium on Social Work in the Caribbean: sponsored by the University of Central Florida, Orlando, Florida. (March, 1998).

Albertini, V.L., "Matrifocality and Child-shifting across the Caribbean: A Historical Overview". A panel discussion at the Annual Conference of the Caribbean Studies Association: Sponsored by Caribbean Sociological Association, Antigua, (July, 1998).

Professional Affiliations:

Council on Social Work Education (2000)

Caribbean Studies Association, (1998-2000) 